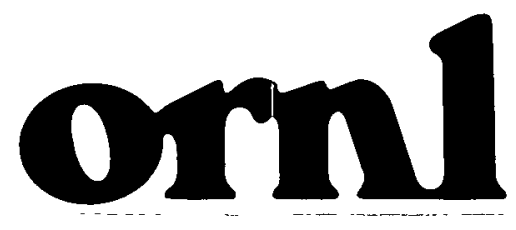

OAK RIDGE NATIONAL LABOFATORY

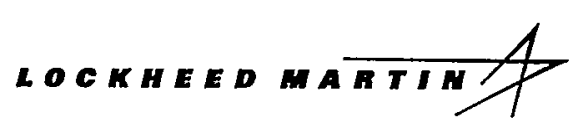

\section{RECEIVED} JUL 231999

OSTI

\section{PERSPECTIVES ON TEMPERATURE IN THE PACIFIC NORTHWEST'S FRESH WATERS}

\author{
Charles C. Coutant
}

Environmental Sciences Division

Publication No. 4849

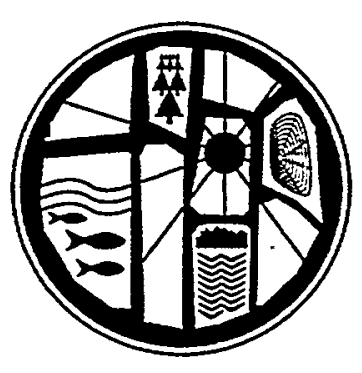


This report has been reproduced from the best available copy.

Reports are available to the public from the following source.

National Technical Information Service

5285 Port Royal Road

Springfield, VA 22161

Telephone 703-605-6000 (1-800-553-6847)

TDD 703-487-4639

Fax 703-605-6900

E-mail orders@ ntis.fedworld.gov

Web site http://www.ntis.gov/ordering.htm

Reports are available to U.S. Department of Energy (DOE) employees, DOE contractors, Energy Technology Data Exchange (ETDE) representatives, and International Nuclear Information System (INIS) representatives from the following source.

Office of Scientific and Technical Information

P.O. Box 62

Oak Ridge, TN 37831

Telephone 423-576-8401

Fax 423-576-5728

E-mail reports@adonis.osti.gov

Web site http://www.osti.gov/products/sources.htm!

Reports produced after January 1, 1996, are generally available via the DOE Information Bridge.

Web site http://www.doe.gov/bridge 


\section{DISCLAIMER}

This report was prepared as an account of work sponsored by an agency of the United States Government. Neither the United States Government nor any agency thereof, nor any of their employees, make any warranty, express or implied, or assumes any legal liability or responsibility for the accuracy, completeness, or usefulness of any information, apparatus, product, or process disclosed, or represents that its use would not infringe privately owned rights. Reference herein to any specific commercial product, process, or service by trade name, trademark, manufacturer, or otherwise does not necessarily constitute or imply its endorsement, recommendation, or favoring by the United States Government or any agency thereof. The views and opinions of authors expressed herein do not necessarily state or reflect those of the United States Government or any agency thereof. 


\section{DISCLAIMER}

Portions of this document may be illegible in electronic image products. Images are produced from the best available original document. 
Environmental Sciences Division

\title{
PERSPECTIVES ON TEMPERATURE IN THE PACIFIC NORTHWEST'S FRESH WATERS
}

\author{
Charles C. Coutant \\ Environmental Sciences Division \\ Publication No. 4849
}

Date Published: June 1999

Prepared for the

U.S. Environmental Protection Agency

Region 10

Seattle, Washington

Budget and Reporting Code 400408000

\author{
Prepared by the \\ OAK RIDGE NATIONAL LABORATORY \\ Oak Ridge, Tennessee 37831-6036 \\ managed by \\ LOCKHEED MARTIN ENERGY RESEARCH CORP. \\ for the \\ U.S. DEPARTMENT OF ENERGY \\ under contract DE-AC-05-96OR22464
}




\section{CONTENTS}

LIST OF FIGURES vii

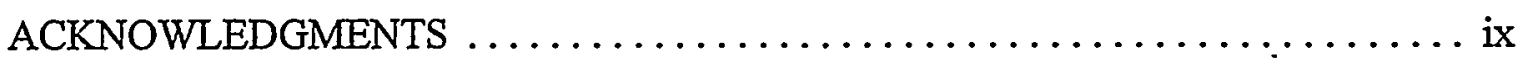

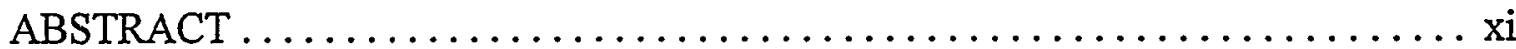

1. INTRODUCTION $\ldots \ldots \ldots \ldots \ldots \ldots \ldots \ldots \ldots \ldots \ldots \ldots \ldots \ldots \ldots \ldots \ldots \ldots \ldots$

2. PACIFIC NORTHWEST'S FRESH WATERS $\ldots \ldots \ldots \ldots \ldots \ldots \ldots \ldots$

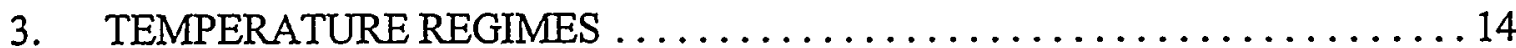

3.1 PROCESSES AFFECTING WATER TEMPERATURES $\ldots \ldots \ldots \ldots 14$

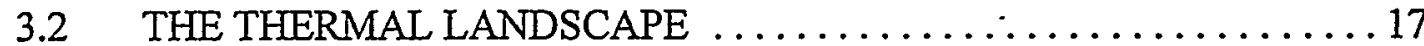

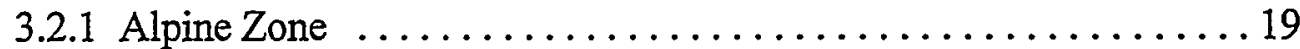

3.2.2 Mountain Slopes .............................. 19

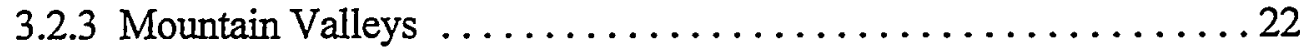

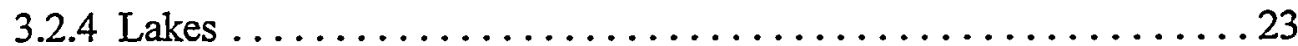

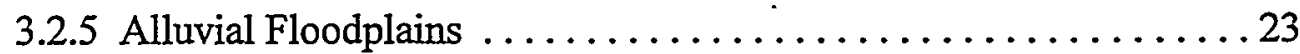

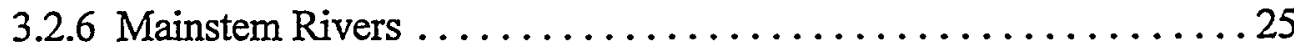

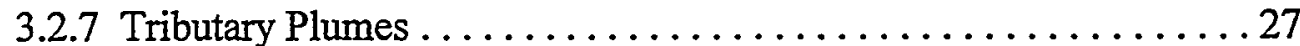

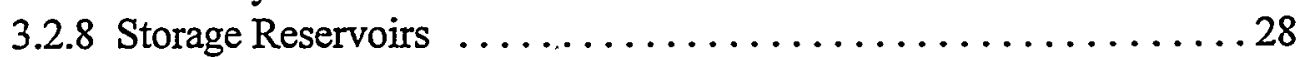

4. BIOTIC ADAPTATIONS TO NATURAL TEMPERATURE REGIMES $\ldots \ldots .32$

4.1 LIFE-CYCLE STRATEGIES $\ldots \ldots \ldots \ldots \ldots \ldots \ldots \ldots \ldots \ldots \ldots \ldots \ldots \ldots \ldots \ldots \ldots$

4.1.1 Fall Chinook Salmon ............................ 32

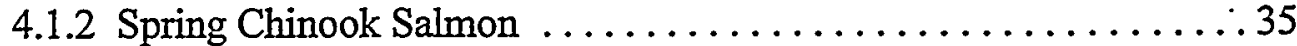

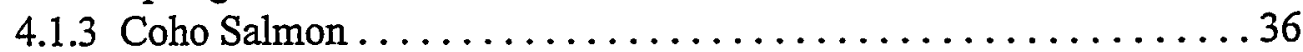

4.1.4 Sockeye Salmon ................................ 37

4.1.5 Steelhead and Rainbow Trout $\ldots \ldots \ldots \ldots \ldots \ldots \ldots \ldots \ldots \ldots \ldots \ldots \ldots$

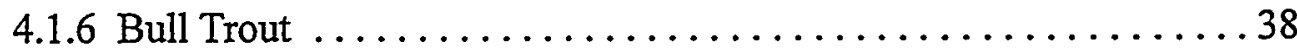

4.2 PHYSIOLOGICAL REQUIREMENTS $\ldots \ldots \ldots \ldots \ldots \ldots \ldots \ldots \ldots \ldots$

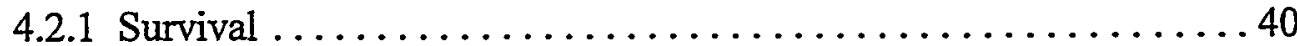

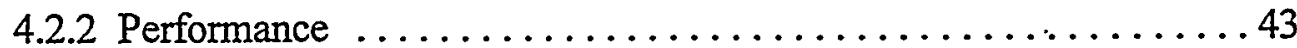

4.2.3 Reproduction ................................ 48

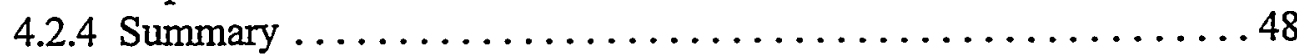

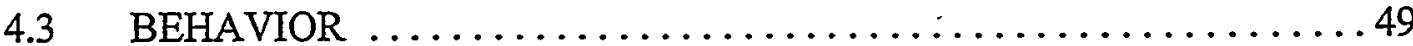

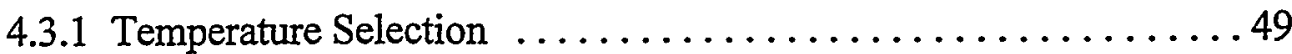

4.3.2 Thermal Refuges .............................. 50

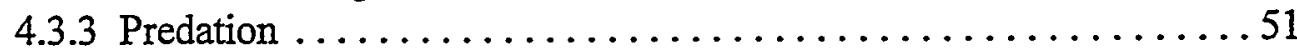

4.3.4 Competition ............................ 51 


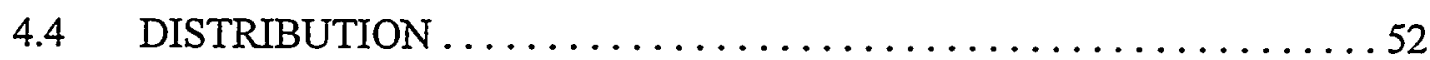

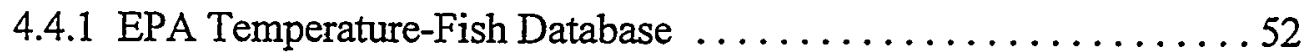

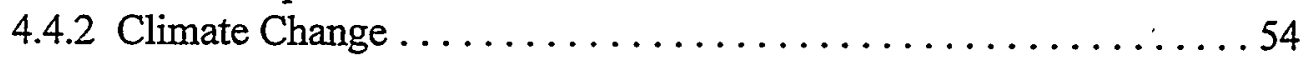

5. EXAMPLE SCENARIOS OF DETRIMENTAL THERMAL EFFECTS

IN THE PRESENT ENVIRONMENT $\ldots \ldots \ldots \ldots \ldots \ldots \ldots \ldots \ldots \ldots \ldots \ldots$

5.1 MCNARY FISH BYPASS THERMAL MORTALITIES $\ldots \ldots \ldots \ldots 57$

5.2 FEVER AND CHILLS-THE MALADIES OF THE SNAKE RIVER FALL CHINOOK SALMON ......................... 59

6. ISSUES IN THE DEVELOPMENT OF THERMAL STANDARDS $\ldots \ldots \ldots .64$

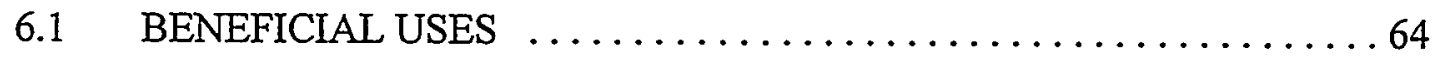

6.1 .1 Social Decisions ...............................65 65

6.1 .2 Biodiversity . . . . . . . . . . . . . . . . . . . . . . 66

6.1 .3 Spatial Scale .............................66

6.1 .4 Degraded Habitats ..............................66 66

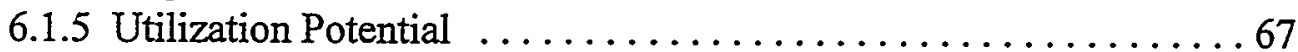

6.1 .6 How Many Segments? .........................67 67

6.1 .7 A Big Job .................................. 67

6.2 TEMPERATURE REQUIREMENTS $\ldots \ldots \ldots \ldots \ldots \ldots \ldots \ldots \ldots 6 . \ldots \ldots$

6.3 REQUIREMENTS FOR SALMONIDS VERSUS REQUIREMENTS

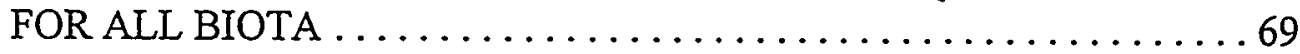

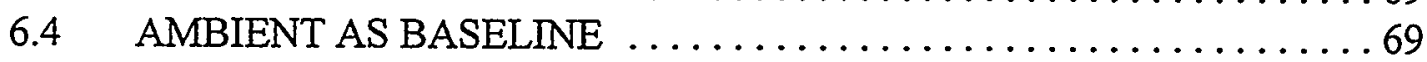

6.5 REGIONAL DIFFERENCES IN THERMAL REQUIREMENTS . . . . . 70

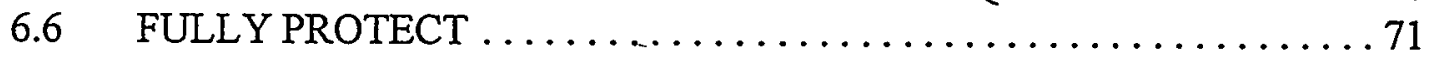

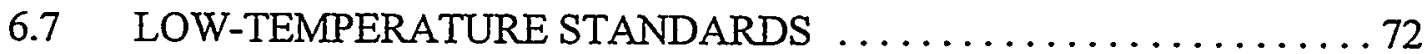

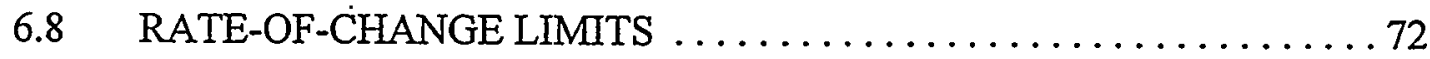

6.9 SPATIAL CONTINUITY OF STANDARDS $\ldots \ldots \ldots \ldots \ldots \ldots \ldots . \ldots 73$

6.10 WHAT TEMPERATURE TO REGULATE? $\ldots \ldots \ldots \ldots \ldots \ldots \ldots . \ldots \ldots$

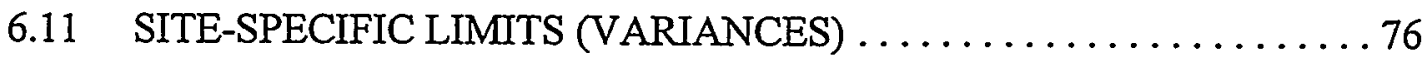

6.12 STEPS IN SETTING REACH-SPECIFIC STANDARDS . . . . . . . . 79

6.13 RESEARCH/ANALYSIS NEEDS FOR REACH-SPECIFIC

STANDARDS ...............................81

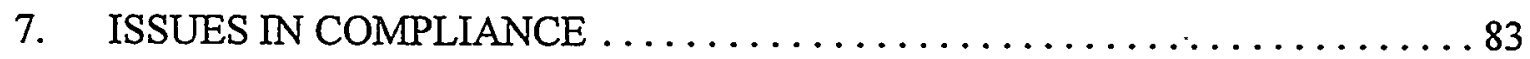

7.1 WHERE TO MEASURE TEMPERATURES FOR COMPLIANCE $\ldots .83$

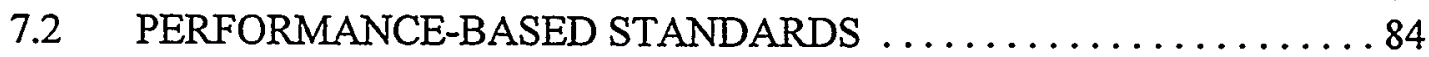

7.3 ALLOWABLE EXCEEDANCES $\ldots \ldots \ldots \ldots \ldots \ldots \ldots \ldots \ldots . \ldots . \ldots \ldots$

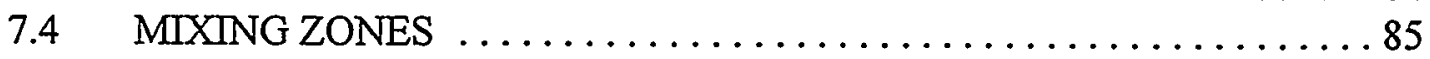


8. DEVELOPMENT OF ALTERNATIVE TEMPERATURE-REGULATING MECHANISMS ................................... 87

8.1 REGULATION OF LAND AND WATER MANAGEMENT PRACTICES AFFECTING TEMPERATURE ...............87

8.2 REGULATION OF NON-POINT-SOURCE INDUSTRIES FOR TEMPERATURE CHANGES ...................... 87

8.3 FLEXIBLE REGULATIONS/FREE-MARKET COMPLIANCE $\ldots \ldots .88$

8.4 FISHERIES MANAGEMENT TOOLS $\ldots \ldots \ldots \ldots \ldots \ldots \ldots . . \ldots 1$

9. ACTIONS TO CONTROL WATER TEMPERATURES ..............93

9.1 SELECTIVE DEPTH WITHDRAWALS FROM DAMS .......... 93

9.2 COLD-WATER DISCHARGES FROM DAMS IN SUMMER . . . . . 93

9.3 REPLANT RIPARIAN VEGETATION ...................994

9.4 REDUCE OVERBANK EXTENSIONS OF RESERVOIRS $\ldots \ldots \ldots .94$

9.5 CREATE/PROTECT THERMAL REFUGES ................ 94

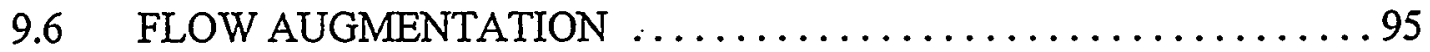

9.7 REDUCE AGRICULTURAL RUNOFF .................. 95

9.8 PHASE OUT FLOOD IRRIGATION $\ldots \ldots \ldots \ldots \ldots \ldots \ldots \ldots \ldots$

9.9 WINTER GROUNDWATER RECHARGE $\ldots \ldots \ldots \ldots \ldots \ldots \ldots 95$

9.10 REESTABLISH SPRING FLOOD PEAKS FOR GROUNDWATER

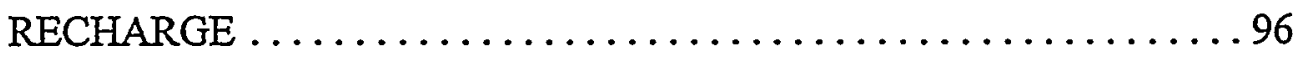

9.11 BREACH LEVEES AND ALLOW FLOODPLAIN FLOODING $\ldots \ldots 96$

9.12 REDUCE FISH EXPOSURE TIMES IN DAM FOREBAYS . . . . . . . . 96

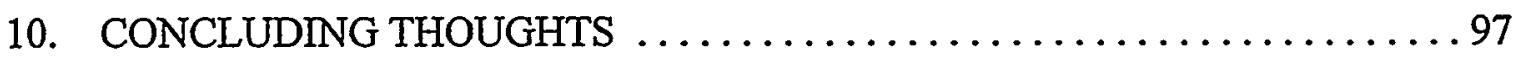

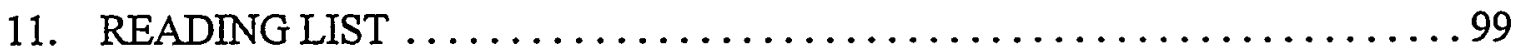

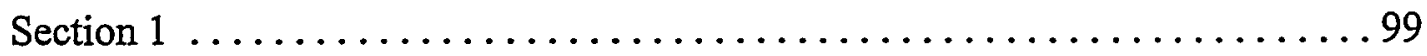

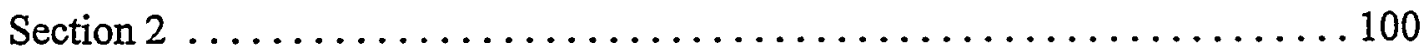

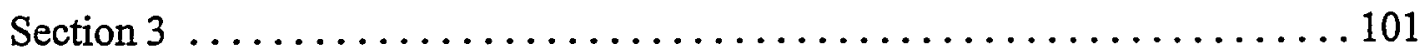

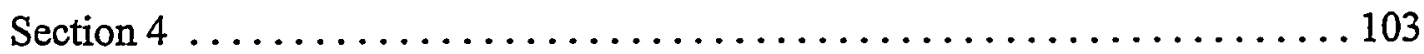

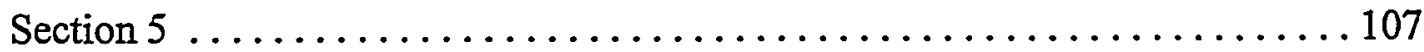

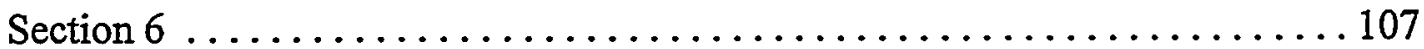

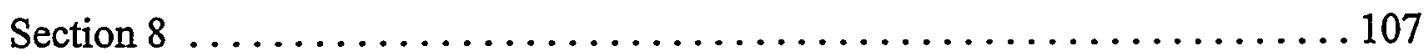

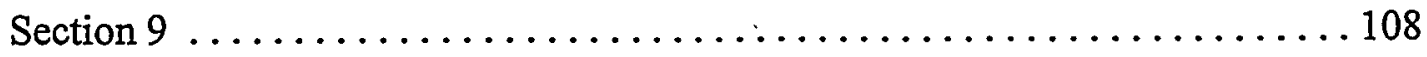




\section{LIST OF FIGURES}

Figure

Page

1 . Conceptual summary of several components of current water temperature

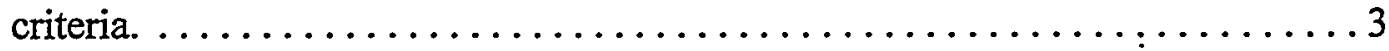

2 A conceptual view of the water-producing processes in the Pacific Northwest. . . . . . . . . . . . . . . . . . . . . . . . . . 7

3 Typical patterns of seasonal water volumes in a westslope river, and the Columbia River before impoundment, and the Columbia River following

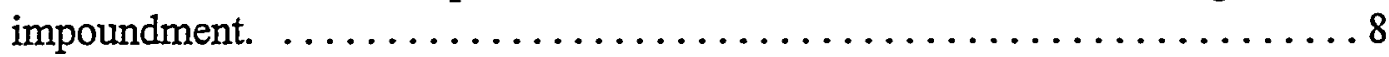

4 Diagrammatic cross sections of a river showing the annual cycle of water storage and return in an unimpounded condition (top three panels) and, for comparison, the annually stable water table of an impounded river . . . . . . 10

5 Diagrammatic longitudinal sections of a river valley between ridges showing (top) typical subsurface (alluvial) water flow and upwelling into the surface water where bedrock nears the surface, and (bottom) the impounded situation in which subsurface flow is hampered or terminated and no cool water returns to the surface. $\ldots \ldots \ldots \ldots \ldots \ldots \ldots \ldots \ldots \ldots$

6 Annual temperature cycles at Rock Island Dam on the upper mainstem Columbia River before (1936) and after (1951) Grand Coulee Dam was in

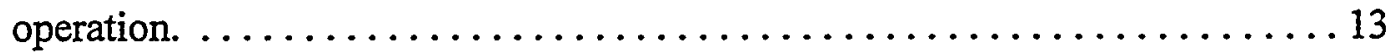

7 Mechanisms of heat transfer in a water body that determine its temperature. . . 15

8 Landscape zones of the Pacific Northwest that influence water temperatures. . . . . . . . . . . . . . . . . . . . . . . . . . 18

9 Water temperatures of the Tucannon River, Washington, from the headwaters to the confluence with the Snake River, in relation to suitability for salmonids (assumed $<20^{\circ} \mathrm{C}$ ). . . . . . . . . . . . . . . . 21

10 Creation of shallow over-bank and erosional zones in alluvial valleys by damming that provide large areas to collect solar radiation and cause temperature increases in river water. $\ldots \ldots \ldots \ldots \ldots \ldots \ldots \ldots \ldots \ldots \ldots$

11 Diagrammatic view of a storage reservoir with a deep (hypolimnetic) discharge, and its influences on downstream temperatures in summer (top) and winter (bottom). 


\section{LIST OF FIGURES}

$\begin{array}{lll}\text { Figure } & \text { Page }\end{array}$

12 Underflows of cool water in Lower Granite (top panel) and Little Goose (bottom panel) reservoirs on the Snake River from addition of $63^{\circ} \mathrm{F}$

$\left(17.2^{\circ} \mathrm{C}\right)$ Clearwater River water from Dworshak Reservoir with $68^{\circ} \mathrm{C}$ $\left(20^{\circ} \mathrm{C}\right)$ water from the Snake River. . . . . . . . . . . . . . . 31

13 Typical life cycle of an anadromous salmon. $\ldots \ldots \ldots \ldots \ldots \ldots \ldots$

14 Temperature tolerance of chinook salmon as determined by J. R. Brett. . . . 41

15 Performance of sockeye salmon as a function of acclimation temperatures, as summarized by J. R. Brett. .................... 45

16 The relationship between temperature and growth rate for sockeye salmon, shown for several levels of food availability and starvation, as determined by J. R. Brett.

17 Grid cells for the Pacific Northwest in the Canadian Climate Center general circulation model of the atmosphere, with projected average July-AugustSeptember air temperature increases accompanying a doubling of carbon dioxide in the atmosphere. . . . . . . . . . . . . . . . . . . 55

18 Temperature requirements of juvenile and adult chinook salmon, compared with scroll-case temperatures of the mainstem Snake River at Lower

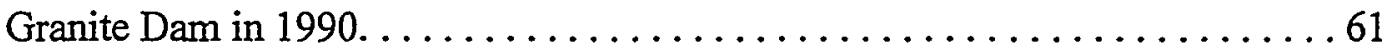




\section{ACKNOWLEDGMENTS}

This report was produced at the request of Marcia Lagerloef, Water Quality Standards Coordinator, U.S. Environmental Protection Agency, Region 10 (Seattle) and funded as U.S. Department of Energy Work for Others Project Number 2246-M125-A1. The scope of the review and its content were negotiated with Cara Berman, Water Quality Specialist, Region 10, to whom the author is grateful for stimulating interactions. The author thanks Cara Berman and D. S. McCullough for valuable comments on drafts. Interactions with regional participants in two thermal workshops in Portland, organized by Mary Lou Soscia, were critical for my ponderings. The ORNL Graphic Arts Department, èspecially LeJean Hardin, turned the author's rough sketches into line drawings. Karla Beason and Lana McDonald assembled the text files and figures into the final document. Many thanks to all.

The author may be reached at 423-576-6830 or coutantcc@ornl.gov. 


\begin{abstract}
This report provides a perspective on environmental water temperatures in the Pacific Northwest as they relate to the establishment of water temperature standards by the states and their review by the U.S. Environmental Protection Agency. It is a companion to other detailed reviews of the literature on thermal effects on organisms important to the region. Many factors, both natural and anthropogenic, affect water temperatures in the region. Different environmental zones have characteristic temperatures and mechanisms that affect them. There are specific biotic adaptations to environmental temperatures. Life-cycle strategies of salmonids, in particular, are attuned to annual temperature patterns. Physiological and behavioral requirements of key species form the basis of present water temperature criteria, but may need to be augmented with more concern for environmental settings. There are many issues in the setting of standards, and these are discussed. There are also issues in compliance. Alternative temperature-regulating mechanisms are discussed, as are examples of actions to control water temperatures in the environment. Standards-setting is a social process for which this report should provide background and outline options, alternatives, limitations, and other points for discussion by those in the region.
\end{abstract}




\section{INTRODUCTION}

Water temperatures in the rivers and streams of the Pacific Northwest exceed current state and tribal water quality standards at times and places. This exceedence has caused concern over temperature's possible role in the regional decline of salmon stocks, particularly those stocks listed under the Endangered Species Act. In addition, the standards themselves are subject to periodic revision by the states under the Clean Water Act, with review by the U.S. Environmental Protection Agency (EPA) in consultation with other resource agencies when endangered species are involved. The state of Oregon has recently adopted revised temperature standards, and the review and consultation process is under way. Other states are also revising standards. An effort is also under way by EPA Region 10 and its contractors to locate available temperature records, better define the locations and degrees of exceedence, model the temperature regimes of the Columbia and Snake river mainstems, and conduct appropriate biological assessments so that alternative standards, methods of enforcement, and remedial measures for the mainstem can be explored. Although present data compilation and modeling is directed primarily at the mainstems, similar attention must also be given to the tributary subbasins.

A synthetic perspective for the biological assessment of temperature effects on important biota and aquatic ecosystems is needed by the EPA, states, tribes, and concerned laymen for development, review, and enforcement of water temperature standards. Temperature standards have generally been established based on the perceived and experimentally demonstrated needs of anadromous and resident fishes and other aquatic life whose propagation is one of the designated water uses. There is abundant technical literature that defines suitable temperature ranges for adult migration, spawning, egg incubation, embryo development, juvenile rearing, smoltification, and juvenile migration (e.g., a recent review by D. McCollough ${ }^{1}$ ). Ways to incorporate such data into water temperature criteria and standards have been evaluated, and generally accepted approaches are used nationwide (e.g., review by the National Academy of Sciences and National Academy of Engineering published in 1973, as discussed further later in this Section and in Section 4.2). Although the biological basis of these (often laboratorybased) numerical standards for protection of salmonid life stages is believed to be generally robust, both standards and remedial measures need to be applied and interpreted in light of current understanding of the biological and ecological functions of the ecosystem and the ways in which water temperatures vary. In some cases, this broader perspective will reinforce earlier approaches. In other cases, it may suggest new ways of applying our overall ecological and physiological understanding to the protection of valued aquatic resources. This review attempts to give that perspective without intrusive details or specific documentation. Although some nontraditional approaches to regulating water temperatures may stand out as appealing, the purpose of this report is not to make recommendations, only to point out potentially promising alternative directions. A reading list of key references is appended to each major section.

${ }^{1}$ To enhance readability, this perspective report provides references as a reading list in section 11 for each major section. 
Temperature effects in the environment are more complex than are represented by most numerical limits. High temperature produces stress effects that are the result of not only to the magnitude of the temperature but also the duration of exposure. The responses often differ among life stages of a species, the prior thermal experience, and any prior or concurrently stressful exposures (such as to toxicants or low concentrations of dissolved oxygen). We know that organisms can tolerate thermal environments where temperatures briefly exceed levels that could be damaging if experienced over a long time. Fluctuating temperatures, rather than constant temperatures, are the norm at most places in the environment. Natural, complex habitats also usually have distinct spatial variations in temperature. Normal animal behavior often exposes mobile fish and many invertebrates to changing temperatures in natural habitats, both spatially and temporally. Most mobile organisms routinely seek temperatures that are physiologically most advantageous, when they have that opportunity.

The EPA's national criteria document for water temperature is about 20 years old, and there have been additional relevant scientific literature and conceptual advances since it was written by this author as a part of the 1970-1972 National Academy of Sciences/National Academy of Engineering study of water quality criteria. The existing criteria rely heavily on physiological tolerances as determined through laboratory experiments. Although still germane and important, that perspective does not always adequately consider the importance of environmental context, including potential sitespecific considerations. The physiological basis will not necessarily change, but the environmental perspective adds dimensions that can assist in setting temperature criteria and standards, monitoring relevant temperatures, and enforcement actions. Figure 1 shows a conceptual summary of current national criteria.

This perspective piece should help the EPA and others focus on realistic and highpriority temperature issues for aquatic life in the Pacific Northwest and assist the agencies in recommending appropriate standards and remedial measures. The overall objective is to provide background information and suggest alternative scenarios related to the EPA's role in ensuring that state water quality standards for water temperature protect the valued aquatic life of the region. The perspective delves beyond the usual numerical standards and into the need to determine, describe, and understand the appropriate spatial and temporal temperature regime that is necessary to sustain viable populations of salmonids throughout their range in Oregon, Washington, and Idaho. Whether a single temperature limit for a state (or a few) is sufficient as a standard will become clear only as the broader picture is understood. Particular attention is given to effects of temperature on the decline and rehabilitation of anadromous and resident cold-water fish stocks. As befitting the status of a work in progress, these ideas are those of the author and not of EPA.

This report attempts to shed perspective on recent technical reviews and recommendations for changes in water temperature standards. Several efforts to summarize the existing scientific literature on temperature regimes and their effects on salmonid life-history stages have been conducted (e.g., by the Oregon Department of Environmental Quality in 1995, M. Karr and colleagues in 1998, Washington Department of Ecology in a review draft made available in 1998, and by D. McCollough published 1999; see reading list below). However, these efforts usually do not provide an in-depth analysis and synthesis of issues of environmental context relevant to EPA's review of 


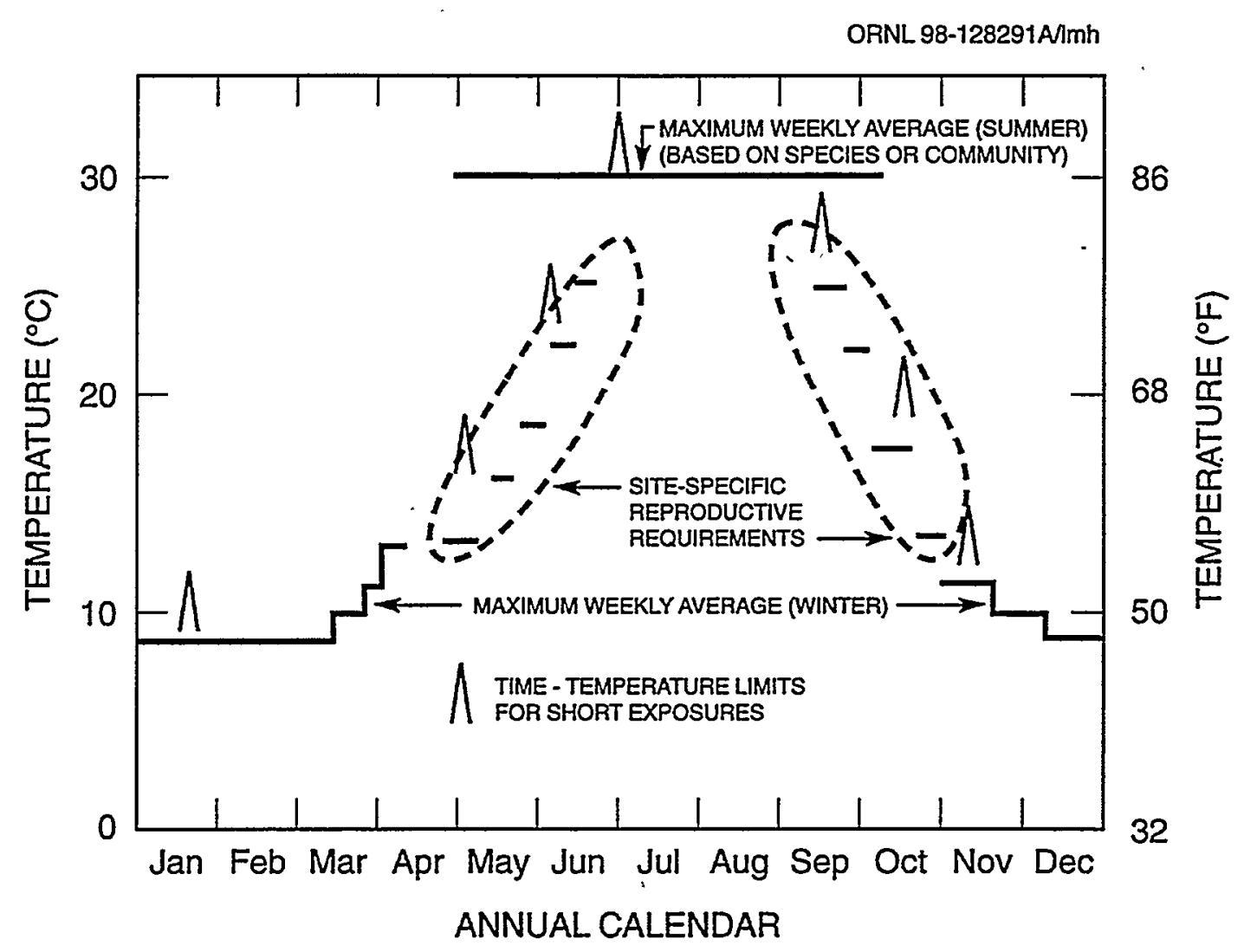

Fig. 1. Conceptual summary of several components of current water temperature criteria. A maximum weekly average temperature in summer protects growth rates of local species and life stages. Reproductive requirements of local species establish bounds for spring and fall changes in temperature to maintain a normal annual cycle. Maximum weekly average temperatures in winter for thermal discharges protect from potentially lethal temperature drops to a cold ambient temperature. Throughout, there are allowable brief excursions (acute exposures) that are known to be tolerated because of short duration. Specific temperatures depend on the species and life stages present. 
proposed temperature standards or its determination under the law that particular standards would "fully" support all salmonid life-history stages. The following list indicates the elements of this synthesis to support EPA's water quality standards review and decision-making process.

1. Ecological Context. The spatial and temporal variability in temperature within intact aquatic systems is described, with examples. Issues of heterogeneity and scale are included. The synthesis relates system pattern and species flexibility. It explores how intact natural systems provide complexity and redundancy to support required temperatures. Our ability to capture the natural context of temperature in thermal measurements (monitoring) for standards is discussed.

2. Processes Affecting Stream Temperature. Natural and anthropogenic processes and disturbances that affect riverine temperatures are critically evaluated. Intact systems are contrasted with altered or managed systems for their abilities to provide needed thermal regimes. The synthesis considers the role of thermal refugia in disturbed and undisturbed systems as well as actions that affect the number, distribution, and accessibility of various thermal refugia types.

3. Lethal and Sublethal Biological Temperature Effects. Available life-history histograms (used to summarize species thermal requirements in the context of annual temperature cycle) are critically evaluated and expanded with additional information (species and responses). The traditional evaluation of temperature effects as lethal responses is extended to the more relevant sublethal effects at different levels of biological organization. Sublethal effects are placed in the ecological context of predation, disease, and other ultimate causes of mortality. The objective is to demonstrate principles, rather than compile a compendium.

4. Intermittent Elevated Temperature Exposure. Because fluctuating temperatures are the norm in the environment, the limited literature base for determining biological effects has been reviewed and methods of analysis presented. Cumulative effects of intermittent exposures are evaluated in terms of the time and extent of excursion above static effects thresholds.

5. Biologically Relevant Temperature Data. Various temperature recording, summarization, and evaluation approaches (e.g., 7-day average of maximums) and their relevance to ecological requirements of salmonids are critically evaluated. The value of field data showing correlations between measured temperatures and species' occurrence . are considered. Approaches are recommended that might allow regulators to assess stream network conditions and the system's ability to fully support salmonids.

6. Regional Criteria. The synthesis indicates elements of a set of temperature standards that should have broad application to salmonid habitats in the Pacific Northwest. It considers the issue of protection of multiple species in a single habitat. The discussion focuses on attributes rather than specific numbers.

7. Site-Specific Temperature Criteria. The synthesis identifies conditions that might lead to naturally high water temperatures or special adaptations of salmonids to warm water. A process is recommended for developing and evaluating site-specific temperature criteria, including minimum database needs.

8. Research Needs and Methodology Development. The synthesis identifies needed short-term and long-term research and methodology development. For example, 
field methods to assess physiological and behavioral responses of salmonids exposed to fluctuating temperature regimes. These needs should be addressed not only by the EPA but by other resource agencies, such as the U.S. Geological Survey (especially the Biological Resources Division), U.S. Fish and Wildlife Service, National Marine Fisheries Service, and state and tribal resource agencies.

9. Practical Objections to Temperature Criteria. Attempts are made to anticipate and respond to possible objections from those regulated as they pertain to selecting defensible standards. These objections include anecdotal observations of fish residence in high temperatures, objections to characterizations of natural stream temperatures, etc.

10. What $\mathrm{Can} \mathrm{Be}$ Done to Control Water Temperatures? We are not at the mercy of uncontrolled processes that affect water temperature. We can modify temperatures to be more suitable for aquatic life, especially salmonids. The synthesis indicates several types of possible actions. 


\section{PACIFIC NORTHWEST'S FRESH WATERS}

The Pacific Northwest is blessed with abundant water. However, it often occurs in places and times that are not always sufficient to meet the needs of both humans and living natural resources. Thus, the region has a complex system of water management. Both the natural system and the present configuration of dams and reservoirs provide the environmental context for temperature regulations.

At a broad scale, the north-south mountain ranges generally capture moisture arriving from the Pacific Ocean in repetitive weather fronts. These fronts are most prominent during the cool seasons of fall through spring. This moisture drains to the ocean via west-side rivers of the coastal mountains, is stored in subsurface aquifers, and is stored through winter as snow and ice at high elevations. Spring initiates melting of the snowpack, and the stored frozen water then continues to recharge aquifers and the excess drains to the sea. Because of the timing of their arrival (winter) or melt (spring), the water supplies of the region are generally cold initially. Figure 2 shows a typical weather front and its deposition of moisture in the Pacific Northwest.

Capture of moisture by mountain ranges, especially the Cascades, creates the major physiographic dichotomy of the Northwest-the wet west slope and the arid east side. The geological Columbia Basin between the Cascades on the west and the Rocky Mountain chain on the east is in the Cascades' rain shadow and receives little direct precipitation in most years. The Rocky Mountain chain, however, captures an additional amount of moisture from the atmosphere. Nearly all of it is stored as snow and ice. The west slope of the Rockies is drained of its snowmelt in spring by the Snake River to the south and the Columbia River to the north, which meet to pass through the Cascade Range in the Columbia River Gorge. These large rivers were naturally characterized by high flows in late spring and early summer when most melting occurs at high elevations in British Columbia, northern and southeastern Idaho, eastern Montana, and extreme northwestern Wyoming. Although passing through arid and sunny terrain, these large rivers were cold in summer because of the combined effects of cold meltwater sources, large volumes, and unique features of the terrain, such as large alluvial (gravel-filled) valleys that stored cold water underground. Figure 3 shows typical pre-dam patterns of water volumes (hydrographs) for a westslope river and the Columbia mainstem. A current hydrograph of the impounded Columbia is shown for contrast and will be discussed in Section 3.2.6.

There is little natural surface-water storage capacity in the region, although natural glacial lakes abound at high elevations and in some low-lying valleys (e.g., Lake Chelan, Wallowa Lake, lakes of the Stanley Basin in Idaho) and there are a few other large geomorphic lakes (Lake Pend Oreille in Idaho and Flathead Lake in Montana). Thus, rivers on the west slope of coastal mountains are characterized by high winter runoff in rivers, such as the Nooksack, Skagit, Cowlitz, Umpqua, and Rogue. Especially high runoff can be caused by a mix of heavy rain on top of snow, which melts rapidly adding to the runoff. Lakes of the interior Columbia River Basin did little to moderate river flow but retained the cold temperatures of meltwater through the summer. 


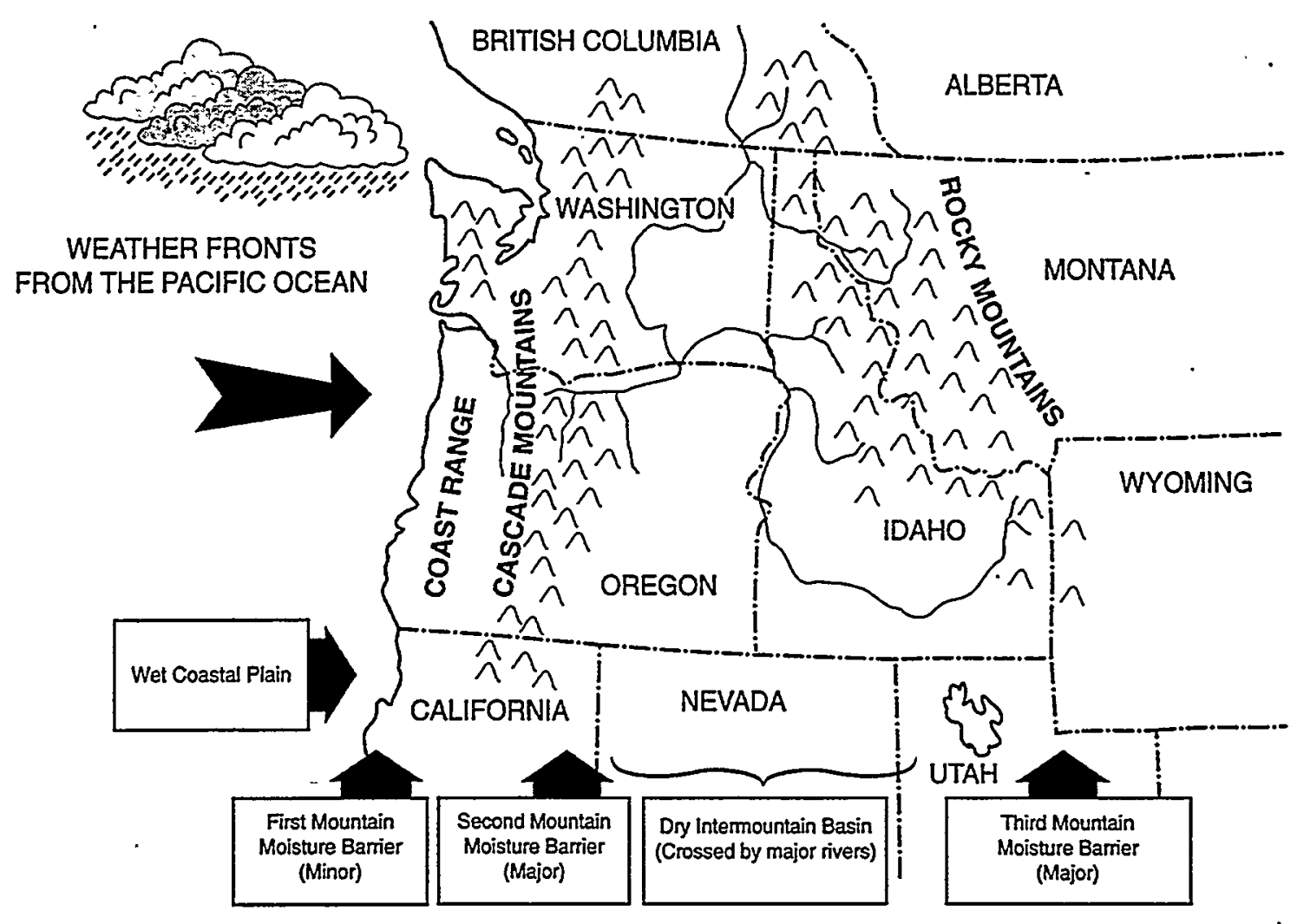

Fig. 2. A conceptual view of the water-producing processes in the Pacific Northwest. Weather fronts arrive from the west, mostly in cool seasons, carrying oceanic moisture. Mountain ranges both intercept the atmospheric moisture flow and store moisture in frozen form at high elevations in winter. A succession of moisture barriers enhances moisture retention in the region. 


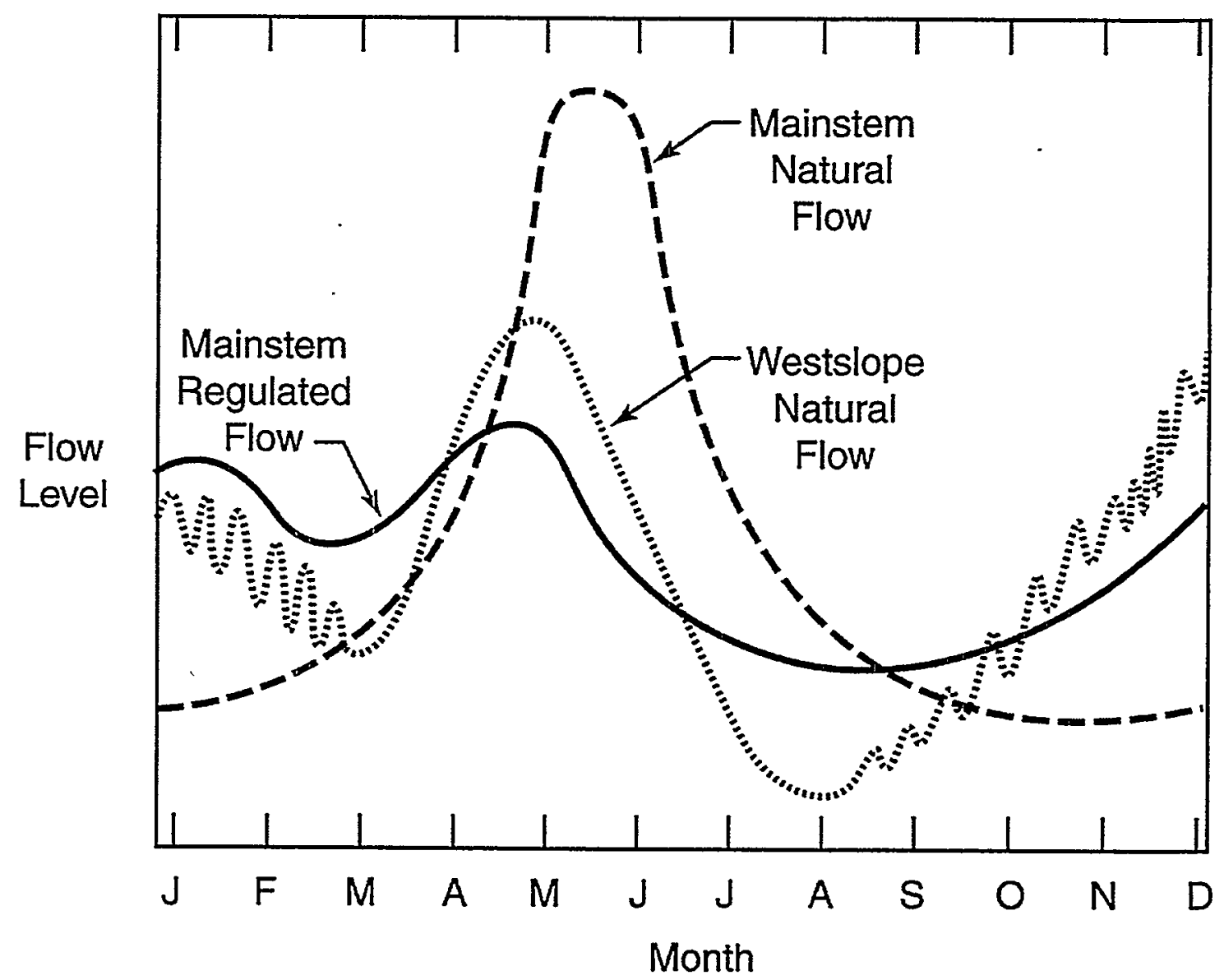

Fig. 3. Typical patterns of seasonal water volumes in a westslope river, and the Columbia River before impoundment, and the Columbia River following impoundment. Westslope rivers are rainfall dominated September-March, with erratic flows. Natural summer flows of both westslope rivers and the Columbia River are dominated by snowpack meltwater. Storage reservoirs, now alter the mainstem flows. 
A poorly appreciated water storage reservoir in the natural environment of the Northwest is its alluvial gravels. The central basin between the Cascade Range and the Rocky Mountains and also the mountain regions themselves are a series of ridges interspersed with alluvial valleys filled with gravel, sand, and silt from erosion of the ridges. These valley sediments have often been reworked by intermittent periods of heavy precipitation and high runoff (including catastrophic meltwater flows from breached ice dams at the end of the last glacial period). Especially large alluvial valleys include the Hanford-Tri-Cities-Walla Walla area of Washington upstream of Wallula Gap, the upper reaches of John Day Reservoir and lower Umatilla River, and the Snake River floodplain upstream of Hells Canyon. Recent research has crystallized the view that these alluvial gravels in natural river floodplains (both large and small) store cold water in the high-runoff periods of spring and release it gradually to maintain surface flow (and cool temperatures) during periods of low runoff in summer and autumn. Adequate recharge of these gravels depended on high spring peaks in river elevation. Figure 4 shows a series of diagrammatic river cross sections, and a three-dimensional perspective that illustrate alluvial water storage during spring high-water periods before rivers were impounded, and for comparison, the stable water-table pattern in an impounded river (which will be discussed below). Figure 5 shows a longitudinal slice along an alluvial valley from ridge to ridge showing how the subsurface water migrates slowly through the gravels and reenters the surface water where bedrock nears the surface. The impounded situation, in which subsurface flow is hampered, is shown for comparison. Similar patterns to those shown in Figures 4 and 5 occur whether the river is the mainstem Columbia or Snake rivers or a small tributary river (although tributary rivers are more likely to have a larger proportion of bedrock substrate and less subsurface water storage).

Humans have intervened in the water cycle of the Northwest in many ways, with effects on water temperatures (some clear, others debated; more discussion will follow). Although the basic cycle of regional water supply as affected by the atmosphere and mountains remains little changed, our capacity to store water in surface impoundments and regulate river flows to aid human uses has increased dramatically. This has occurred mostly in the arid interior basin, although also elsewhere to a lesser degree. Most important for water storage in the Columbia-Snake mainstem are large reservoirs in the headwaters: Dworshak (Idaho), Libby (Montana), Hungry Horse (Montana), and Mica, Arrow, and Keenleyside (British Columbia). Grand Coulee, although large, is usually not operated for water storage but for hydropower and irrigation water diversion. Water storage is usually combined with hydropower production. Most tributaries to the Snake and Columbia also have smaller storage reservoirs, usually in conjunction with hydropower. The list of these is long, but includes Timothy Meadows (Willamette system), Round Butte (Deschutes River), Post Falls (Spokane River). Reservoirs in the Pacific Northwest are shown on numerous maps, such as one from the Bonneville Power Administration (DOE/BP-1721). Although most of the mainstem dams impound considerable quantities of water, the reservoir elevations are maintained within narrow limits to serve navigation and hydropower generation needs on daily cycles rather than seasonal storage and release of water. Exceptions include the major Snake River hydropower projects, Hells Canyon and Brownlee, which are operated to include 

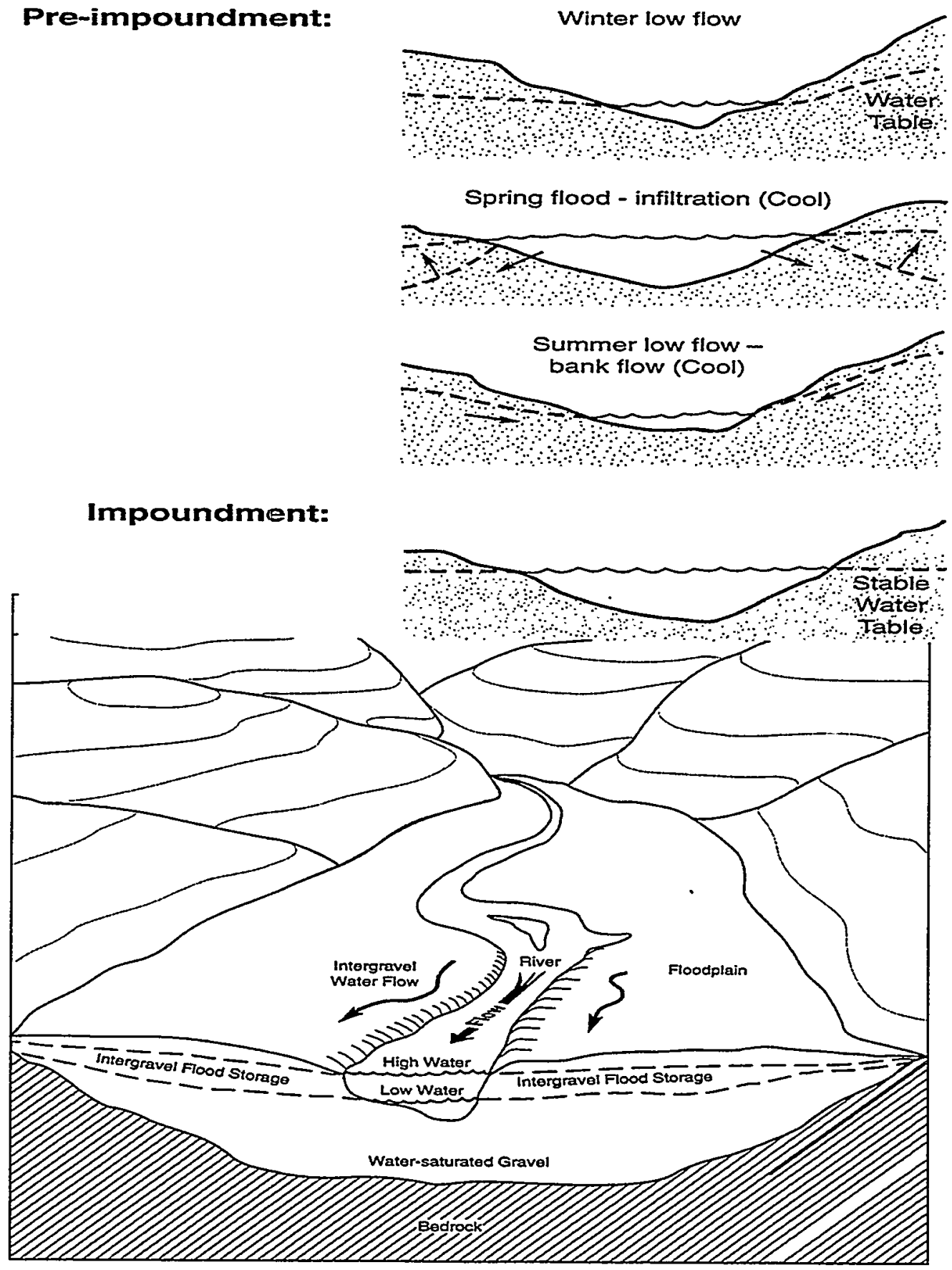

Fig. 4. Diagrammatic cross sections of a river showing the annual cycle of water storage and return in an unimpounded condition (top three panels) and, for comparison, the annually stable water table of an impounded river. 


\section{Pre-Impoundment}

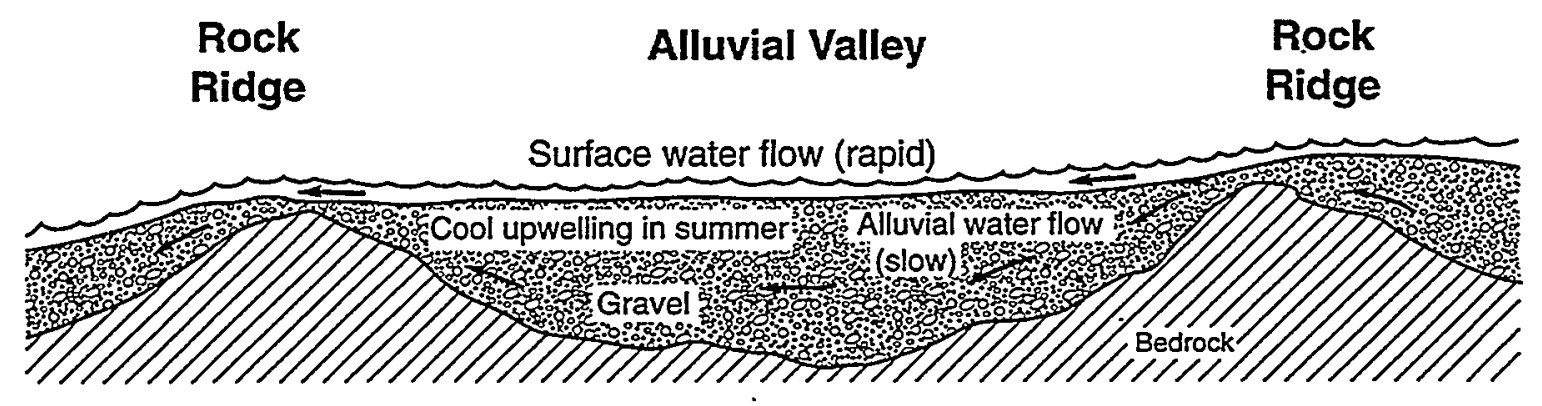

\section{Post-Impoundment}

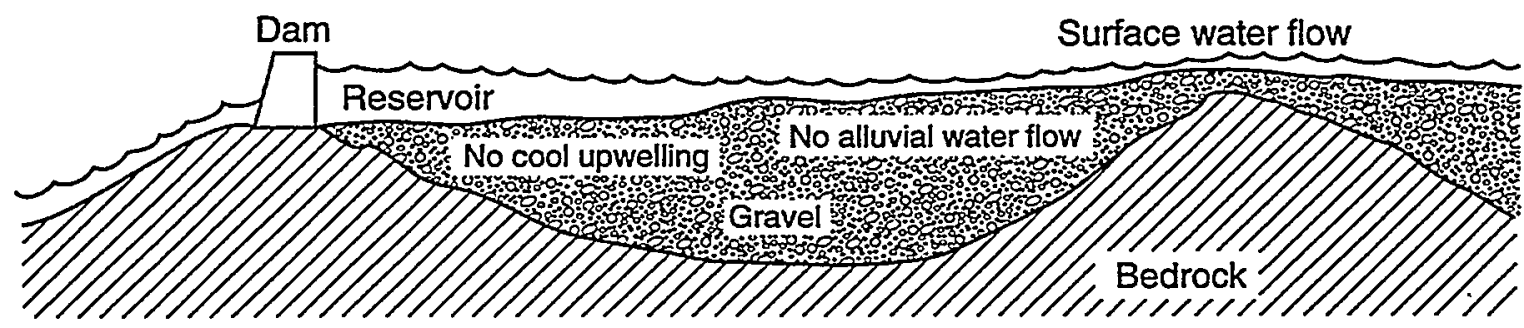

Fig. 5. Diagrammatic longitudinal sections of a river valley between ridges showing (top) typical subsurface (alluvial) water flow and upwelling into the surface water where bedrock nears the surface, and (bottom) the impounded situation in which subsurface flow is hampered or terminated and no cool water returns to the surface. 
considerable seasonal storage capacity. Reservoirs on tributaries often are operated for seasonal storage and hydropower.

The result of seasonal water storage in man-made reservoirs is to temper the annual flow periodicity for major rivers, often to the point of reversal of natural seasonality. This is shown in Figure 3. High spring runoff is stored in the surface reservoirs and released at other times of the year when human demands for electricity (winter) and irrigation water (summer) predominate. Flood peaks of spring are greatly reduced and low flows are augmented. Reduction of peak flows markedly reduces the amount of recharge of alluvial valleys with cold water, as shown in Figure 4.

The operations of reservoirs to manage water flows in the region combine to secondarily create unnatural temperature cycles in dam tailwaters and downstream rivers. This unintended effect will be discussed more later in this report, but it is important to recognize it here. The stored cold water from spring runoff is intentionally released later in the year when rivers would normally be warming. There is an important time-delay effect of this storage. Most storage reservoirs are designed to release water from deep layers, which remain cold through much of the summer because of thermal stratification. This deep, cold water is gradually depleted by autumn, and then stored water warmer than natural is released through the winter. This is illustrated in Figure 6, which contrasts the annual temperature cycle of the unimpounded Columbia River upstream of Rock Island Dam in 1936 with temperatures after Grand Coulee Dam was in operation (1951) but before Grand Coulee releases were managed to provide cooling for the downstream Hanford Works. Even more striking thermal changes occur below tributary storage reservoirs, as will be discussed in Section 3.2.8.

Whereas hydropower has affected the seasonality of flows, irrigation has reduced or nearly eliminated streamflows of several rivers in the growing season. Irrigation diversions both remove cool stream water and return water from fields that is warm and poor in general water quality. The normal spring recharge of alluvial gravels underlying floodplain agricultural fields by cold floodwaters has been replaced with infiltration by warm irrigation water in summer. 
ORNL 98-128284A/mhr

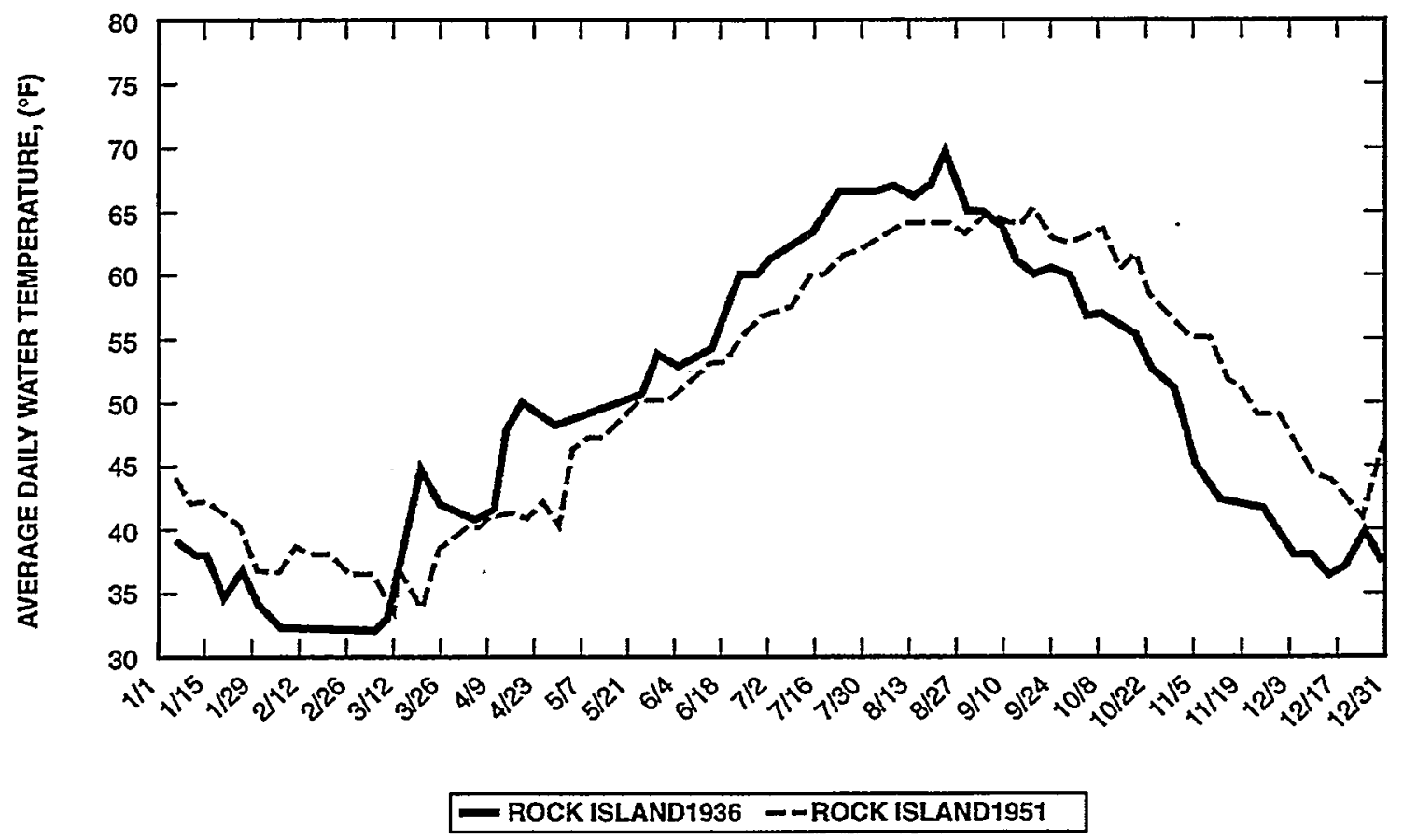

SOURCE: DATA FROM DAVIDSON, 1964

Fig. 6. Annual temperature cycles at Rock Island Dam on the upper mainstem Columbia River before (1936) and after (1951) Grand Coulee Dam was in operation. 


\section{TEMPERATURE REGIMES}

\subsection{PROCESSES AFFECTING WATER TEMPERATURES}

Although the Northwest's water supplies generally originate at cold temperatures as a result of either cold winter rains (west side) or snow melt (mountains), many factors combine to change water temperatures in the region as water flows from the sources to the ocean. Often the change is progressive warming. There are several principles of heat balance in the environment that determine water temperatures in reaches of streams, rivers, lakes, and reservoirs. They act together, often creating complex thermal situations on a local scale. Our view of any particular situation is given perspective when we consider the basic physical principles that are at work. The discipline of hydrothermal modeling is an active field of research that involves integration of these principles and local conditions through mathematical calculations in order to predict water temperatures. Figure 7 illustrates the mechanisms of heat transfer to a water body.

First, it is necessary to understand the difference between heat and temperature, especially as these differences relate to effects on organisms. The two terms are often used loosely and interchangeably without considering their very important difference. As explained by the water quality criteria panel of the National Academy of Sciences/National Academy of Engineering at the outset of the chapter on Heat and Temperature in its report Water Quality Criteria 1972, living organisms do not respond to the quantity of heat but to the degrees of temperature or to temperature changes caused by the transfer of heat. Heat usually refers to an amount of energy, in units of British Thermal Units (BTUs), joules, ergs, or other quantitative measures. Temperature, on the other hand, is the measure of the energy concentration in a body, measured as degrees on Fahrenheit, Celsius (centigrade), or Kelvin (absolute) scales. A certain amount of heat can be transferred to a large body with a small increase in that body's temperature. Conversely, that same amount of heat added to a smaller body will cause a larger increase in temperature. The energy concentration determines the movement of atoms and molecules in organisms and their environment and thus establishes the upper and lower limits of biological functioning and the rates of functioning in between. Heat (energy) is transferred in many ways that affect the temperature of water bodies. If we wish to manage water temperatures to meet standards or for other purposes, we must influence these heat-transfer processes in relation to the size (e.g., volume or surface area) of the water body or stream reach. Numbers for the following paragraphs correspond to numbers on Figure 7. Detailed descriptions are available in standard thermodynamic textbooks.

1. Heat is gained or lost by water across the open surface depending on the difference between water temperature and air temperature. Part of this transfer is by direct conduction and convection (often called "sensible" heat transfer). For every air temperature, there is an equilibrium water temperature, although true equilibrium is rarely reached. When water is cooler than air, the water will generally tend to warm over time; when water is warmer than air, the water will tend to cool. It is often said as a matter of

principle that river systems tend to get warmer as they flow from headwaters to the 

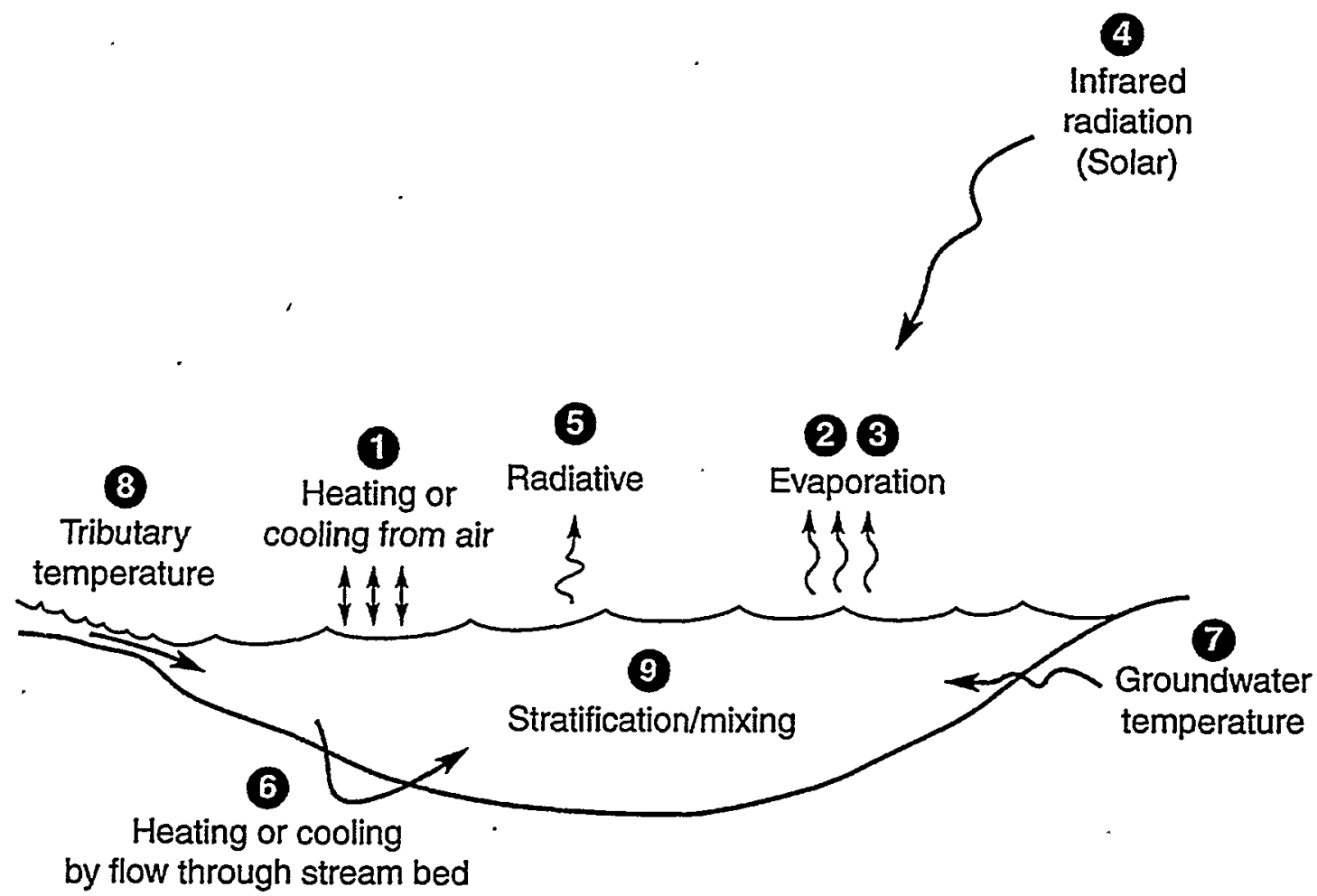

Fig. 7. Mechanisms of heat transfer in a water body that determine its temperature. Numbered items refer to mechanisms discussed in the text. 
mouth. This is true mostly in the warm seasons when warm air temperature tends to lead to warming of the water. The reverse occurs in winter.

2. The equilibrium water temperature is determined by not only the temperature difference between water and air, but by humidity in the air. Evaporation from the water surface is a major cooling agent (heat is extracted to turn water from liquid to a vapor); this occurs less efficiently when the air is humid.

3. Wind speed at the water surface affects the equilibrium temperature between water and air greatly. Higher wind speeds induce greater evaporative cooling and greater direct heat conduction across the water surface. Wind also generates waves, that effectively add surface area to the waterbody.

4. Incident solar radiation (sunlight) exerts a major warming influence. Solar radiation, mostly short-wave, infrared rays (heat), is absorbed by water, bodies in the water, and shoreline structures in contact with water, with heat energy being released. The more a volume of water is exposed to open sunlight or to solid structures (e.g., rocks) in sunlight, the more the water will gain heat. Shallow, sunlit streams warm rapidly because of their small volume and can soon exceed the equilibrium temperature with surrounding air. The amount of heat provided by sunlight varies latitudinally, seasonally, and with local weather conditions (clouds). Overhanging vegetation can absorb most incoming solar radiation before it strikes the water.

5. There is radiation of heat to the atmosphere (space) by long-wave, back radiation, which exerts a cooling effect. This occurs at all times of day and night, but its resulting effect on water temperature is most evident in the dark, when the radiative heat loss is not balanced or overpowered by incoming solar radiation. Much of the long-wave radiation emitted by the water surface is absorbed by clouds and water vapor content of the atmosphere and is re-radiated back to the water surface. Nonetheless, there is generally a net heat loss at night. Because of this net radiative heat loss at night, the equilibrium temperature is lower at night. A daily cycle of daytime warm water and night time cool water in streams is usually the combined result of daytime sunlight and warm air temperatures contrasted with nighttime darkness (net outgoing radiation) and lower air temperatures. The daily cycle is more prominent in small, shallow, unshaded streams without significant groundwater input than in larger or shaded streams with subsurface flow.

6. Subsurface flow in the gravels of a streambed influences aboveground stream temperatures. A large subsurface flow could mean simply that the stream volume is greater than it appears to be at the surface, and the rates of heating and cooling are affected accordingly. However, there are additional effects. Long reaches of slow intergravel flow (such as in long gravel bars or alluvial floodplains) can induce a time lag both daily (instream gravel bars reduce the amplitude of daily temperature cycles) and seasonally (alluvial floodplains delay stream warming in spring and cooling in autumn through contact of subsurface flows with cooler or warmer gravel, respectively). Subsurface storage is augmented when surface stream elevations are high and returned to the surface stream when surface elevations decline. Subsurface flows can reenter a stream through side channels, sloughs, or springbrooks as well as in the main channel. Reentry can be at discrete patches determined by the local layering of buried gravels. 
7. Groundwater derived from sources outside the streamflow (as opposed to subsurface streamflow) can either cool (in summer) or warm (in winter) a stream. Groundwater draining from headlands is usually at or near a constant annual temperature that is characteristic of latitude and altitude and generally reflects the annual average temperature for the location. Groundwater can enter a stream or lake in discrete springs, side seeps, or upward through the stream bottom, all of which can occur in side channels or sloughs as well as in the main channel. Distinguishing subsurface streamflow from true groundwater can be difficult.

8. Tributary inflows can warm or cool a receiving body, depending on the difference in temperature and the relative volumes of water.

9. In standing or slowly moving water, different temperatures can cause the water body to stratify into distinct thermal layers and impede mixing. This happens because the density of water changes with temperature, being heaviest at $4^{\circ} \mathrm{C}\left(39.2^{\circ} \mathrm{F}\right)$. In warm seasons, cooler water tends to lie at the bottoms of stream pools, lakes, and reservoirs. In winter, the coldest water (cooler than $4^{\circ} \mathrm{C} / 39.2^{\circ} \mathrm{F}$ ) and ice come to the surface. Stratification and inflow through the substrate provide relatively cool zones in summer and warm zones in winter near the bottoms of natural waterbodies. Seasonal formation and breakup of stratification can greatly affect the temperatures available to aquatic organisms. Temperature-density differences often determine how, and how well, water masses mix when they merge, as when a stream enters a pool or a river enters a reservoir. The inflowing water will usually join the stratum that matches its own density (temperature). Cold discharges from an upstream reservoir will often flow as an "underflow" beneath the warmer and less dense water of a downstream reservoir. Establishing a regulatory temperature standard for such thermally complex stratified systems is a challenge.

\subsection{THE THERMAL LANDSCAPE}

The water sources and processes that affect water temperature combine to yield a Pacific Northwest water landscape that is naturally both characteristic and heterogeneous. Both the characteristic features and the heterogeneity have been altered by human development in ways that can detrimentally change the thermal environments needed by salmonids and other living natural resources. An understanding of the natural thermal landscape [the "normative condition" in the sense of the Independent Scientific Group's report Return to the River (1996)] will foster our ability to retain and restore the key features. The environmental context of water temperatures is discussed in this section in somewhat arbitrary categories progressing from alpine headlands to the lower reaches of the mainstem. It is not intended that these be zonations for precise temperature expectations or application of zone-specific standards. Nor is it intended or possible to specify and recreate exactly what streams were like when they existed in a pristine condition: But it is useful to visualize the geographic context of water temperatures as we contemplate how to protect the thermal resources needed by salmonids. Figure 8 represents the movement of water from the sources in the mountains, through the various characteristic landscapes, and into the ocean. 


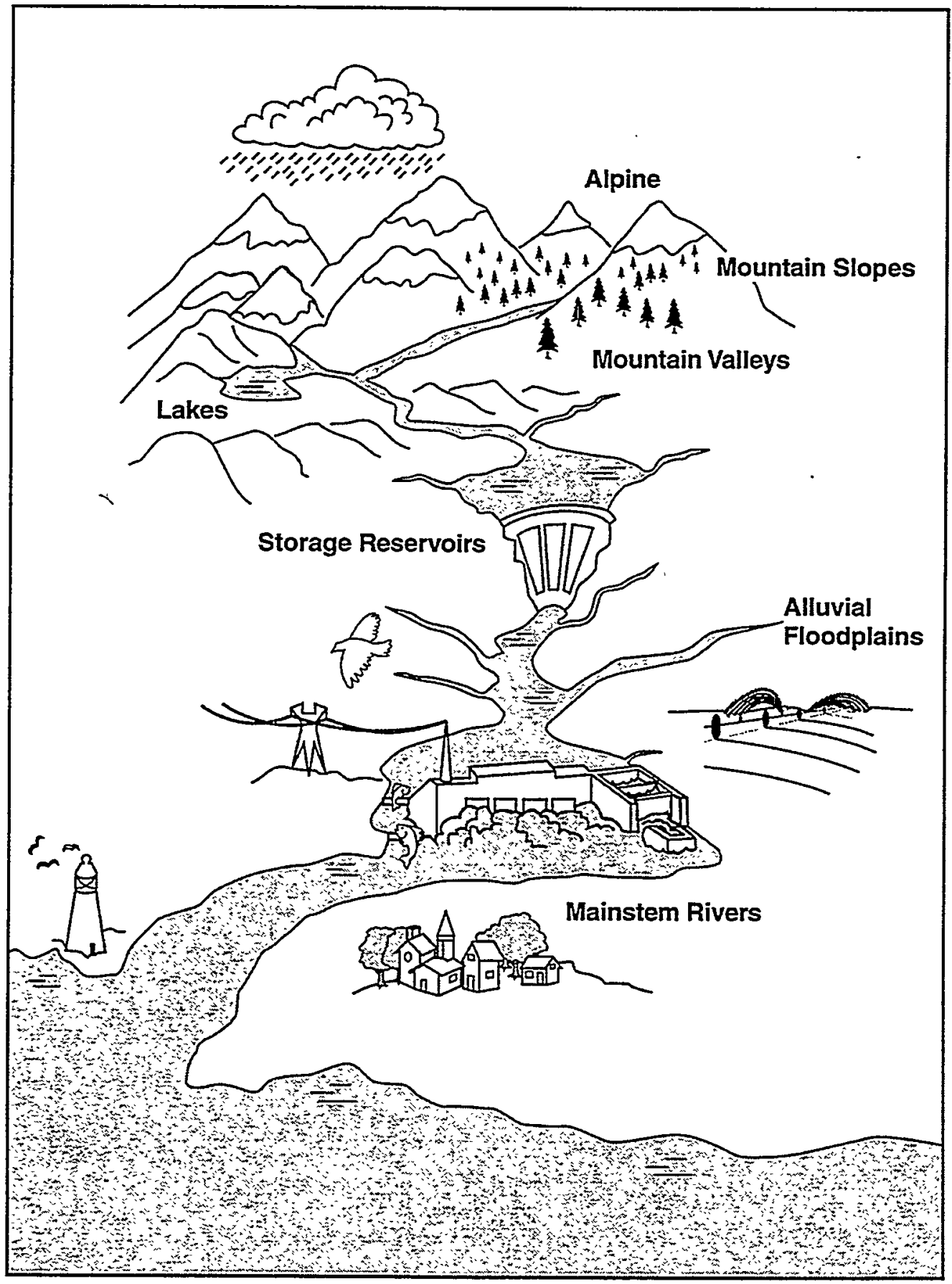

Fig. 8. Landscape zones of the Pacific Northwest that influence water temperatures. 


\subsubsection{Alpine Zone}

A useful starting point is spring in an alpine meadow above the tree line in a mountain range such as the Cascades, Bitterroots, or Wallowas. Snow from winter storms is packed into the glacial cirques, or bowls, carved by long-ago-melted glaciers. The meadow itself is snow-covered. With the advent of spring and summer sun and warmer winds, the snowpack melts slowly. There is a flush, buit not flood, of meltwater followed by more gradual draining. Accumulated gravel talus from shattering rock peaks and organic bogs in the meadow become deeply saturated with meltwater as if they were a big sponge and they release the cold water slowly to meandering streams. Small cirque lakes at the bases of bowls are often shaded by the surrounding peaks, warm little, and are both fed and drained by cold subsurface flow. Although an occasional thunderstorm adds more and warmer precipitation, the meadow streams drain through the warm, dry season mostly from stored meltwater and continued melting of the last remaining snowfields. These streams are generally deep for their width and have overhanging mats of alpine vegetation including ferns and mosses. Little sunlight hits directly on the water and the streams remain cold (nearly at the freezing point of water for much of the summer). The return of snows and cold in early fall or late summer ends most of the drainage.

Fortunately, there have been few human alterations of these alpine landscapes. A century ago, and locally still, an occasional mining operation was established in the uplands. Their churning of rock and meadows disrupted local stream zones and undoubtedly opened waterflows to greater solar radiation and stream heating. Areas of the Upper Grande Ronde basin and elsewhere were subjected to placer mining and have not recovered to any semblance of natural structure and function in more than a century. Leaching of toxic materials from mining wastes and milling sites can permanently contaminate and impair the productivity of stream and riverine ecosystems many kilometers downstream, as is most evident in the Upper Clark Fork and Coeur d'Alene river basins in the headwaters of the Columbia, where native salmonids have been virtually eliminated from the affected waters for a century or longer. It appears likely that elsewhere the scars have generally been healed by time and vegetation regrowth. Most disruptive mining has ceased in most of the landscape of the Northwest (what remains is centralized). More recently, recreational use of the uplands has been emphasized. Trails and compacted camping sites tend to channel more warmer surface runoff to streams. With an eye to erosion, most recreational uses are managed so that such effects are kept within acceptable limits. Thus, the alpine meadows of the mountain ranges continue to provide the initial cold water to the rivers of the Pacific Northwest.

\subsubsection{Mountain Slopes}

Lower in elevation and generally within the forest cover, the streams on mountain slopes become alternating reaches of steep grades with rocky torrents and more level meadows with meandering streams. The rocky torrents are themselves a series of waterfalls, chutes, and deep pools, usually in dense forest and thick understory vegetation (even on the dry east side, the mountain valleys are thickly vegetated). On the westside slopes where intense winter rainfall with only intermittent snowpack is the rule, this 
stream type predominates to the highest elevations. Elsewhere, winter snow often lingers in shaded pockets of forest to provide cool meltwater and retain cool air above the streams well into summer. The streams of forest meadows, as in more alpine meadows, are relatively deep, narrow, embedded in the mat of meadow vegetation and offer little surface area to the sun for warming. The meadow alluvium and bogs store and release accumulated winter snowmelt or rainwater through the summer. The dense shade of the torrential reaches and the embedded nature of meadow streams keep water temperatures low, although there is a gradual warming from the temperatures of the stream's origins at higher elevations. Wherever streamflow is slow enough to prevent vertical mixing, cool inflow from subsurface streambed flows and groundwater provide cooler strata in deep pools. The pools are often the result of damming or scour at fallen logs and other woody debris from the surrounding riparian forest. The inverse can occur in autumn, as the sheltered environments of forest and meadow insulate the stream from the rapid onset of cooling and maintain moderate temperatures later into the season.

There is human encroachment into this mountain zone, mainly in the form of logging and accompanying road development. As timber is fully harvested in lower elevation forests of the Northwest, more and more upland forests are being logged. Timber removal has major effects on stream temperature and morphology (Figure 9). Tree removal in riparian zones along streams opens the stream to sunlight and solar heating during the warm seasons. It also opens the stream to heating by airflow from the surrounding hillsides, which has been warmed by passing over sun-warmed, newly bare rock and soil. Tree and understory removal hastens the melting of winter snows. As important as these direct thermal effects can be, damaging effects also come from changes in stream morphology and the lost interplay of subsurface and groundwater flows. Tree removal and accompanying road development foster erosion of clearcut hillsides. Most eroded material is deposited in streams, filling pools and rocky reaches with impacted silt. Waves of sediment derived from barren hillsides progress downstream, well beyond the actual logged stream reach. Disruption and erosion of the forest litter fosters rapid runoff of precipitation and diminishes seepage into groundwater. Woody debris that created pools is either removed or its replenishment prevented by harvest of riparian trees. The result is a shallower stream mostly devoid of deep pools and with decreased quantities of both cool groundwater and subsurface streamflow. Such a stream is far more susceptible to warming by sun and air than was the original stream configuration. Cool, stratified refuges for fish in the deep pools are gone. Thus, the combined result is a stream reach that heats rapidly each summer day and contains water that cumulatively warms at a faster rate as it moves downstream than was the case before timber harvest. Because stream temperature at this elevation is usually below the air equilibrium temperature, the increased heat content persists to affect temperatures in lower river reaches. Although time heals some wounds, the sediment deposited in streams, and the resulting effects on stream temperature dynamics, can remain long after vegetative cover has been restored sufficiently to shade the stream. 


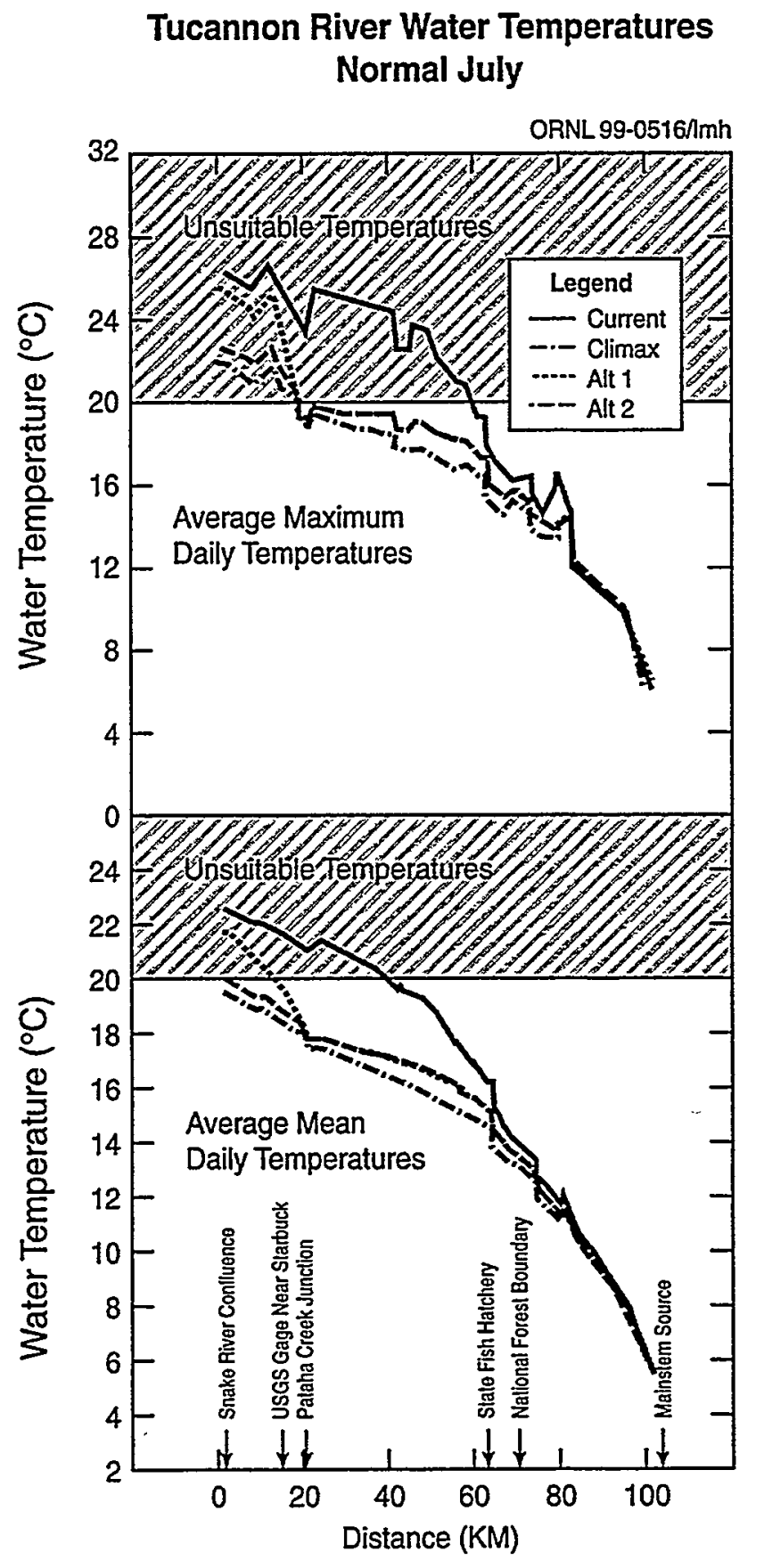

Fig. 9. Water temperatures of the Tucannon River, Washington, from the headwaters to the confluence with the Snake River, in relation to suitability for salmonids (assumed $<20^{\circ} \mathrm{C}$ ). Upper panel = average maximum daily temperatures; lower panel $=$ average near daily temperatures. Current temperatures and estimates under three scenarios of forestation are shown. (After Theurer et al., Water Resources Bulletin $21: 53)$. 


\subsubsection{Mountain Valleys}

Progressing farther downstream, the typical Northwest stream has increased in volume and decreased in overall slope. The stream is wider and shallower, although often with a deep gravel substrate, floodplain of alluvial gravels, and significant subsurface flow. The channel is often active, with the meandering stream undercutting banks, creating gravel bars and riffles, and digging pools where debris dams of logs, stumps, and brush create obstacles. There is strong interaction between the stream and its fairly narrow floodplain. Although some streams may have heavy timber in riparian zones, most have a typical riparian community of willows, alders, and cottonwoods. Riparian vegetation and the active streambed-floodplain are maintained in a state of flux by recurring floods, a natural feature. Cold water temperatures provided by upstream sources tend to be maintained in summer by extensive subsurface flow, despite greater exposure of surface flows to solar radiation. Often, the entire floodplain is underlain by actively moving subsurface water, kept at nearly constant annual-average temperatures by the long time delays of passage through gravels (thus, in winter the subsurface flow tends to warm the otherwise frigid water, cooled by the air and radiation). In the moister parts of the Northwest, groundwater from adjacent slopes can add considerable cool groundwater flow laterally into the stream in summer and relatively warm water in winter. Sloughs, seeps, and side channels often abound, and are usually supplied with percolating subsurface flow and groundwater input. Deep pools in slowly moving reaches often stratify, with cold water at the bottom.

Logging, grazing, irrigation diversions, and general human habitation alter stream morphology, flow, and temperature in this zone. The logging effects are similar to those on steeper slopes, except that erosion-deposition can be less severe and riparian zones often contain less harvestable timber (to change shading). Nonetheless, historical patterns in which precipitation and meltwater entered groundwater can be altered toward an increase in surface runoff (more in equilibrium with air, and thus warmer in summer). Reduced infiltration, particularly in cool months, means less stream cooling by groundwater. Siltation tends to clog stream and floodplain sediments and reduce subsurface flow and its cooling effects on surface flows. The frequency and severity of flash floods can be increased by greater surface runoff, which leads to abnormally rapid destruction of riparian vegetation and shade and can cut new, shallow channels across floodplains (leading to increased solar exposure and more warming in summer). The flashiness of floods does not foster recharge of alluvial gravels. Grazing also tends to remove vegetative cover, which directly affects streamside shading. Grazed cover on hillslopes also encourages surface runoff, erosion, and siltation of stream gravels. The physical trampling of stream banks by cattle introduces silt to streams during low-water (non-flushing) periods that clogs gravels and reduces subsurface flow. Irrigation practices often involve water withdrawals in this zone for use in floodplain fields. Small diversion dams can expose more stream water to warming by solar radiation, partly by increasing the percentage of aboveground water. Water removal from a stream whose bed is sized for larger flows simply makes the remainder more susceptible to warming. Irrigation of floodplain fields in summer recharges the subsurface with warm water rather than the historical recharge with cold spring floodwater. Human habitation also tends to 
increase surface runoff from roads, parking lots, and other developed areas, which are usually unshaded and warm in summer.

\subsubsection{Lakes}

The Pacific Northwest's natural lakes (aside from cirque lakes in alpine headwaters) are mainly glacial moraine lakes, that is, they lie in river valleys once filled by glacial ice and dammed at their downstream ends by rock and soil debris gouged out and deposited by the glacier. Examples are Lake Chelan (Washington), Wallowa Lake (Oregon), Flathead Lake (Montana), and Lake Pend Oreille (Idaho). They are fed by streams coming down the glacial valley from the mountains. These streams have generally achieved the above "mountain valley" status before reaching the lake. The lake water typically stratifies seasonally, with deep water (hypolimnion) remaining cold and near the highest density year-round. Surface waters (epilimnion) may warm by solar radiation and achieve equilibrium with air in summer to near $20^{\circ} \mathrm{C}\left(68^{\circ} \mathrm{F}\right)$. The intermediate-depth water (thermocline or metalimnion) is a zone of relatively rapid temperature change vertically. Both the amount of surface heating and the amount of wind determine the stability of the stratification and the vertical thermal profile. Generally, the Northwest's lakes have abundant cool water in the deeper layers through the warm months (and sufficient dissolved oxygen to sustain fish). Natural lakes generally have surface overflows that contribute water to the downstream reach that is somewhat warmer than the inflow. The actual temperature difference depends on both lake-surface heating and the degree to which inflowing water mixes with cool, deep water before passing through the outlet.

Humans have not (yet) been able to alter lake temperatures much except where lakes are downstream of artificial impoundments with abnormal discharges (discussed in Section 3.2.8). Changes in inflowing stream temperatures have minor effects on lakes because of the large water residence time in most lakes. Outflows of some lakes (e.g., Flathead Lake) have been "regulated" by addition of low-head dams and hydropower facilities. These changes generally have little effect on downstream temperature. However, humans have affected lake temperature relationships for aquatic organisms by virtue of temperature availability for them. Nutrients added to inflowing water (sewage, fertilizers, cattle runoff, excess feed and wastes from aquaculture) can cause increased algal growth with a subsequent decrease in dissolved oxygen in deep waters (eutrophication). This effect has been of long-standing concern for urban lakes, such as Lake Washington. Although of potential concern for the long term in less urbanized Northwest lakes, this has not been a major problem.

\subsubsection{Alluvial Floodplains}

Mountain valleys with narrow floodplains generally open up to broad floodplains currently used heavily for agriculture. Often, there is an alternation between typical mountain valley zones and agricultural, alluvial floodplains as streams traverse a series of narrow canyons and alluvial valleys (sometimes referred to as a "beads on a string" sequence) that depends on the local geology. In times before European settlement, 
streams in the alluvial floodplain zone were typically low in slope and had highly vegetated riparian zones with sandy or silty banks. Long pools and runs formed by frequent flooding were interspersed with occasional riffles of fine gravel. The broad floodplains contained large amounts of subsurface flow, which was a blend of true groundwater from surface infiltration and subsurface flow derived from the stream. The stream and drier floodplain interdigitated with numerous side channels, sloughs, and seeps (in fact, many floodplains were mostly an amalgam of such stream appendages in a jungle of trees and understory vegetation). Despite a seemingly sluggish (implying warm) nature, streams of alluvial valleys remained cool because of abundant riparian shading, frequent interchange with subsurface flow, and addition of cool groundwater.

Groundwater was formed by cool-season precipitation in areas far removed from the stream, and thus the groundwater itself was cool.

Especially important recharge of cool water to the stream occurred in summer at the "nodes" of the "beads on a string" where the alluvial valley was narrowed by rock formations. On being dammed by a rocky ridge, the subsurface flow in the alluvial gravels was forced to return (cool) to the stream channel just upstream of a canyon reach. This process was shown in Figure 5. Mixing of the upwelling water then cooled the surface streamflow. On reaching the next alluvial valley, the stream lost water to the subsurface which spread both laterally and vertically into cool gravel to repeat the sequence. Water transit times in subsurface flows lateral to the main channel are generally long enough that the entire gravel bed of the floodplain cannot warm greatly before the next winter season.

Alluvial valleys also cool surface streamflows in summer through the annual flooding cycle. Most high streamflows (and stream elevations) in the Pacific Northwest occur in the cool months, either in winter or during the spring snowmelt. High stream elevations force cold surface water laterally into floodplain gravels. Especially high streamflows will overtop banks and add water vertically. The result is a raised water table throughout the floodplain and floodplain gravels chilled to winter and early spring temperatures. During low streamflows of summer, there is a net draining of this stored, cold, subsurface water into the stream, which partially compensates for atmospheric and solar warming. This process of alluvial recharge and drainage through a flooding cycle was shown in Figure 4.

To a certain extent, there is a cumulative increase in temperatures of streams that progress from the alpine zone to alluvial valleys and beyond in spring and summer. This may be most evident in the alluvial floodplains where temperatures begin to reach levels high enough to limit cold-water organisms, especially fish. However, unlike what might occur in an open channel, the process of cumulative heat gain in natural streams is not uniform or even consistently in a warming direction. Heat-transfer processes vary in intensity from reach to reach, especially shading and interactions with subsurface water. Some reaches warm whereas other reaches cool as water moves downstream. Recent studies in Oregon have clearly demonstrated this spatial heterogeneity.

Human influences on the alluvial floodplains have been drastic and have had major effects on stream temperatures. First, the floodplains have been drained, filled, and denuded of riparian vegetation, with the stream increasingly relegated to a narrow channel poorly connected to the subsurface water with which it previously interacted. 
Historical riparian zones of sloughs, side channels, and seeps where cool water traditionally entered have been converted to agricultural fields. The fields are stripped of much vegetation, allowing direct solar heating of soil. Subsurface water storage has been markedly reduced by drainage ditches and tiles to ensure that agricultural fields are not waterlogged in spring (the cool water that does accumulate is drained to the surface stream in spring or early summer rather than throughout the warm season). Winter and spring flooding peaks have been reduced by upstream dams so that annual peak flows are not high enough to create as much subsurface recharge of cold water in the floodplain as previously. This natural winter-spring flooding has been replaced by warm-season irrigation of floodplain fields, which pumps water warmed by surface soil into the subsurface. This warm summer irrigation water replaces the normally cold winter water, heats the gravels, and enters the stream much warmer than historically. A simulation model of the effects of irrigation diversions on surface water temperature in the Yakima River Basin has been developed. The author projected that removing the effects of irrigation diversion could cool summertime temperatures in critical salmon habitats by up to $2^{\circ} \mathrm{C}$. This effect was most pronounced at lower elevations where larger, alluvial reaches of the river and its tributaries once supported abundant salmon production.

Perhaps most critical for altering stream temperatures on a broad scale has been the construction of dams at natural canyons (the nodes of the beads on a string). Damming of the canyon reach generally creates a reservoir atop the downstream end (or sometimes the whole) of the alluvial reach. The natural pattern of upwelling of cold subsurface water into the surface stream in summer is terminated. The reservoir is often maintained at a near-constant elevation, which terminates the natural cycle of recharge and draining of the cool subsurface water storage with annual flooding. The reservoir, itself, opens wide areas of water to solar heating and equilibration with hot summer air. Figures 4 and 5 show the effects of dams on subsurface upwelling and the annual recharge cycle, respectively. Figure 10 illustrates how an impoundment that encroaches over the floodplain (overbank zone) and erodes its banks greatly expands the ratio of surface area to volume such that heating of the main watermass is enhanced.

\subsubsection{Mainstem Rivers}

The sequence of alluvial valleys and rock canyons discussed in the previous section is repeated through the Columbia and Snake river mainstems, but on a larger scale than in tributaries. As indicated, major alluvial reaches occur in the Snake River, Idaho, upstream of Hells Canyon, in the Hanford Reach of the Mid-Columbia, and in the vicinity of John Day Reservoir. Undoubtedly, these huge alluvial valleys (remnants of catastrophically high streamflows at the end of glacial times) contributed greatly to storage of cold water in spring and its release during summer months. Although the calculations have not been made, the alluvial storage of cold water in these basins certainly rivals any cold-water releases that could be made today from storage dams. Cold upwelling upstream of Wallula Gap from the alluvium in the Hanford-TriCities-Walla Walla area probably countered the warm summer temperatures of the Snake River and maintained cool temperatures in the Lower Columbia River. The localized 

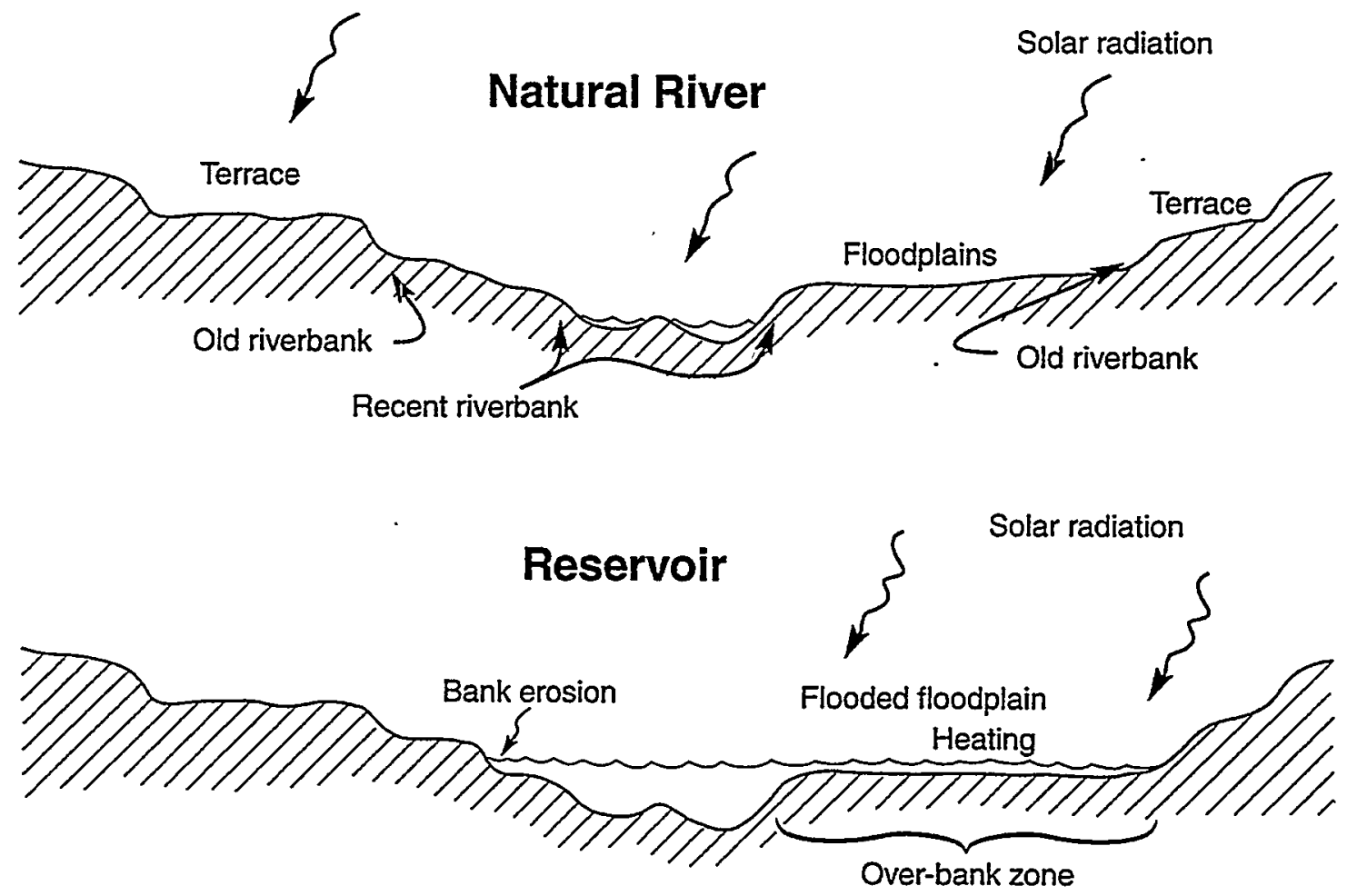

Fig. 10. Creation of shallow over-bank and erosional zones in alluvial valleys by damming that provide large areas to collect solar radiation and cause temperature increases in river water. 
cool spots where subsurface flow reenters the river (that serve as temporary refugia for fish) may have been as important ecologically as the cooling of the main channel flows.

Dams are the primary human influence on the mainstem. From the headwaters of the Snake River in southeastern Idaho and the Columbia River in British Columbia, the mainstems of the large rivers are nearly completely transformed into a stair-step of dams and reservoirs. As occurs on a smaller scale in other alluvial valleys, the mainstem dams have eliminated most subsurface storage as a temperature-regulating mechanism for the river system. Reservoir elevations are maintained nearly constant during flood and drought, thus eliminating any cycle of subsurface recharge and return of cool water to the channel. Only the Hanford Reach remains undammed, and there the annual flood peak (and likely the subsurface recharge with cool water) has been markedly reduced. Sloughs and backchannels that provided the reentry points for cool subsurface flows into the surface river flow in summer no longer exist in most mainstem reaches. They have been replaced by overbank reservoir zones that function in the reverse direction, thermally-they provide broad, shallow, exposed areas of water surface where solar radiation is absorbed and water temperature equilibrates rapidly to warm air temperatures in summer (as shown in Figure 10). The result is shoreline zones of water warmer than in the main channel rather than cooler, as previously. These effects are particularly pronounced because much of the mainstem Columbia and Snake rivers passes through the arid east side, where there is little cloud cover in summer to block a strong sun and air temperatures often rise above $38^{\circ} \mathrm{C}\left(100^{\circ} \mathrm{F}\right)$ in the daytime. Although there is strong radiative cooling at night in the dry air, water tends to retain heat better than land surfaces so the water does not cool significantly overnight.

Mainstem reservoirs are often characterized as well mixed, although vertical temperature differences do occur (as well as the clear horizontal differences just discussed). True stratification, as discrete and seasonally persistent layers of warm, cold, and transitional temperatures, rarely develops. However, solar and air-contact heating and mixing with warmer water from the shallows cause surface waters to be a few degrees warmer than the main channel flow in summer. Conversely, they can be somewhat cooler in winter, although the difference is less pronounced than in summer. A pool of warm surface water often forms in the forebays of dams that are not spilling, above the main water flow to the turbines. This pool can be transient depending on river flows, winds, and turbine operations, and its formation is highly site-specific. When bulk river flows are at their highest temperatures in summer, the seemingly small temperature elevations in these forebay pools can be sufficiently close to tolerance levels of salmonids as to be significant.

\subsubsection{Tributary Plumes}

Wherever tributaries enter a stream, regardless of the zone, there is a reach of mixing that can extend downstream for many kilometers. Often, the water contributed by each branch of the union will remain discrete along its respective shoreline until mixing is forced by some geographic feature such as a bend (which imparts a spiral rolling effect that enhances mixing). Water temperatures can thus differ markedly across the combined 
stream when the tributaries have different temperatures. Eventually, mixing blends the two water masses and a common temperature is reached.

\subsubsection{Storage Reservoirs}

Storage reservoirs are superficially like natural lakes but they can have major effects on stream temperatures by virtue of their location, design, and operation. To serve their primary function of storing water during high runoff times for release to lower river water users during low runoff times, storage reservoirs are generally located in the headwaters. In the context of the discussed zonation, they are generally located in the mountain valley zone (the exceptions are Brownlee and Hells Canyon, which are located in the middle Snake River, and Grand Coulee, which is located in the upper mainstem of the Columbia River, although all three are not typical storage reservoirs). They are thus located to affect flows many kilometers downstream.

The design of a storage dam's release structure causes the greatest influence on downstream temperatures. Although the dam and reservoir can have effects on the local stream dynamics of surface and subsurface flows that influence water temperatures (similar to those discussed), these effects are vastly overshadowed by the effects of thermal stratification in the reservoir and the release of water from the deep hypolimnion. The essential difference between a storage reservoir and a natural lake is the designed method of water release. Natural lakes generally have surface overflows. Storage reservoirs, on the other hand, often release water from depths below the thermocline where water is colder in summer and warmer in winter than normal surface water temperatures. The natural water stratification cycle operates in reservoirs as was discussed earlier for lakes. Cold water from winter flows and spring snowmelt is retained in deep hypolimnia near the maximum density of water $\left(4^{\circ} \mathrm{C}, 39.2^{\circ} \mathrm{F}\right)$ into summer. The long retention time of these reservoirs (a low volume rate of inflow compared to the volume of the reservoir) ensures that cold water can be present nearly throughout the year. Whereas much of the concern for stream temperatures in the Northwest generally has been for undesirable summer warming, the concern over storage reservoirs is for abnormal cooling of downstream reaches in summer and warming in winter. Figure 11 shows a deep-discharge dam and downstream reach with temperature-affecting processes in summer and winter.

Stream water downstream of storage reservoirs that is abnormally cold in summer and warm in winter begins immediately to seek its proper seasonal equilibrium temperature. Cold summer releases, for example, warm in sunlight and with air contact, as shown in Figure 11. Warm winter releases cool mostly by thermal radiation to the sky, by air contact, and evaporation. Because the temperature disequilibrium is large at the dam outlet, the heat exchange is rapid in the stream reaches closest to the dam. As the equilibrium temperature is neared, the rate of change slows. Tributary inflows downstream of a dam that are near the equilibrium temperature will change the main streamflow temperature to a more normal level by mixing and dilution. The equilibrium temperature is reached sooner when the tailwater stream is small and shallow than when it is large and deep (reflecting the effects of relative surface area on rates of heat exchange discussed earlier). 


\section{Summer}
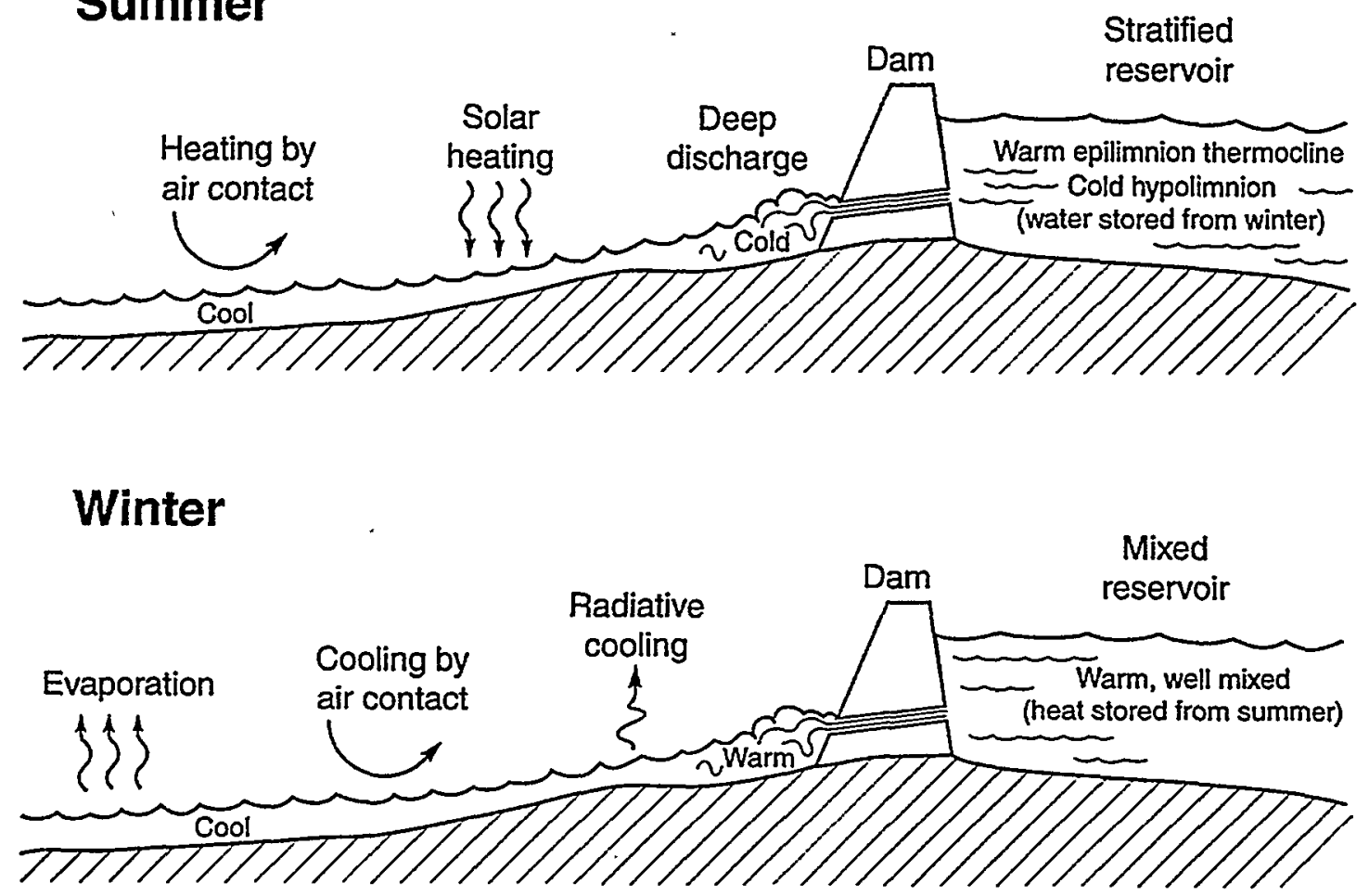

Fig. 11. Diagrammatic view of a storage reservoir with a deep (hypolimnetic) discharge, and its influences on downstream temperatures in summer (top) and winter (bottom). The most relevant heat-transfer processes that warm (summer) and cool (winter) downstream temperatures toward normal are shown. 
In some cases, the equilibrium temperature is not reached before the river enters a downstream reservoir (in the case of the Dworshak, the Clearwater and Snake rivers become the Lower Granite Reservoir). If the temperature difference between the streamflow and the reservoir is great and turbulence is low, the inflow may not mix with the reservoir water but form a discrete underflow along the bottom, an interflow at some intermediate depth, or surface flow (depending on the relative water temperatures and densities). Experimental cold-water releases from Dworshak formed an underflow in summer through the Lower Granite Reservoir that became mixed with the main Snake River water only after passage through several dams. Figure 12 shows summer temperatures cooler in bottom of the reservoir channel in cross sections of Lower Granite and Little Goose reservoirs on the Snake River.

Some storage reservoirs in the Northwest have been designed (or retrofitted, e.g., Libby) with outlets that can release reservoir water from multiple water elevations. In such cases, the depth at which the outlet is operated can determine outlet temperatures. There is a trend toward retrofitting and operating storage dams so that more normal downstream temperatures can be maintained. However, many Northwest reservoirs do not yet have this option. 

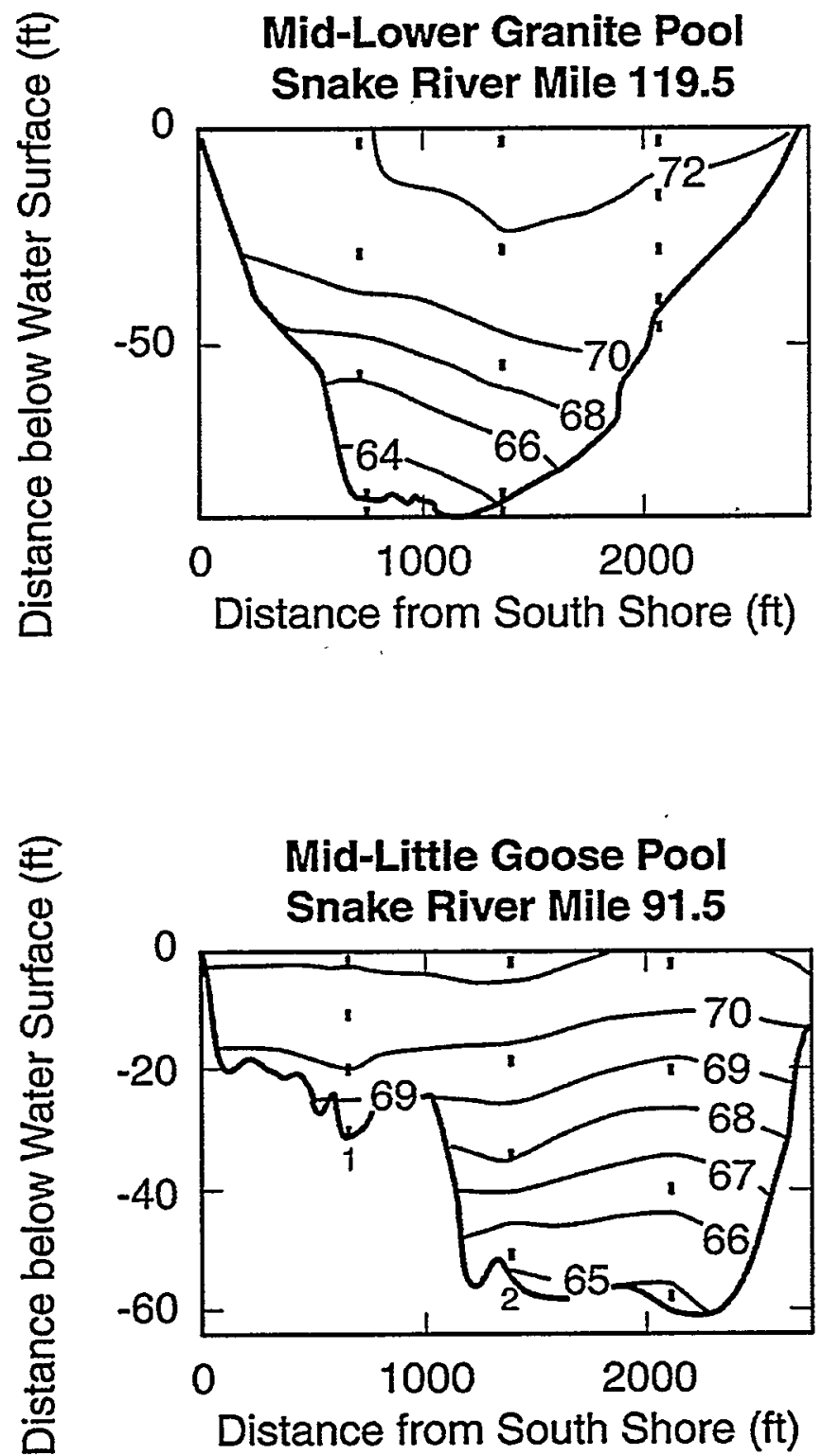

Fig. 12. Underflows of cool water in Lower Granite (top panel) and Little Goose (bottom panel) reservoirs on the Snake River from addition of $63^{\circ} \mathrm{F}\left(17.2^{\circ} \mathrm{C}\right)$ Clearwater River water from Dworshak Reservoir with $68^{\circ} \mathrm{C}\left(20^{\circ} \mathrm{C}\right)$ water from the Snake River. Adapted from Karr et al. 1998. 


\section{BIOTIC ADAPTATIONS TO NATURAL TEMPERATURE REGIMES}

\subsection{LIFE-CYCLE STRATEGIES}

Salmonids evolved to take advantage of the prevailing cold, freshwater, natural environments of the Pacific Northwest. The diversity of habitats in the region fostered a diversity of species and generated locally adapted stocks, which because of their wide diversity and fidelity to specific localities are considered "species" under current administrative procedures for the Endangered Species Act. The species and stocks do not have just physiological temperature requirements in the sense of most water temperature criteria (and the legal standards derived from them). They have adapted to annual patterns of many habitat resources within the Northwest landscape including temperature. Life cycles and physiological requirements have been described in two recent texts, by Groot and Margolis (1991; life histories) and Groot, Margolis, and Clarke (1995; physiological ecology). In some cases, the present environments of the Pacific Northwest have the requisite physical habitat but not the required temperatures. In other cases, the temperatures are correct but the proper physical habitat is missing. In still other cases, both features are altered beyond acceptability for the particular stocks, species, or even for any salmonids whether anadromous or not (questions of locally adapted stocks for standards setting are discussed further in Section 6.5). Salmonids, particularly anadromous ones that migrate to freshwater to spawn and rear as early juveniles while spending much of their life in the ocean, and potadromous ones that carry out a similar life cycle moving to and from large lakes, require connectedness among the various habitats that they use sequentially through their life cycle. Thus, "habitat" has a large scale that includes the pattern and distribution of linked habitat elements. Connectedness involves appropriate temperatures as well as physical linkage by water flows. Figure 13 shows a typical life cycle of a salmon.

Different salmonid species (and sometimes stocks) have developed different lifehistory strategies, some of which seem to be in response to specific natural thermal conditions. It can be somewhat misleading to generalize categories, because the natural resilience of salmonids as a group in the Northwest depended on a continuum of diverse life-history types that intergrated and were often flexible within a single genetic stock (changing as environmental conditions changed). This continuum of differing strategies ensured continued overall salmonid survival in fluctuating environmental conditions. Nevertheless, the typical, established categories are instructive.

\subsubsection{Fall Chinook Salmon}

The fall chinook salmon (Oncorhynchus tshawytscha) is the species and lifehistory type that has most clearly adapted its life-history strategy to a restrictive annual temperature cycle. It is not simply coping marginally with warm temperatures at the southern end of the chinook salmon's geographic range (as one might expect from overall zoogeography of a latitudinally homogeneous species), but has developed a specific lifehistory strategy. This race occurs at the most southern latitudes along the Pacific coast of 


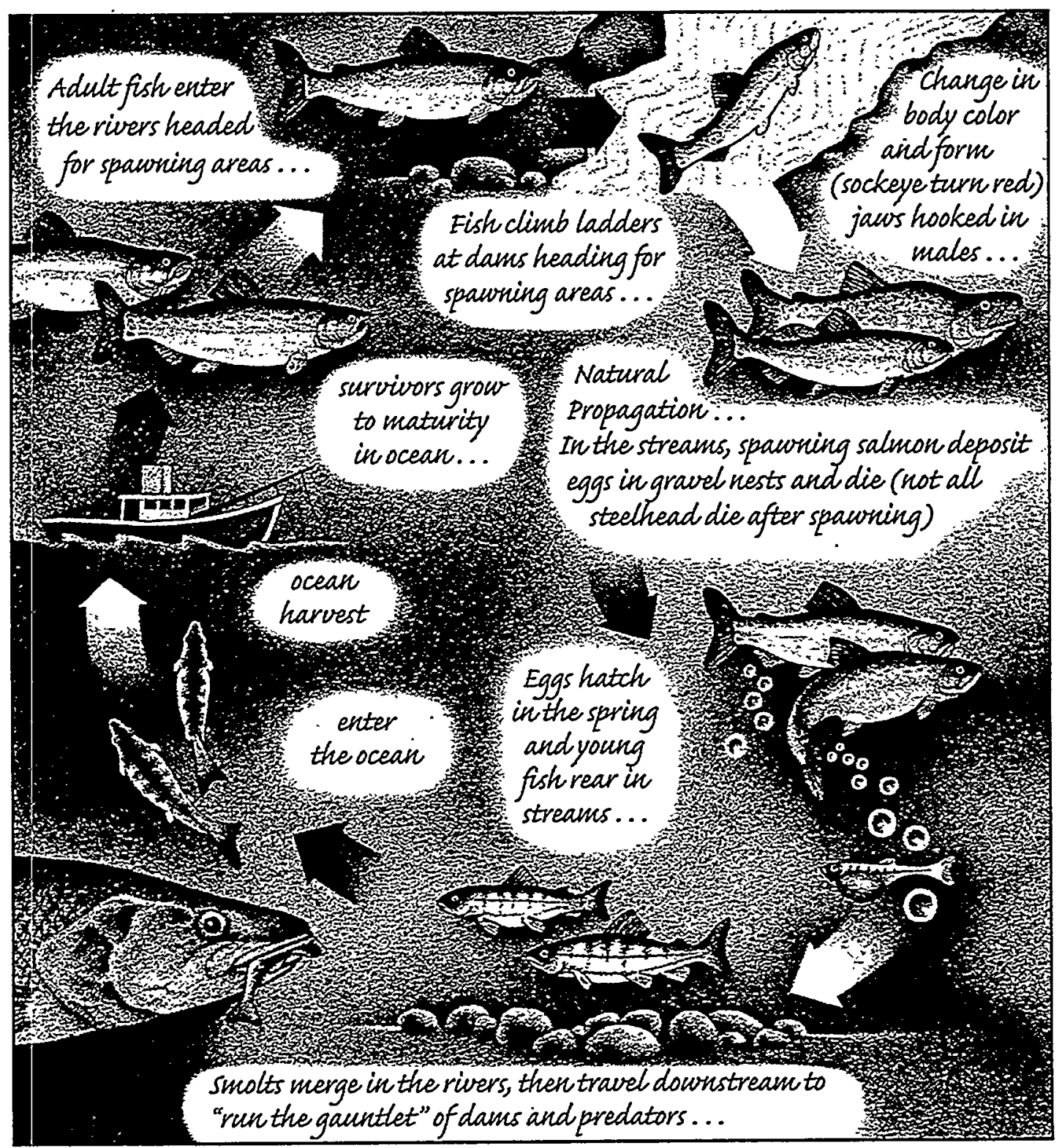

Fig. 13. Typical life cycle of an anadromous salmon. 
any salmon other than steelhead. It currently occurs as far south as the San Joaquin River system, California, where it ascends rivers on the western slope of the Sierra Nevada range. It was also abundant in the coastal rivers of northern California, Oregon, and Washington and in the mainstem Columbia and Snake Rivers (and lower reaches of their major tributaries into southwestern Idaho). It is listed as threatened in the Snake River system although it is highly successful in the mid-Columbia (Hanford). Its strategy is simply to get adults into the rivers in the fall after temperatures have dropped below about $16^{\circ} \mathrm{C}\left(60^{\circ} \mathrm{F}\right)$, get its spawning and juvenile rearing completed in the cold-water season (less than about $10^{\circ} \mathrm{C}$ or $50^{\circ} \mathrm{F}$ ) before temperatures rise markedly in spring, and get its 2-3 month-old juveniles out of the freshwater system before river temperatures rise above detrimental levels again in summer (about $20^{\circ} \mathrm{C}$ or $68^{\circ} \mathrm{F}$ ).

At the two ends of its freshwater season, the fall chinook salmon has particular behavioral traits that protect it from warm temperatures that could constrict the coolseason time available for completion of the reproductive cycle. In fall, adult migrations into the rivers are often timed to coincide with surges of runoff, which often are cooler than the general flows of late summer and early autumn. In spring, the rearing juveniles feed and grow while moving along shaded shorelines where normally there would be temperature moderation by seepages of subsurface water (aquatic insect food, especially emerging chironomids, also occupy this near-shore zone abundantly in spring, in part because the seepages are rich in nutrients). Fall chinook salmon have a fairly high optimal growth temperature for juvenile salmon, near $18-20^{\circ} \mathrm{C}$ (about $64-68^{\circ} \mathrm{F}$ ) compared to near $15^{\circ} \mathrm{C}\left(59^{\circ} \mathrm{F}\right)$ for other salmon species according to extensive research by J. R. Brett at Naniamo, British Columbia. When temperatures have risen sufficiently (usually correlated with a specific fish size of about $50 \mathrm{~mm}$ ), the fish seek the main channel at night to speed downstream migration. In the middle of freshwater residence, between the potentially lethal thermal restrictions of fall and spring, eggs are laid for slow incubation in zones where there is consistent subsurface water flow at temperatures generally somewhat warmer than surface flows (minimum of $3-4^{\circ} \mathrm{C}$ or $37-39^{\circ} \mathrm{F}$ in icecovered rivers). Temperature-dependent rates of incubation and early fry growth at this time must occur within limited bounds that yield smolts of the correct size in time for outmigration.

With minor variations, this is its recurrent strategy for this race throughout the Northwest and elsewhere. Fall race chinook salmon transplanted to the Great Lakes carry out the same life-cycle strategy in tributary rivers and creeks. Although summer stream temperatures may reach above $30^{\circ} \mathrm{C}\left(86^{\circ} \mathrm{F}\right)$ in California, arid eastern Washington and Oregon, and Great Lakes tributaries, the fall chinook that reproduce successfully in these streams in the cold part of the year are not there in summer to be affected. With this coolseason strategy, the geographic range of salmonids is greatly extended, as has been clearly documented.

In the Columbia River, the summer run of chinook salmon bound for the midColumbia follows the life-cycle strategy of the fall race. We can presume that this represents an early entrance of "fall" fish to this part of the basin. The Columbia River was once cold even at its mouth in summer, which would have allowed early entry of adults (assuming temperature was a prominent cue). The categorization of runs in the lower Columbia is somewhat arbitrary. 
There are strong suggestions from recent studies of fall chinook salmon migration, spawning, and rearing in the Snake River by biologists of the U.S. Geological Survey, Biological Resources Division, that production of the Endangered Species Act (ESA)-listed stock upstream of the Lower Granite Reservoir is constrained by water temperatures. The current seasonal sequence of river temperatures does not allow the salmon to incubate, grow, become smolts, and migrate seaward on the same time schedule as they had prior to temperature changes caused by upstream dams and lowerriver warming. All temperatures are within physiological limits, but timing is askew and thus population success is low. The case of fall chinook salmon in the Snake River will be discussed in more detail in Section 5.2.

In tributary basins, loss of habitat connectivity, partly the result of water withdrawals and partly lethally high summer water temperatures in the lower reaches occupied by fall chinook (juveniles out-migrating in early summer and adults in-migrating in late summer), was a major contributor to the loss of the underyearling-migrant life-history in the Columbia River Basin. High temperatures in the lower sections of subbasins, resulting from a cumulative effect of watershed-wide habitat degradation, severed the connectivity of the chain of habitats linking the subbasins to the mainstem Columbia and Snake. In many subbasins, alteration of habitat in the migration corridor through excessive temperatures or other barriers eliminated life histories like the ocean-type fall chinook that were dependent on migration in the early summer and fall months. In contrast to findings early in this century, stream-type juveniles (migrating in their second year of life) are far more abundant now than ocean-type (underyearling) migrants, indicating a substantial loss of production of fall and summer chinook, probably to high temperatures.

\subsubsection{Spring Chinook Salmon}

Although the same species, the spring chinook salmon shows a distinctly different life-cycle strategy from the fall race. However, it is no less well adapted to water temperature. This race has a more northerly southern limit of distribution and is present only where there are abundant cold pools in mountain streams and high-elevation alluvial valleys. It had been abundant in the Willamette, Columbia, and Snake drainages, but is now greatly restricted (ESA listed in the Snake river drainage). The spring chinook's strategy is to have adults migrate in spring when mainstem and lower tributary temperatures are still cool, have them oversummer in abundant cold and low-velocity pools and riffles in the high-elevation streams, spawn in stream gravels in the fall (with slow incubation over winter in relatively warm subsurface flow), allow the young to rear in the cool upland streams and cold pools for one year after spring hatch, with migration out of the system before mainstem temperatures rise to detrimental levels in their second spring. For this race, the thermal limitations in their chosen ecosystem (although not their physiological limits) are somewhat different than for fall chinook. The availability of cold, low-velocity pools with high water quality in summer is perhaps most critical, especially for adults. These pools have been filled by sediments from timber harvest, and the subsurface flow systems that sustained cool seepages in alluvial valleys have been disrupted by agriculture. As land-use changes raise peak stream temperatures in summer, 
the adults rely on the few cold pools (refuges) that are the remnants of a once abundance resource. As a generalization, the cool oversummering thermal habitats for both adults and juveniles are now missing or severely restricted except in designated wilderness areas. These wilderness areas are generally at the highest elevations where temperatures are coldest and aquatic productivity for juvenile food is low. The Forest Ecosystem Management Team estimated that the number of pools per stream mile in National Forest streams has declined from a typical value of 25 to 60 historically to 0 to 30 in many westside tributary basins today.

In the Columbia River, the summer run of chinook salmon bound for the Snake River tributaries (especially the Salmon river) follow the life-cycle strategy of the spring race. We can assume that these fish are simply late entrants of the Snake River spring race. Probably because of this late entry and exposure to higher temperatures in the mainstem, the summer run has declined even more markedly than the designated spring run.

Extensive evaluation of monitoring data and mathematical population analyses by the regional PATH (Plan for Analyzing and Testing Hypotheses, a multi-agency working group organized by the National Marine Fisheries Service to evaluate management options for the Columbia River basin hydrosystem) process has centered on spring chinook salmon populations in the Columbia River Basin. This work will be discussed in relation to available thermal habitat in a later section.

\subsubsection{Coho Salmon}

Coho salmon (Oncorhynchus kisutch) have had a distribution similar to fall chinook, extending southward into central California, where they are now rare. Coho have been generally abundant, although cyclic, in coastal rivers of northern California, Oregon, and Washington (although recent declines of coastal stocks from California to British Columbia have caused alarm and restrictions on harvest of all species in coastal waters). In the interior, they had colonized as far into the Mid-Columbia as the Wenatchee River and the Snake as far as the Grande Ronde. They no longer occur now in the Snake River while hatchery production maintains a few in the mid-Columbia. The coho's life-cycle strategy is to enter the rivers in fall after temperature has dropped (often entering during high runoff, as do fall chinook); spawn in the fall or winter with slow incubation in subsurface flow; rear juveniles for a year or more in a succession of sloughs, backwaters, side channels, and small creek mouths, especially shady areas with overhanging vegetation (with gradual movement downstream); and outmigration in spring of their second or third year before temperatures rise markedly. Coho adults may enter freshwater earlier in summer and hold for varying periods of time. The critical thermal habitat characteristic of this species seems to be the cool backwaters fed by subsurface flow in summer that are used by juveniles for one or two summers of growth. These same habitats remained relatively warm in winter and maintained activity and growth year around. This habitat type is almost nonexistent now after channelization of rivers, "reclamation" of riparian land for agriculture, disruption of subsurface flows, and warming of subsurface waters by irrigation. 


\subsubsection{Sockeye Salmon}

The anadromous sockeye salmon (Oncorhynchus nerka) is at the southern limit of its geographic range in the Columbia River Basin. The sockeye lakes of the Northwest had been Wenatchee, Chelan, lakes in the Okanagan River drainage in British Columbia, lakes in the Stanley Basin of central Idaho, and Lake Washington (after access was provided). Lake stocks in Wenatchee, Okanagan, Redfish (Stanley Basin), and Washington remain, with the Redfish Lake stock an Endangered Species. The sockeye's life-cycle strategy is to return to fresh water in late summer and early autumn when temperatures have cooled, to use cold lakes and their tributaries for spawning and rearing of young, and to have juveniles leave the lakes in early spring before mainstem river temperatures warm to intolerable levels. The young leave the lakes after 1 to 3 years of rearing in the cold, well-oxygenated lake waters. When surface temperatures reach levels too high for adequate growth rates, the fish seek deeper and cooler strata. Juveniles in some lakes carry out daily vertical migrations to feed on abundant plankton in surface or mid-depth waters that may exceed temperatures best for growth and food conversion and return to cooler water to digest and grow.

Within this general strategy, there are more variations in stock-specific sockeye strategies than in any other anadromous salmon species. Specific stocks are adapted to spawning along lake shores, in lake outlets, and in lake tributaries. Newly emerged fry of different stocks move downstream to lakes or upstream in lake outlets to reach the lake. Length of juvenile residence varies greatly. There is a non-anadromous form, the kokanee, that carries out its entire life cycle in the lake and its tributaries. Some genetically anadromous sockeye also become residual, i.e., remain in fresh water and do not migrate to the sea.

The essential features for the sockeye, however, seem to be cool fall migrations, cold lakes with access by adults in autumn after temperatures have fallen, and cool mainstem rivers in spring for outmigration before temperatures rise. These temperature resources have not changed much, although physical access to critical lakes (especially in the Stanley Basin of Idaho) has been blocked repeatedly.

\subsubsection{Steelhead and Rainbow Trout}

The steelhead and the rainbow trout (Oncorhynchus mykis) are anadromous and resident stocks of the same species. The rainbow trout, especially, has many stocks with apparently diverse life cycles, and it has been transplanted nearly everywhere in North America where there is cold water. However, both forms exhibit the same general lifecycle strategy. Steelhead are generally found coincident with chinook salmon, currently extending to central California's Sacramento-San Joaquin Basin. Steelhead had been abundant throughout the Columbia Basin, although stocks have declined in many tributaries to the point of ESA listing. The life-cycle strategy of steelhead and rainbow is to enter rivers in late summer to midwinter when water is cool (there are summer, fall, and winter races of steelhead in different or the same tributaries), overwinter in cold riverine water, spawn in spring in tributaries as temperatures begin to warm, incubate eggs rapidly in the warming subsurface flow that is dominated by short-term infiltration 
from the surface flow, rear juveniles for a year or more in cool streams and pools (with gradual downstream displacement), and outmigration in early spring of the second year before mainstems warm. Adult steelhead can (and often do) return in early spring to the ocean and spawn more than one year. Rainbow follow a similar movement pattern within fresh water, often moving to distant spawning streams from river reaches, lakes, or reservoirs with no spawning habitat. Critical thermal points for both races appear to be suitable spawning sites with proper temperatures of subsurface flow in spring and cool streams (and pools) for oversummering juveniles.

\subsubsection{Bull Trout}

The bull trout (Salvelinus confluentus) is a resident trout species that is limited to the coldest habitats in the Pacific Northwest. The species was formally recognized as distinct from the Dolly Varden (S. malma) in the late 1970s. It is also a close relative of the eastern brook trout ( $S$. fontinalis), with which it competes and interbreeds wherever the brook trout has been introduced or spread (brook trout can also displace bull trout and sometimes replace them completely). Although once found in the McCloud River (a tributary to the Sacramento River) in California, its current southernmost distribution is the upper Klamath Basin of Oregon. There are scattered populations in the Columbia River Basin from the Willamette to the headwaters in Montana and Canada. Although not generally anadromous, the bull trout often exhibits extensive spawning movements from large lakes (e.g., Flathead, Pend Oreille) and reservoirs (e.g., Libby) to spawning rivers (adfluvial populations). There are also populations restricted to rivers and streams alone (fluvial populations).

The life-history strategy of bull trout is highly tuned to water temperature, keeping cool in warm seasons and warm relative to surrounding surface water in cold seasons. Adults reside in large lakes, rivers, or (more recently) reservoirs where temperatures are below $15^{\circ} \mathrm{C}\left(59^{\circ} \mathrm{F}\right)$. Highest densities occur where temperatures are below about $12^{\circ} \mathrm{C}$ $\left(53.6^{\circ} \mathrm{F}\right)$. Adults move up into larger tributary rivers in late spring during snowmelt. They move upriver slowly, entering cold tributary streams in late July through September. They hold in deep, cold pools with a high amount of cover until spawning occurs August-October in large streams with groundwater or subsurface flow infiltration, particularly springs. Eggs incubate in relatively warm subsurface flow with optimal survival near $2-4^{\circ} \mathrm{C}\left(36-39^{\circ} \mathrm{F}\right)$. While adults return to lakes or river mainstems after spawning, the eggs incubate slowly until hatch near late January. Fry and juveniles remain in rock interstices for much of their rearing, apparently seeking relatively warm subsurface flow depending on season, surface-water temperature, and fish age. They move to lakes or mainstem rivers at 1-3 years in spring, summer, or fall. Critical thermal habitats seem to be summer-stratified lakes with oxygenated hypolimnia, cold mainstem rivers, tributary streams with cold meltwater, cold pools for prespawners, and subsurface flow of (relatively) warm water in winter for incubation and juvenile rearing. It appears that the species attempts to keep as near a constant temperature as possible through an annual cycle.

Although dams have blocked many migrations, the species seems to have found acceptable subadult and adult habitat in upper-elevation storage reservoirs, where 
adfluvial populations seem to have adapted from fluvial ones or ones that migrated to lower-elevation lakes (e.g., Hungry Horse populations that probably once ranged into Flathead Lake). Disruption or over-warming of subsurface flow would seem to be critical for maintaining thermal habitat for spawning and juvenile rearing.

\subsection{PHYSIOLOGICAL REQUIREMENTS}

A physiological framework exists for establishing thermal limits for natural waters based on exemplary research with several species of fish, particularly salmonids important in the Northwest. By "physiological," we generally mean the biochemical, metabolic, and behavioral functions of an individual organism that allow it to eat, grow, reproduce, and generally survive as a fully functioning individual. We justify the use of physiological criteria by assuming that temperature regulations for water bodies should be designed to protect the biological functioning of individuals of desirable aquatic species and life stages found there. Physiological criteria include a wide variety of temperature limitations from direct lethal effects of high and low temperature to subtle changes in the rates of bodily functions affecting growth and reproduction. Thermal requirements of the average individual organism are usually sought through experiments and use of appropriate statistics. "Physiology," once thought of as whole-organism responses, now encompasses ever-finer-scale studies at cellular and molecular levels. There is a vast literature on the effects of temperature on the physiology of fishes and other aquatic life. The "forest" of the framework of organism responses can easily be obscured by the myriad of available details ("trees").

The physiological framework was developed in the 1960s and early 1970s, was synthesized by a panel of the National Academy of Sciences, and is embodied in national water temperature criteria endorsed by the EP.A. The physiological framework (based on requirements of the individual organism) is only part of an ecological framework that has gradually developed more recently, but which has yet to be fully set down in regulatory criteria or standards. The ecological framework includes more consideration of effects at the population level for a species and more consideration of how organisms experience temperatures that vary in the environment. A central question is whether physiological considerations alone are an accurate and sufficient reflection of temperature requirements in the environment. This issue is discussed in a Section 6.

The aquatic species (fish and invertebrates) that we wish to protect are nearly all referred to as "cold-blooded." That is, they have little or no ability to regulate their body temperatures and thus live at the temperature of the water in which they are immersed. However, such species have developed a suite of internal biochemical adjustments that they make at a holding temperature (acclimation) that maximize their functioning at that temperature. The acclimation process takes hours to days to accomplish after change from one temperature to another and essentially "resets" the organism's physiology to the new temperature. This adjustment has limits, however, and organisms eventually reach lethally high or low temperatures. 


\subsubsection{Survival}

Each species of organism (and often each distinct life stage) has a characteristic physiological tolerance range of temperature at each acclimation (prior holding) temperature. These physiological tolerance ranges can be distinguished from ecological tolerance for extreme temperatures (often called collectively "sublethal effects"), which may be more restrictive because of environmental variability, other stressors, predation, etc. However, it is useful to first consider our understanding of directly lethal physiological effects. Integrators of the "sublethal effects" that may ultimately affect persistance of populations are discussed under the heading of "Performance," below.

Ordinarily, the ends of the thermal tolerance ranges, or lethal thresholds, are defined by survival of $50 \%$ of a sample of individuals (the most statistically valid percentage to represent a sample) for a week's exposure in tests in the laboratory. These temperature tolerance ranges at different acclimation temperatures have traditionally been illustrated in a "temperature tolerance polygon" as shown in the upper panel of Figure 14. Lethal thresholds are typically referred to as "incipient lethal temperatures" for each acclimation temperature. The tolerance range is shifted upward by acclimation to warmer water and downward by acclimation to cooler water, although there is a limit to such accommodation. The lower end of the range of acclimation (the "ultimate lower incipient lethal temperature") is usually at $0^{\circ} \mathrm{C}\left(32^{\circ} \mathrm{F}\right)$ for species in temperate latitudes including salmonids (somewhat less for saline waters). The upper end of the range of acclimation (the "ultimate upper incipient lethal temperature") differs greatly among species, although there are commonalities within taxonomic groups like the salmonids (which differ greatly from the sunfish family, for example). The ultimate upper threshold temperature represents the breaking point, so to speak, between the highest temperature to which an animal can be acclimated and the lowest of the extreme temperatures that will kill the warm-acclimated organism. This is often called, uncritically, "the" lethal temperature. Any rate of temperature change that is applied over a period of only a few minutes to a few hours will not greatly affect the thermal tolerance limits because acclimation to changing temperatures requires several days. The aggregate of the physiological tolerance ranges for all acclimation temperatures for a species or life stage as diagramed in the polygon of Figure 14 can be calculated as a geometric area of the polygon that is an index of how thermally sensitive (small area) or insensitive (large area) is a species or life stage. The polygons defining suitable temperatures for functions other than survival are smaller, and are shown conceptually by the dashed perimeters in Figure 14 (see text below).

At temperatures above and below the incipient lethal temperatures, survival depends not only on the temperature but also on the duration of exposure. Mortality occurs more rapidly the further the temperature is from the incipient lethal temperature threshold, creating a pattern of "resistance times" at particular acclimation and test temperatures, as shown in the bottom panel of Figure 14. Organisms thus respond to extreme high and low temperatures in a manner similar to the dosage-response pattern that is common to toxicants and pharmaceuticals, and presented in a classic work by Bliss in the 1930s and interpreted for thermal responses of fish by F. E. J. Fry in several papers. 

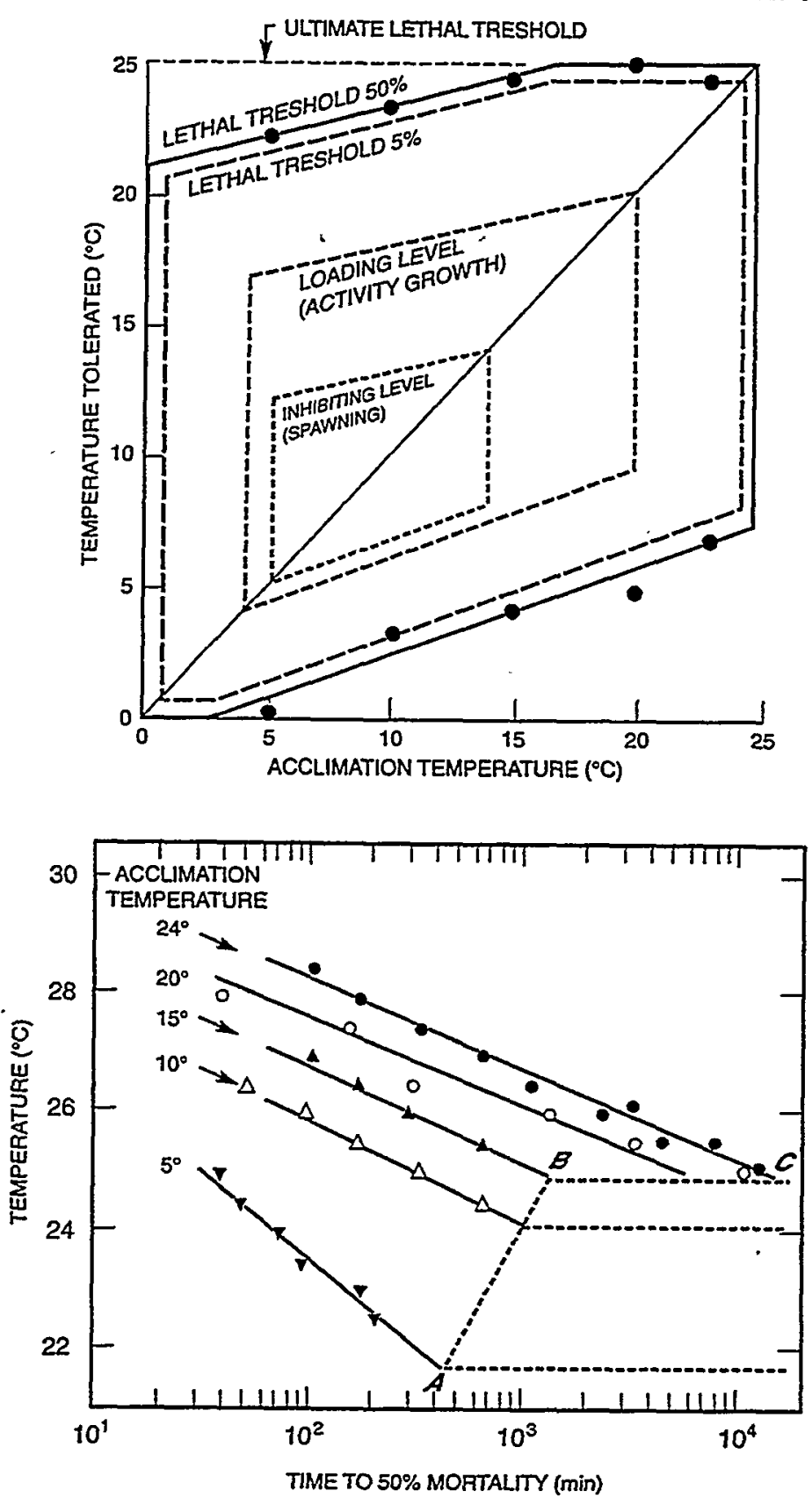

Fig. 14. Temperature tolerance of chinook salmon as determined by J. R. Brett. Upper panel: The thermal polygon showing upper and lower thermal thresholds ("incipient lethal temperatures") for acclimation temperatures from 0 to $25^{\circ} \mathrm{C}$ and the ultimate upper lethal threshold ("ultimate upper incipient lethal temperature"). The ultimate lower incipient lethal temperature is approximately $0^{\circ} \mathrm{C}$. Thresholds for $5 \%$ mortality and more restrictive temperature ranges for activity, growth, and spawning are indicated within the lethal thresholds. Lower Panel: Resistance time relationships between exposure temperature and duration to $50 \%$ mortality for samples of fish previously acclimated to temperatures from 5 to $24^{\circ} \mathrm{C}$. Dashed lines represent continued survival at temperatures that correspond to the lethal thresholds of the upper panel. 
This recognition gives confidence that extreme temperature is not unique physiologically, but that it has stress-response characteristics in aquatic organisms that follow fundamental "laws of nature." Time-versus-temperature, resistance-time mortality tests usually cover times from a minute to a week in duration at constant test temperatures. Such tests can be viewed from two perspectives: one in which the data define when an average fish will die at a given extreme temperature, and the other the converse, the lengths of brief exposures that an average fish can survive at temperatures that might ultimately be lethal over a sufficiently long duration. This latter perspective is important for real-life environmental exposures, which are often transient.

Realizing that most exposures to potentially lethal high temperature in the environment (e.g., in thermal discharges or sun-heated pools) are not at constant temperatures similar to the laboratory tests, early investigators (e.g., F. E. J. Fry and colleagues) and the National Academy of Sciences panel emphasized the utility of resistance time data for predicting the effects of fluctuating thermal regimes over a cumulative thermal-exposure history. Resistance-time lines for each acclimation temperature (e.g., in Figure 14) can be expressed as statistical regression equations fitting a semilogarithmic model of exposure temperature and time to $50 \%$ mortality. Each equation reflects a dying rate at each test temperature. An environmental temperature curve that fluctuates over time can be divided into time segments (e.g., minutes) for which a dying rate is applied from the resistance-time equation. Simple summation of dying rates through the fluctuating-temperature exposure appears adequate to estimate whether $50 \%$ of individuals of that species (or life stage) could be expected to die and how soon (based on laboratory tests in fluctuating lethal temperatures). In practice and in the EPA criteria, a safety factor of $2^{\circ} \mathrm{C}$ is applied to approximate zero mortality (the exposure temperature is assumed to be $2^{\circ} \mathrm{C}$ lower). The $2^{\circ} \mathrm{C}$ number has its basis in two observations: (1) in a typical sigmoid dose-response curve representing the conditions causing each organism in a test group to die, $2^{\circ} \mathrm{C}$ lower than the $50 \%$ level usually will encompass the first deaths, and (2) experiments on susceptibility to predation following acute thermal stress indicated a threshold for increased rates of predation at about $2^{\circ} \mathrm{C}$ below tempeatures that caused $50 \%$ direct mortality.

The National Academy of Sciences/National Academy of Engineering review indicated how the resistance-time equation can be manipulated to estimate mortality under fluctuating temperatures in calculations or simple computer models. This type of analysis has been used extensively to estimate the directly lethal effects (or demonstrate quantitatively the lack of direct lethality) of thermal discharges from power stations. Despite the focus in the 1970s and 1980s on evaluating point-source thermal discharges, the technique can be used to evaluate other brief excursions into lethal-temperature ranges in the environment. However, its application deserves rigorous, quantitative testing. Recent studies have shown an apparent recovery or repair mechanism operating when temperature cycles below the incipient lethal level, which causes the time of $50 \%$ mortality to be predicted to occur too soon.

A short cut to determining lethal temperatures is often seen in the literature, but it must be used with extreme caution. Early temperature-effects studies with terrestrial reptiles emphasized the importance of overheating by the sun and subsequent loss of equilibrium so that the animal could not find shade and cool down (with subsequent 
death). These studies introduced a concept of a "critical thermal maximum" (subsequently extended to include a "critical thermal minimum" for cold temperatures) to be determined by tests involving slow heating (or cooling) of an organism to the point of its losing equilibrium. The test approach has been applied to fish and has several proponents for its use in rapid assays of thermal tolerance. On the positive side, the idea of an endpoint at loss of equilibrium has appeal ecologically (and has subsequently been applied as an endpoint for more traditional resistance time and incipient lethal tests). However, establishing a thermal tolerance limit by slow temperature change has several drawbacks, each of which results in estimates of tolerance of temperatures that are, in fact, demonstrably too high (or low for cold tolerance) for long-term survival. Estimates of tolerable temperatures are too high (or low for cold tolerance) because the temperature in the test continues to rise (or fall) as the dying process takes place before the endpoint is reached (recall that it takes a certain time-the resistance time-for an organism to die at an extreme temperature). The tests also merge the variables of temperature and time in ways that eliminate predictive value for other rates of temperature change and do not consider the ability of the animal to acclimate when temperature-change rates are slow. Several reviews (such as those by D. K. Cox, and C. D. Becker and R. Genoway in the 1970s) have focused on how to select rates of temperature change that maximize usefulness of the critical thermal tests, but the approach remains a poor way to delimit the thermal tolerance ranges of organisms. Its main usefulness is in making rapid and direct comparisons of relative temperature sensitivity between subjects (e.g., two species or treatment groups) using an identical assay technique.

Standard, short-term, thermal-tolerance tests leading to an incipient lethal temperature, as described, may adequately describe the directly lethal physiological effects of high or low temperature extremes, but organisms may continue to die within the limits of the incipient lethal temperatures. After about a week of exposure, other factors begin to cause indirect mortalities, as was recognized by the earliest investigators, such as F. E. J. Fry and J. R. Brett. These factors typically include disease, poor feeding or food conversion to body tissue, or parasites. Such secondary effects of extreme temperature exposures on survival need to be taken into account for establishing acceptable thermal limits. The somewhat arbitrary $2^{\circ} \mathrm{C}$ "safety factor" discussed above is one way. Another way was conceived by staff of the EPA's Duluth, Minnesota, laboratory and consists of defining a temperature for zero net growth in laboratory tests. In such tests, generally carried out for one year on a large group of organisms, a longterm holding temperature is determined at which biomass added through growth of surviving test animals balances the loss of biomass from those that have died during the course of the experiment. This temperature of zero net growth generally lies in a temperature range between the ultimate incipient lethal temperature and the temperature for maximal growth (optimum growth temperature), discussed in the following section.

\subsubsection{Performance}

Mere survival of individuals over the short term (even a week) is not sufficient to maintain productive populations. Aquatic organisms are rarely found in natural habitats for very long at temperatures at the upper end of the physiological thermal tolerance 
(survival) range. This limitation is the result of impaired physiological performance above a physiologically optimum temperature range. This impaired performance is the quantitative expression of the general terms "sublethal effects" and "chronic effects." Impaired performance occurs over extended period of time and is often cumulative during this time. Although acute exposures are relevant in some instances, a greater concern in developing thermal criteria and legal standards is for long-term, pervasive and persistent thermal changes in the high sublethal range.

Many temperature-dependent physiological functions for sockeye salmon (e.g., growth, metabolic capacity for sustaining swimming activities, appetite, food conversion efficiency, swimming performance) were summarized by J. R. Brett, and are illustrated in Figure 15. Many of these functions decline rapidly at temperatures above an optimum and cease at temperatures somewhat below the ultimate upper incipient lethal temperature, as shown in the upper panel. Other functions may continue to occur more rapidly indefinitely (e.g., digestion rate) or continue at reduced levels at temperatures above lethal until the organism dies (lower panel). As physiological research has continued, the list of temperature-dependent functions has grown markedly. To use all of them separately for defining criteria and setting standards is unrealistic. An integrator of all of them is needed.

Growth rate, which is an integrator of all other physiological measures, shows a typical pattern that is useful for characterizing sublethal, chronic, and cumulative physiological responses. Growth rates increase as temperature rises at low temperatures, there is a broad plateau over a temperature range that includes a definable maximum (or optimum growth temperature), and growth rate declines rapidly at temperatures above the optimum, with loss of body mass occurring at temperatures somewhat below the lethal level. When food is restricted, the optimum tends to occur at lower temperatures and with lower growth. This general pattern was shown for sockeye salmon by J. R. Brett (Figure 16) and has been demonstrated for many other species and life stages.

Performance measures such as these, as aggregated in a growth rate vs. temperature curve, represent the elusive "sublethal effects" of high temperatures (which we often wish to protect against) at the physiological level. There are a host of other physiological measures that might be used as indexes, and often are the legitimate focus for protecting particular life-history functions for specific populations of organisms (e.g., temperaturedependent activity of the enzyme ATP-ase as an index of salmon smoltification). Other functions, such as reproduction, are often protected separately (Figure 1). However, growth rate has proven to be a useful overall index of most physiological functions for standards-setting purposes.

Two aspects of physiological performance need to be distinguished in the context of identifying sublethal effects that might be cumulative over time and affect survival or population success of organisms. F. E. J. Fry and his colleagues in the 1950s and 1960s called these two aspects "limiting" and "controlling," and they are identified on-Figure 15. The first (limiting) is impairment of functions. At high-temperature extremes (above the optimal temperature range), high temperatures impair or limit biochemical processes. This is often called thermal stress (although only in the general sense, not necessarily causing the strict biochemical stress responses). There is a balance between damage and natural repair mechanisms in cells and tissues, with the damages occurring 

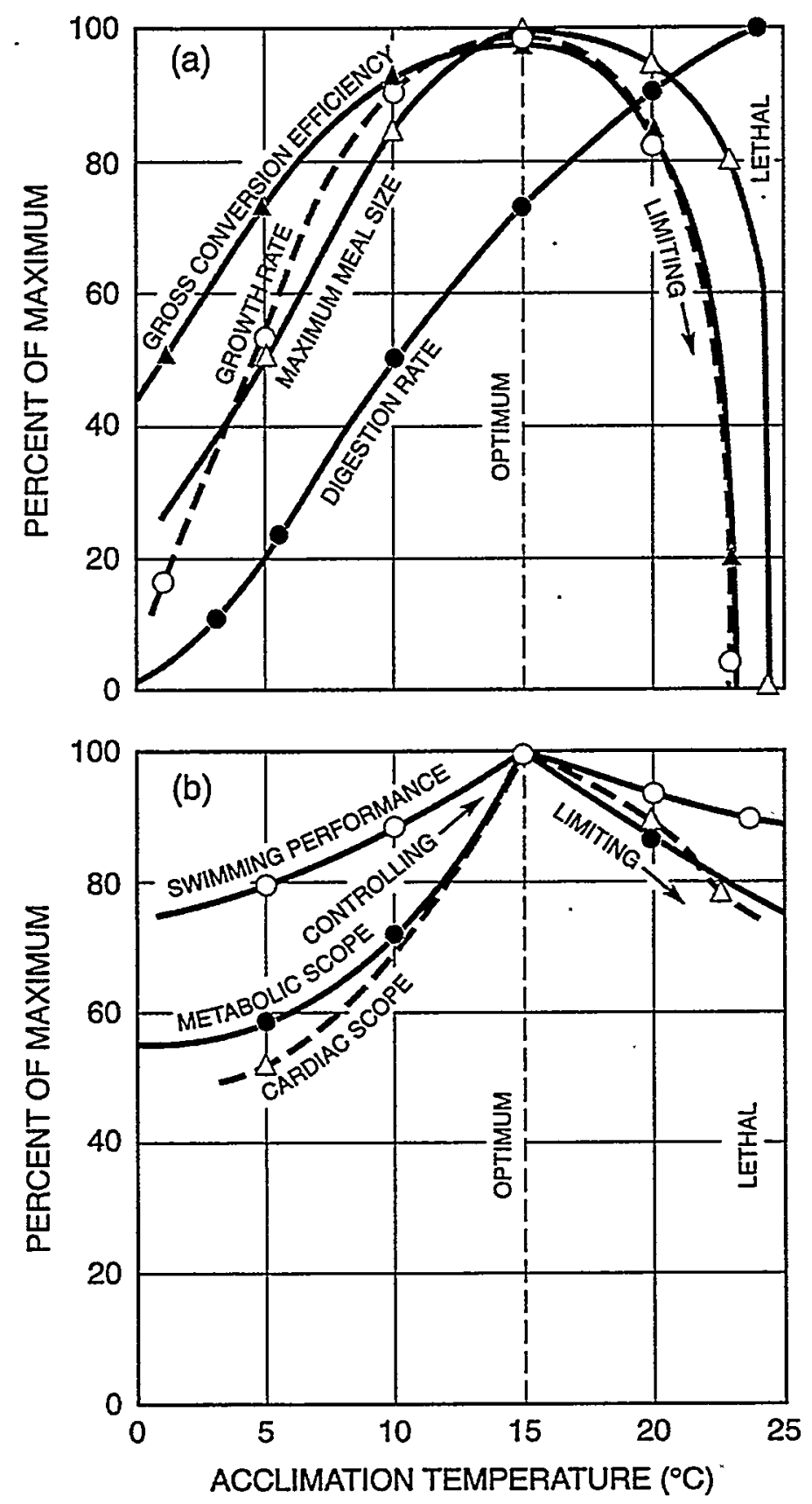

Fig. 15. Performance of sockeye salmon as a function of acclimation temperatures, as summarized by J. R. Brett. These data indicate the types of physiological information that are useful for determining optimum temperatures and distinguishing the rate-controlling role of temperature at below-optimum temperatures and the decline of physiological performance (performance-limiting role) as temperatures exceed the optimum. 


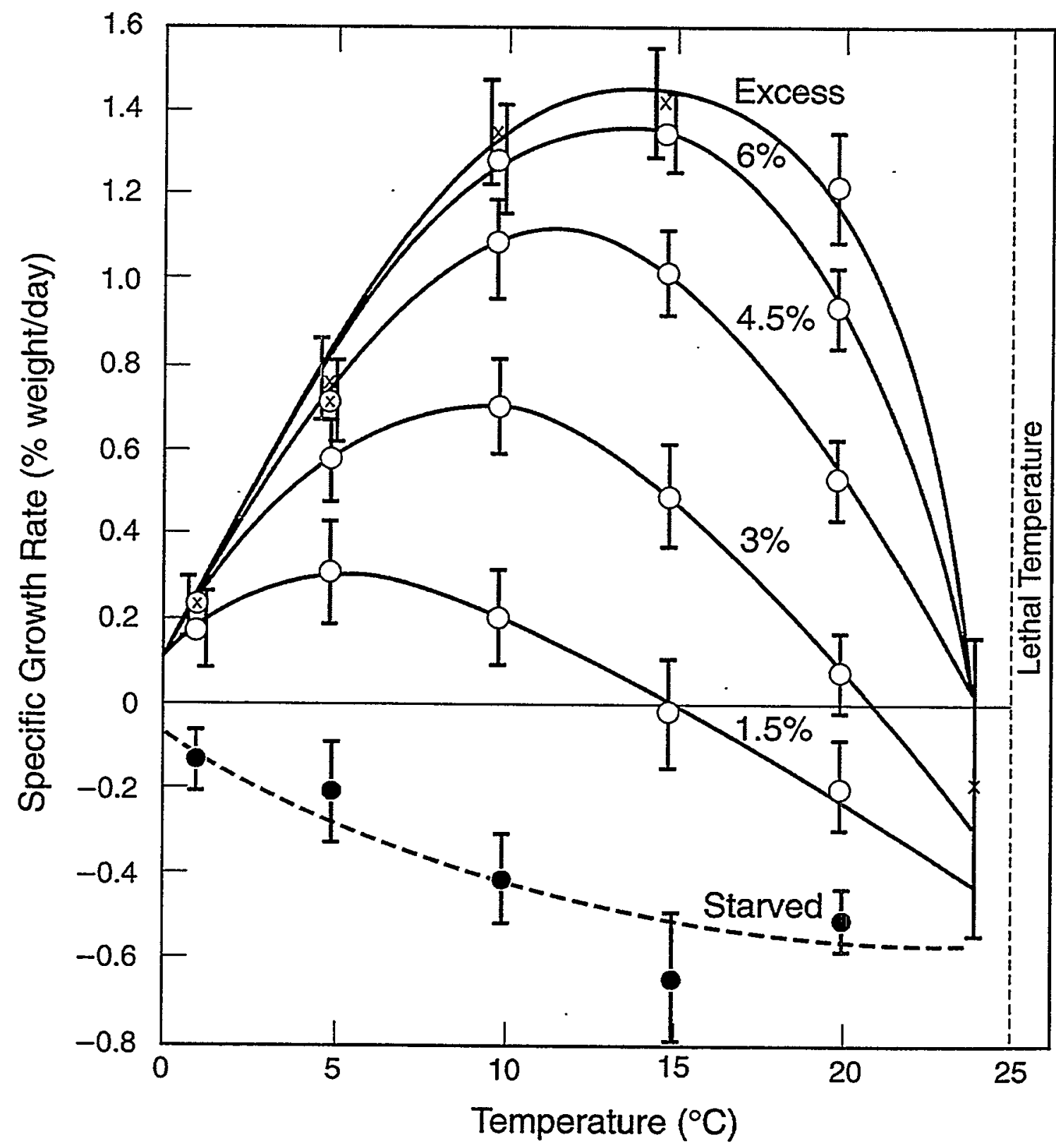

Fig. 16. The relationship between temperature and growth rate for sockeye salmon, shown for several levels of food availability and starvation, as determined by J. R. Brett. 
relatively faster at higher temperatures above optimum. The higher the temperature above optimum, the more the damages limit performance (even well within the physiological survival range). At some temperature, this balance becomes tilted to net damage and the organism does not perform satisfactorily and eventually will not survive (this is the incipient lethal temperature, which takes time to be expressed).

The second aspect of performance is the controlling function, which refers to the effect of temperature on rates of biochemical reactions. Following standard chemical $\left(Q_{10}\right)$ laws, the rates of chemical reactions double with about every $10^{\circ} \mathrm{C}$ increase in temperature. At temperatures below the physiological optimum for a species or life stage, temperature effects are most apparent physiologically as effects on rates of bodily functions. No significant sublethal thermal damage is occurring in the temperature range between lower tolerance limit and the physiological optimum, but rates differ markedly, as illustrated in Figure 15. It is the sum of these physiological rates that causes growth to be lower at lower temperatures below the optimum. In many environmental settings, both rate (controlling) effects and damage (limiting) effects on organisms can be distinguished. The following scenario (Section 5.2) illustrates the differences and the results.

Although perhaps desirable, optimal temperatures through the cumulative exposure history of organisms (such as those producing the fastest growth rates) are not necessary at all times to maintain thriving populations and are often exceeded for many species in nature during summer months. A true upper temperature limit for exposures long enough to reflect metabolic acclimation and sustained physiological performance must lie somewhere between the physiological optimum (the temperatures at which physiological functions perform maximally) and the ultimate upper incipient lethal temperatures. J. R. Brett, in careful reviews of salmonid physiology in relation to habitats successfully occupied, observed that a performance level of about $75 \%$ of maximum at high temperatures was satisfactory using sustained growth rate as the integrator of other maintenance physiological functions (excepting specific life-cycle requirements such as reproduction which are treated separately). A provisional limit of the temperature above the optimum that represents about this $75 \%$ of optimum physiological performance (usually about $1 / 3$ of the range from optimal growth temperature with abundant food to the ultimate upper incipient lethal temperature minus a $2^{\circ} \mathrm{C}$ safety factor) has been accepted for many years. The National Academy panel and EPA have interpreted this limit as applying to the weekly average exposure temperature.

As physiological performance declines at higher temperatures, interspecies competition, disease, predation, and other subtle ecological factors come into play. These factors do not operate in a simple dose-response fashion. Also, they operate more at population levels than at the level of individual physiology. This is the environmental context that must be applied to straightforward use of physiological indicators in setting temperature limits. The $2^{\circ} \mathrm{C}$ safety factor applied to the physiological index for the upper limit for a species or life stage was intended as a recognition that many of these ecological factors were poorly quantified but needed inclusion. 


\subsubsection{Reproduction}

At some times of year, especially spring and fall, reproductive events are especially vulnerable. The sequence of physiological events relating to gonad growth, gamete maturation, spawning migration, release of gametes, development of the egg and embryo, and commencement of independent feeding represents one of the most complex phenomena in nature, for both fish and invertebrates. These events are often the most thermally sensitive of all life stages. For anadromous salmon that do not feed on entering freshwater, temperature effects on energy reserves during upstream migration can be important. Other environmental factors, such as light, which are often seasonal in nature, can affect the response to temperature. Tolerable temperatures or tolerable variations of temperature throughout development differ among species. The physiological requirements for reproduction are generally agreed to supersede all others during times when the species are in the reproductive mode. This philosophy is represented in the general view of water temperature standards illustrated in Figure 1, in which preservation of the annual temperature cycle is important. Fortunately for salmonid work, there is a long history of hatchery practice from which to obtain thermal limits for reproduction. Much of this is anecdotal but generally agreed to be reliable.

\subsubsection{Summary}

In summary, much physiological information can be useful for establishing temperature limits to protect wild species, especially salmonids. We have a great deal of information, from quantitative laboratory experiments and extensive (but often anecdotal) hatchery experience. This information, conceptualized in Figure 1, uses tolerance limits obtained under controlled conditions for long-term and short-term survival, the physiological performance optimum (as determined by studies of growth rates, swimming speeds, food conversion efficiencies, oxygen consumption, etc.), temperatures that prevent growth, and physiological requirements for successful reproduction. The framework of needed information is viewed as an annual temperature cycle. Field data generally correlate well with these laboratory data (see below), although more rigorous comparisons would be helpful. Many state regulatory agencies have established temperature standards with different maximum monthly temperatures (occasionally shorter or longer intervals), to match the basic annual pattern shown in Figure 1. Although not all information may be available for every species or stock, the framework is available for using known thermal requirements for salmonids and new data obtainable with standard techniques to develop similar annual temperature standards for the Northwest.

The physiological information has perceived shortcomings, however. These shortcomings fall into two general categories: (1) the physiological information itself and (2) the relationship between physiological data and population success in an ecological context of the actual inhabited environment. The available physiological information may be deficient for standards-setting purposes for even the gross indicators described above (no optimum growth temperature data for a particular species, for example). Also, there are a myriad of physiological functions that might be used instead of those just 
discussed (and used nationally for nearly three decades). In an era of expanding . physiological research and knowledge, every physiologist seems to have his or her favorite limiting factor, process, enzyme, etc. Whether these alternatives are better than present indexes has not been clearly demonstrated, but may be the case. Our biggest challenge, however, is in how to apply this accumulated physiological knowledge to the behavioral and ecological setting of salmonids, the main subject of this report.

\subsection{BEHAVIOR}

\subsubsection{Temperature Selection}

Although cold-blooded organisms like fish are not able to change their body temperature to any extent from that of the water they occupy, most do not just passively occupy whatever temperatures are presented to them. They will behaviorally select temperatures that are advantageous. Most fish species have preferred temperatures for each acclimation temperature; that is, given a gradient of temperatures, a fish will tend to move to a certain temperature (or narrow range) that is specific for its prior holding temperature. Over the full range of possible acclimation temperatures, and over time for a fish given a wide gradient of temperatures and time to fully acclimate or adjust physiologically, fish will congregate at a "final preferred temperature" or "final preferendum," which usually is a narrow range of temperatures that coincides with the temperature of their optimal physiological performance. This coincidence is so common that the thermal preferendum is often used as a surrogate for other measures of optimal physiological performance, such as growth rate.

A corollary to temperature preference is temperature avoidance. It is often more obvious that fish are avoiding certain temperatures (either high or low) than that they are actively selecting others. Migrating salmonids, particularly, will cease migrations when they encounter high temperatures. Documented "thermal blockage" has been observed for sockeye salmon entering the Okanagan River and chinook salmon entering the Snake River from the Columbia River mainstem when temperatures are about $20^{\circ} \mathrm{C}$. Often, the avoided temperatures are about $3-4^{\circ} \mathrm{C}$ above the preferred temperature range, according to experiments by J. Magnuson and colleagues and reviews by this author.

Temperature preference is important in the natural settings of many fish species because it fosters habitat partitioning, or the allotment of certain territory for certain species or life stages based on temperature preferences. In this sense, temperature is a habitat resource in the niche context of $\mathrm{G}$. E. Hutchinson, not unlike other habitat features, such as cover, substrate, or water velocity. A species or life stage will have its "thermal niche" as well as its niche with respect to other environmental features. In the context of habitat partitioning and thermal niches, one is interested in what is called the "thermal structure" of a water body, that is, the spatial arrangement of different temperatures. Salmonids have a certain degree of habitat partitioning by differences in preferred and tolerated temperatures. Juvenile salmon generally have slightly higher temperature preferences and incipient lethal temperatures than do adults, thereby being able to occupy warmer habitats (such as shallow shorelines) than would be favored by adults. Some other species in the Northwest have pronounced differences in thermal 
preferences (and habitats occupied) by different life stages. An example is the striped bass, a fish originally from the U.S. east coast and now prevalent in Oregon coastal estuaries like Coos Bay. The juveniles of this species are truly warm-water fish, preferring and having optimal temperatures near $27^{\circ} \mathrm{C}$. Adults, on the other hand, have temperature preferences below $20^{\circ} \mathrm{C}$ and cannot long tolerate temperatures above the $25-27^{\circ} \mathrm{C}$ range (they are quite like other cold-water fish like salmon). For these superb fish predators, it makes great sense to have the juveniles segregated from the voracious adults!

A fish or other organism will not always be able to find its preferred temperature in a natural habitat. It may have to settle for temperatures other than its preferred thermal niche. The term "realized niche" has been applied to the next-best alternatives. Often, the realized niche is as close to the preferred temperature as the organism can get without violating its other habitat requirements (such as cover, distance from the surface, etc.). Competition among species in a common habitat with a thermal gradient can force each species to occupy temperatures somewhat different than it would occupy if it had the entire habitat to itself. Field data on fish occurrence are often interpreted as showing preferred temperatures when actually it is a realized niche that might be different under different environmental circumstances.

\subsubsection{Thermal Refuges}

In a perfect world, each species and life stage would have sufficient space (volume of water) to occupy at its preferred and physiologically optimal temperatures. But it is not a perfect world. Natural seasonal temperature cycles force fish to occupy temperatures lower than their preferred temperatures for much of the year. During particularly cold seasons, fish, including cold water fish like salmonids, typically move to the warmest waters available to them for overwintering. These locations in streams are often groundwater springs or intergravel upwellings of groundwater (groundwater being warmer than surface water in winter); in lakes they are the deeper layers (where the densest water is near $4^{\circ} \mathrm{C}$ compared to freezing at the surface). During warm seasons, fish will often move to the coolest water available to them because the ambient temperatures are above their preferred temperature ranges. Whether at the cold or warm end of the thermal spectrum, spatial temperature variability in the environment allows fish to find temperatures closer to their preferred temperature range and to maintain bodily functions as close to optimal as possible. When the spaces occupied are a small percentage of the general environment and the remainder of the environment is outside the bounds of survivability, then the occupied zones are often called "thermal refuges." The fish (species or life stage) may be able to survive in the general vicinity only by finding and occupying the thermal refuges during the physiologically most stressful periods.

Refuges as emergency sanctuaries from extreme conditions elsewhere in the environment integrate with the normally changing availability of cold-water (or warmwater in winter) habitat on an annual basis. Cold-water habitat suitable for salmonids normally shrinks in warm seasons and during warm, dry climate events. The phenomenon of habitat shrinkage in summer and the importance of thermal refuges is 
well known for other species, for example, striped bass studied extensively by C. C. Coutant and colleagues in Southeastern reservoirs. We do not understand, however, how much habitat can be pre-empted by unsuitable temperatures, or how much a waterbody can be fragmented into discontinuous refuges, and still maintain viable populations.

The life-cycle strategy of the spring chinook salmon, for example, depends on the availability of cool habitat in summer. As described earlier, the adults migrate upriver into tributary streams in the spring and early summer before spawning in the fall. They depend on oversummering in cold water, usually deep pools, at a time when stream temperatures outside the pools can rise well above their optimum and upper avoidance temperatures. Less obvious is the need by overwintering juveniles to find winter thermal refuges that may be warmed by the same groundwater seepages. Both contiguous cold water in summer and the number of deep pools have declined in Northwest rivers. The decline in number and size of deep pools in spring chinook salmon spawning streams of the Northwest over the past century, as documented in the 1993 report of the Forest Ecosystem Management Assessment Team, is probably related to declining salmon stocks.

\subsubsection{Predation}

Behavior has another dimension relevant to thermal standards-stress-related, abnormal behavior of small-fish that leads to predation. It is useful to visualize a typical ecological food web diagram, in which everything is eaten by something else. Rarely do small animal carcasses appear, even from directly lethal events, and last long enough to be seen and counted (an exception is for fish kills due to cold, in which the predators are often not feeding). Long before exposures of high temperature directly kill a young fish in the field or cause its physiological performance to deteriorate greatly, predators sense a weakened condition and selectively eat the stressed individuals. Thermal stress, therefore, is usefully viewed as causing abnormal behavior leading to increased susceptibility to predation- or "ecological death." This occurs with exposures that are both acute (as in potentially directly lethal temperatures) and chronic (longer-term exposures in which other factors like disease participate). Some changes in performance or behavior of several fish species have been quantified for acute exposures in a manner similar to the dose-response relationships of direct death. For example, visible loss of equilibrium and statistically significant increase in susceptibility to predation have been quantified by this author for juvenile salmonids. The endpoint for increased susceptibility to predation in these laboratory experiments occurred about $2^{\circ} \mathrm{C}$ cooler than for direct mortality for equivalent exposure durations and is one reason for the National Academy of Sciences panel recommendation to use a $2^{\circ} \mathrm{C}$ safety factor when physiological data are used for water temperature criteria.

\subsubsection{Competition}

The prevailing temperature can affect the outcome of competition among species with different temperature requirements. There is a long history of anecdotal evidence that salmonids give way to warm-water species when temperatures in summer are near $20^{\circ} \mathrm{C}$ 
$\left(68^{\circ} \mathrm{F}\right)$. Because many salmonids can survive at these temperatures and somewhat above, it is assumed that the relative performance levels of the species, including relative levels of activity and feeding behavior, affect competition for resources. Rarely has this assumption been tested, but S. Bowen conducted experiments in 1970 in which rainbow trout and bluegill competing for the same food introduced into cohabited tanks demonstrated a reversal near $21^{\circ} \mathrm{C}$ in the species that captured the food.

\subsection{DISTRIBUTION}

Intuitively, there should be nothing quite like a species' geographic distribution for a reflection of its ability to cope ecologically by integrating its inherent physiological and behavioral capabilities with the surrounding environment. Despite our attempts to decipher indexes of likely success from physiological tolerances and behavioral prerogatives, as discussed above, the organism must function effectively in its ecosystem to be present there. It has, therefore, been tempting for investigators to try to correlate species' occurrence with environmental temperatures. There is logic to a belief that we will not any time soon understand all the physiological and behavioral reasons why a species does or does not function effectively enough to maintain its population. Yet we can view the result in the form of where the species occurs and with what population abundance relative to other locations, in relationship to environmental factors. Placed in a historical context, it should be possible to establish for changing environments the conditions that may have caused population losses or expansions.

Temperature is clearly one of the main factors affecting organism distribution. Latitudinal gradients among species and in abundance of individuals of any species are well known. Similarly, there are altitudinal gradients in occurrence and abundance that parallel latitudinal ones, suggesting temperature as the main driver. The Northwest is blessed with both latitudinal and altitudinal gradients. There have been both retrospective and predictive attempts to relate temperature and population distributions.

\subsubsection{EPA Temperature-Fish Database}

In the early 1970s, the EPA embarked on an ambitious project to catalog and compare the occurrence of freshwater fish species and their environmental temperatures. Streams were selected as the focus, under the logic that stream water would be well mixed and temperatures at monitoring sites would be a fair representation of those that the species encountered in its full life cycle nearby. The maximum weekly average temperature at which a species occurred was hypothesized to be the long-term upper limiting temperature for the species, ecologically, and was selected as the temperatures to summarize. Thermal refuges were acknowledged, but thought to play a minor role in determining general fish distribution. Although the specific premises that underlay this work can be questioned, the results are informative.

Species of interest to the Northwest were estimated according to this method by J. Eaton and colleagues (1995) to have the following maximum temperature tolerances based solely on occurrences in the field (tolerable maximum weekly average temperature), in order of increasing tolerance: 


$\begin{array}{ll}\text { chum salmon } & 19.8^{\circ} \mathrm{C}\left(67.6^{\circ} \mathrm{F}\right) \\ \text { pink salmon } & 21.0^{\circ} \mathrm{C}\left(69.8^{\circ} \mathrm{F}\right) \\ \text { brook trout } & 22.4^{\circ} \mathrm{C}\left(72.3^{\circ} \mathrm{F}\right) \\ \text { mountain whitefish } & 23.1^{\circ} \mathrm{C}\left(73.6^{\circ} \mathrm{F}\right) \\ \text { cutthroat trout } & 23.3^{\circ} \mathrm{C}\left(73.9^{\circ} \mathrm{F}\right) \\ \text { coho salmon } & 23.4^{\circ} \mathrm{C}\left(74.1^{\circ} \mathrm{F}\right) \\ \text { chinook salmon } & 24.0^{\circ} \mathrm{C}\left(75.2^{\circ} \mathrm{F}\right) \\ \text { rainbow trout } & 24.0^{\circ} \mathrm{C}\left(75.2^{\circ} \mathrm{F}\right) \\ \text { brown trout } & 24.1^{\circ} \mathrm{C}\left(75.4^{\circ} \mathrm{F}\right) \\ \text { walleye } & 29.0^{\circ} \mathrm{C}\left(84.2^{\circ} \mathrm{F}\right) \\ \text { smallmouth bass } & 29.5^{\circ} \mathrm{C}\left(85.1^{\circ} \mathrm{F}\right)\end{array}$

Eaton and his colleagues compared these data with laboratory-derived upper temperatures for zero net growth, that is, temperatures at which growth in body tissue is matched by loss of weight of individuals or of biomass through deaths. The matches were close, within $1.4^{\circ} \mathrm{C}\left(2.5^{\circ} \mathrm{F}\right)$.

For some species, avenues of dispersion (especially after the last continental glaciation) are obstacles to the expression of ecological thermal tolerances by geographic distribution. That is, physical barriers may prevent species from colonizing areas where they could tolerate the thermal environment. However, this should not be a problem for anadromous salmonids of the Northwest, which essentially recolonize with each generation. Resident salmonids, though, are clearly limited by geographic barriers. For them, the fish and temperature database matching system may not reflect adaptations of local stocks or sub-species.

For other species in the database, environmental temperatures may not have reached levels that were limiting. Warm-water species, especially, probably did not experience limiting high temperatures in the stream systems included in the EPA database. This was not the case, however, for salmonids.

There are many practical limitations to this approach to determining acceptable temperatures. How well occurrence reflects ecological success is a persistent question about geographic-distribution data. Fish occurrence data may be sufficient for evaluating stable environments. However, in rapidly changing environments, such as the Northwest, fish populations may be in decline and conditions thermally marginal or unsatisfactory yet not so bad as to cause the species to disappear immediately. There is interannual variability in numbers of fish in any stock because of reproductive year-class strength and success during the remainder of the life cycle that can mask effects of temperatures where the species occurs. The gradually declining stocks of anadromous salmon may be the case in point. Occurrence coupled with estimates of population sizes and long-term population trends may be more useful.

The constancy of stream temperatures during the warmest times of year is questionable. Thermal refuges, noted above, occur in nearly every stream studied. Groundwater is a normal contributor to streamflow in most regions, and always has a temperature below prevailing summer temperatures (unless derived from geothermal waters or artificially warmed aquifers). Fish are adept at finding cool places, especially when stressed by high temperatures (as has been demonstrated repeatedly with telemetry techniques). 
Although initially appealing, the EPA fish-temperature database is probably not a good basis for establishing standards for maximum temperature exposures in the Northwest. If the approach is pursued further, studies should include more consideration of environmental variability in index sites, population levels as well as occurrence, and trends in population sizes in relation to historical temperature records.

\subsubsection{Climate Change}

A great deal of thinking has recently been devoted to the effects of global warming on distribution of fish populations in North America, and the logic and results are informative for consideration of Northwest temperature standards. The purposes of the analyses are different, but the limitations of the information for making unequivocal judgements are similar.

Climate change as a result of increased concentrations of so-called "greenhouse gases" in the atmosphere (largely from the burning of fossil fuels) is projected to warm the global atmosphere by $1-5^{\circ} \mathrm{C}$ in the next half century. Warming would be greatest in the colder, northern latitudes. A warmer overall atmosphere is expected to result in warmer streams, rivers, and lakes, on average. How much warmer is uncertain. How this increase in temperature is expressed across annual temperature cycles (maximum temperatures during each season, variability within seasons, interannual variability, etc.) is even less clear. Global circulation models for the atmosphere, which are the basis for broad-scale temperature projections, use a coarse spatial scale (12 grid cells of the Canadian Climate Center's global circulation model, for example, cover the entire Pacific Northwest, from northern California-Nevada-Utah to southern British Columbia-Alberta and west to central Montana-western Wyoming). The grid scale of a General Circulation Model over the Northwest is shown in Figure 17.

Numerous authors have exercised their knowledge of heat transfer mechanisms to predict temperatures in water bodies from the air temperatures estimated by the global circulation models. Both predictions from physical principles and statistical correlations between historical air and water temperature data have yielded reasonable projections of altered stream and lake temperatures, lake stratification patterns, and seasonal ice cover. Much of the effort has been centered in the Great Lakes region (where introduced Pacific salmon are now an important resource); few projections have been made for the Pacific Northwest.

The cold-water species of interest to the Northwest are expected to take the greatest hits in the regions where they are at the southern limits of distribution or are restricted by altitude, although conditions for these species may improve in some northerly locations. For example, cold-water fish in the mountainous North Platte River drainage of southeast Wyoming studied by F. Rahel and his colleagues(1996) (one of the detailed studies most similar to the Northwest) are expected to show a noticeable loss of stream habitat to summer warming for even minor increases in temperature. Based on the use of summer water temperatures to define geographically the thermal limits of cold-water species in this region where altitude establishes suitable temperatures, losses of $16-69 \%$ of presently suitable stream length were projected for temperature rises of $1-5 \mathrm{C}^{\circ}\left(1.8-9 \mathrm{~F}^{\circ}\right)$, respectively. Because cold-water fish would be restricted to higher and 


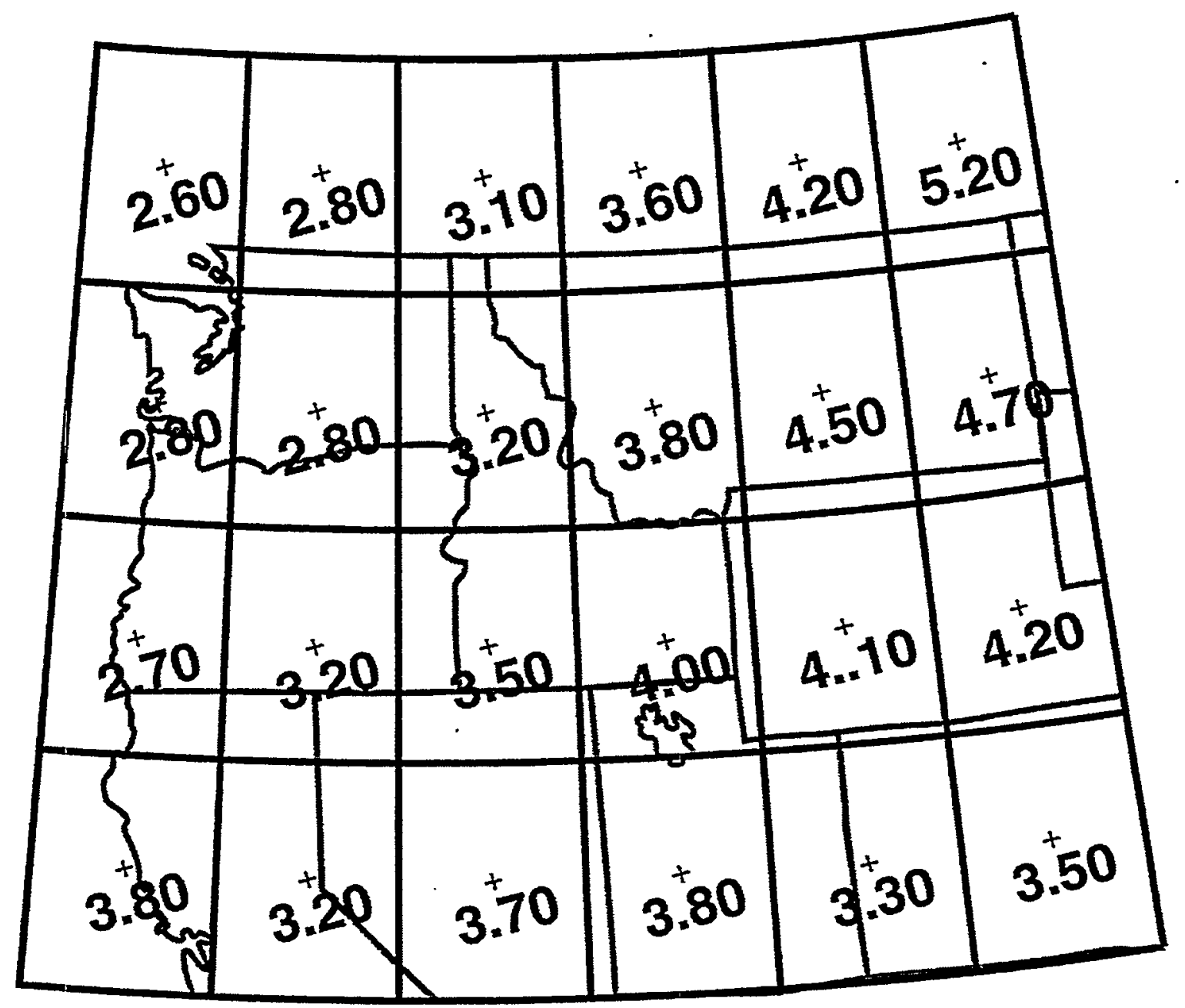

Fig. 17. Grid cells for the Pacific Northwest in the Canadian Climate Center general circulation model of the atmosphere, with projected average July-AugustSeptember air temperature increases accompanying a doubling of carbon dioxide in the atmosphere. 
higher elevations in the mountainous region, populations in headwater tributaries would become increasingly fragmented into progressively smaller enclaves. One enclave examined would shrink from 4,128 interconnected kilometers of stream reaches at present to a maximum of 2,191 linked $\mathrm{km}$ with an increase of $3^{\circ} \mathrm{C}\left(5.4^{\circ} \mathrm{F}\right)$ in maximum summer water temperature to only $404 \mathrm{~km}$ with a $5^{\circ} \mathrm{C}\left(9^{\circ} \mathrm{F}\right)$ increase. All other remnants would be isolated in summer and the viability of their populations would be in doubt.

The critical question for these studies and issues of other anthropogenic changes in temperature (dams, agriculture, etc.) is where, in the mosaic of water temperatures across a mountainous landscape, does habitat for cold-water species end? There seems to be a consensus among researchers evaluating effects of climate change that the cold-water guild of fishes is limited to stream reaches where the maximum July water temperature is less than or equal to about $21^{\circ} \mathrm{C}\left(69.8^{\circ} \mathrm{F}\right)$.

Summer habitat restrictions may not be indicative of overall restriction of distribution by high temperature. Restriction of geographic ranges in summer and likely isolation of fish into smaller enclaves by climate warming, as noted, could be ameliorated by the ability of fish to move to lower elevations and between watersheds during cooler months of the year, assuming that these habitats are in acceptable condition. The amount of such fish movements is clearly relevant to the projected "isolation" of populations and heightens the complexity of an evaluation. Anadromous fishes must move to complete their life cycles, so the question is whether the temperatures throughout the migration corridor are suitable during normal migration seasons. Those migrating in early spring or late fall may successfully move despite warm summers, although the suitable zone for juvenile rearing in summer would be constricted. Resident fish may also disperse in cooler seasons. Winter is an unlikely time for movement, for most salmonids show restricted activity as water temperatures approach freezing. Although some studies show long movements of resident trout in spring or fall (up to $20 \mathrm{~km}$, for example), other studies conclude that stream-dwelling salmonids are usually sedentary and those that move usually do so over distances of less than one kilometer. Thus, it seems unlikely that movement in cooler seasons would compensate for thermal habitat constriction and population isolation in summer months, for either anadromous or resident cold-water fish.

It is clear from this short example of climate-change studies that the resource-effects analysts in the climate-change arena face technical difficulties similar to those faced by people interested in water temperature standards. The true temperature limits for coldwater fish populations are not well known. Environmental complexity is recognized as important. However, the climate-change analysts have progressed further in evaluating the likely effects of temperature changes on fish distribution patterns than has the thermal-standards community. It would be useful to increase collaboration between these two groups. 


\section{EXAMPLE SCENARIOS OF DETRIMENTAL THERMAL EFFECTS IN THE PRESENT ENVIRONMENT}

Two timely scenarios have been assembled to provide examples of the environmental complexity of temperature exposures experienced by salmon and their effects on normal functioning. These examples illustrate how in these situations simply setting an upper temperature standard alone would not suffice to protect the temperature-related functioning of salmon in their present ecosystem. A more comprehensive approach is needed that addresses both the controlling and limiting roles of temperature and the timing of different temperature exposures in relation to the life-history functions of the salmon. Such a comprehensive approach is a major challenge for standards-setting.

\subsection{McNARY FISH BYPASS THERMAL MORTALITIES}

There have been recurring summertime mortalities of juvenile salmon (primarily outmigrating fall chinook) at the McNary Dam fish bypass and collection facility that strongly appear to be influenced by high temperatures. At this facility, juvenile migrants are collected from turbine flows by screens and held in raceways until they are transported by barge to the lower Columbia River downstream of Bonneville Dam. Transportation is preferred by the National Marine Fisheries Service to allowing the fish to remain in the river and experience high temperatures, predators, and other stressors in downstream John Day, The Dalles, and Bonneville reservoirs. In 1998, with water temperatures reaching above $21^{\circ} \mathrm{C}\left(70^{\circ} \mathrm{F}\right)$, mortality levels in the McNary raceways soared on June 10-12. On July 10, the mortality was 11,170 or 3.63 percent of the 307,839 fish collected for transportation or sampling. On July 11 , the mortality rate was 3.05 percent or 11,274 of the 369,539 fish collected. Mortality rose to 8.07 percent or 12,459 of the 154,371 in the collection system July 12 . On July 27,1998 , the daily average temperatures of water passing through Bonneville and McNary Dams were $23.3^{\circ} \mathrm{C}\left(74^{\circ} \mathrm{F}\right)$, well in excess of the $20^{\circ} \mathrm{C}\left(68^{\circ} \mathrm{F}\right)$ required by state water-quality standards. Meanwhile, the daily average temperature reached $22.2^{\circ} \mathrm{C}\left(72^{\circ} \mathrm{F}\right)$ at Ice Harbor Dam on the Snake River. These temperatures were below the ultimate upper incipient lethal temperature estimated by J. R. Brett (about $25^{\circ} \mathrm{C}$, representing a $50 \%$ mortality level for a sample). The measured temperatures were of the bulk channel flow, and forebay temperatures were generally a few degrees higher. An examination of the probable (somewhat speculative) scenario leading to these mortalities is instructive for appreciating both our alteration of the natural river temperature system and the effects of our handling of fish for bypass and transportation.

Juvenile migrants arrive at McNary Dam in May-August from upstream spawning and rearing areas in the Columbia and Snake Rivers. This fall race of chinook salmon has the general life-cycle strategy of having young fish migrate to sea in their first year. A major risk for population survival is failure of juveniles to reach the ocean before temperatures in their mainstem migration route become too high for survival. For reasons that are not completely understood, but partly because of altered timing of river temperatures in the Snake River (see separate scenario Section 5.2), the outmigration of 
underyearlings seems to have extended longer into summer. Thus, underyearling chinook pass McNary Dam near the peak of solar warming and air temperatures.

The exposure pathway and timing for smolts during their migration is important for evaluating thermal mortalities at the dam. Fish often receive abnormally high temperature exposures en route to McNary Dam. The Snake River is generally warmer at this time of year than is preferred for smolt migration $\left(<20^{\circ} \mathrm{C}\right)$, partly the result of the four lower Snake River reservoirs. The water from the Mid-Columbia is generally somewhat cooler. At the confluence of the Snake River with the Columbia, the warm Snake River water maintains its integrity for many kilometers downstream in the Columbia. Thus, fish originating in the Snake system remain exposed to warmer Snake River water rather than being mixed rapidly with cooler Columbia River water at the confluence. Although the fish migrate through McNary pool in the upper third of the water column in the bulk flow near center channel, they make stopovers along shorelines for feeding (as shown by radiotelemetry data). Whereas the center channel is well mixed and still moderate in temperature, the shorelines (especially on the Snake River side) are shallow and warm. A series of flooded ancient river channels (Burbank Slough) and the flooded mouth of the Walla Walla River between the Columbia-Snake confluence and the dam provide large areas for solar warming and air equilibration. This water becomes considerably warmer than the main flow. There is also a tendency for juveniles that enter these flooded zones for feeding to have difficulty finding the main channel to continue their migration, thus extending the duration of their exposure to the warm water.

On reaching the vicinity of the dam, the fish tend to remain in the upper third of the water column rather than descend immediately to the turbine intakes along with the bulk flow. They thus enter the pool of warmer water (above $24^{\circ} \mathrm{C}, 75.2^{\circ} \mathrm{F}$ in July 1998) that typically lies in the immediate forebay when there is little spill. Spill serves two favorable functions at this time, passing fish through the dam quickly and passing enough surface water from the forebay that pooling of warm water does not occur or is less pronounced. Spill generally does not occur at this time of year unless prescribed for fish passage and it operates contrary to the objectives of collecting fish for barging. There is typically a delay of migration as fish seek a surface passage around the dam obstruction, which introduces a certain extra duration of exposure to warm water (up to several days, if telemetry data for other sites are representative).

At some point in time, usually at night when the fish are more attuned to follow flow, the fish are drawn into turbine entrances where they are screened from the flow by McNary's submersible traveling screens. Fish enter gatewells above the screens, are collected by piping, pass through dewatering devices, are sampled at a biological monitoring facility, and end up in the holding raceways to await loading onto barges. Fish densities in the raceways are often high, especially when compared to normal densities in the river environment. Although the piping is designed to minimize physical damage and usually shaded to prevent warming, the fish undoubtedly receive a certain level of abnormal physical and thermal stress. Physical damages would likely contribute synergistically with thermal stress. Fish are held for varying lengths of time in the raceways, which are exposed to air and solar radiation (and exceeded $24^{\circ} \mathrm{C}, 75.2^{\circ} \mathrm{F}$, essentially the upper incipient lethal temperature, in July 1998). In summer 1998, some 
fish were held in these conditions for more than one day as barging was conducted every other day (barging was changed to every day later in the summer).

Fish that eventually die in the McNary raceways almost certainly do so because of cumulative thermal dose from high-temperature exposures received for several days previously. Although temperature records are never complete enough to reconstruct such a thermal dose precisely, the pattern of likely high-temperature exposure in summer is clear. The temperatures themselves are the result of human alterations of the riverine system, and include warming of the Snake River in lower river reservoirs, creation of shallow heating basins in the Burbank slough vicinity, dispersal of the historical subsurface flows that undoubtedly entered and cooled the main river (or provided localized thermal refuges) as the alluvial valley was terminated by the rock of Wallula Gap, pooling of warm water in the forebay behind McNary Dam where fish are delayed in their migration, and finally the warm piping and raceways at the dam.

With so many parts of the summer-warming chain of factors near McNary, it does not seem reasonable to expect an easy solution to this problem by lowering temperatures in the holding facilities. A better approach would be to address it through the life-cycle strategy of the fish. Temperature management in the upper reaches of the Snake River may return the migrants to a more normal annual timing that could get them out of the McNary area sooner when water is cooler.

\subsection{FEVER AND CHILLS-THE MALADIES OF THE SNAKE RIVER FALL CHINOOK SALMON}

In a scenario that is only now emerging with field data to it back up, the plight of the ESA-listed Snake River fall chinook is becoming clearer. An important problem leading to endangered status (in addition to simple loss of spawning habitat to reservoirs) is an altered timing of temperatures that has apparently damaged adults (through near-lethal temperature stresses) and caused later juvenile migration (tbrough changes in the rates of normal growth and development) resulting in low survival (from near-lethal temperatures for juveniles). The scenario demonstrates the interplay between limiting and controlling roles of lethal and sublethal temperatures in the life-history of this species and race.

The scenario begins with adults migrating upriver in late summer and early fall in temperatures that are too warm for their physiological tolerances. The lag effect of water storage by reservoirs has caused the summer peak temperatures to occur later in the year. Whereas historically these high temperatures occurred in July or early August, they now occur in late August or early September, just when the fall chinook adults move upriver. Although river temperatures have changed, adult migration timing has not (mean passage dates for adults at Lower Snake River dams has been near the third week in September since the early 1960s). Migrations have been reported elsewhere to stop when temperatures exceed about $21^{\circ} \mathrm{C}\left(70^{\circ} \mathrm{F}\right)$. The temperatures encountered in the lower Snake River at the end of August and early September in typical flow years are above the incipient lethal level for adults $\left(21^{\circ} \mathrm{C}\right.$ or $\left.70^{\circ} \mathrm{F}\right)$. This means that exposures of greater than one week can be expected to kill more than $50 \%$ of the adult population from high temperature alone, based on laboratory tests on adults and jacks. When coupled with the exertion of active migration (should the adults continue to migrate), the mortality rate is 
probably higher. Disease in adults is often noted to become prevalent when waters exceed about $15.6^{\circ} \mathrm{C}\left(60^{\circ} \mathrm{F}\right)$. With the reservoirs altering subsurface flow patterns, it is unlikely that cool refuges once present still occur along the river channel. Figure 18 summarizes the thermal requirements of chinook salmon adults and juveniles during their migrations as an overlay to scroll-case temperatures measured for the Snake River at Lower Granite Dam in 1990. Summer temperatures exceed most upper thermal requirements.

The eggs produced by females that survive migration in river temperatures near or above the incipient lethal level are likely deficient in number and quality by the time spawning occurs. The limiting effects probably occur at temperatures well below this level. There are numerous references in the literature to decreased egg viability of hatchery brood stock when migration and holding temperatures exceed about $15.6^{\circ} \mathrm{C}$ $\left(60^{\circ} \mathrm{F}\right)$, clearly in the sublethal range for the adult. In one study, eggs removed from females held at $16.7^{\circ} \mathrm{C}\left(62^{\circ} \mathrm{F}\right)$ were all dead. Eggs also tend to be smaller, with less energy stored, when females have been held in warm water. Less energy storage in the egg means less energy for alevin development and the necessity for earlier feeding to sustain life.

Spawning might be delayed by warmer river waters. Field observations elsewhere show spawning at about $5-19^{\circ} \mathrm{C}$ (about $40-67^{\circ} \mathrm{F}$ ), but the usual (preferred) range is more like $7-15^{\circ} \mathrm{C}\left(45-59^{\circ} \mathrm{F}\right)$. Telemetry studies at the Columbia-Snake confluence in the 1960 s showed fish congregating rather than moving upstream in the Snake when temperatures exceeded about $20^{\circ} \mathrm{C}\left(68^{\circ} \mathrm{F}\right)$. Either slow upriver migration or holding in the river until appropriate temperatures arrive could cause late spawning. If females spawn on schedule (by date), they likely will deposit eggs in water temperatures higher than normal.

There is likely low survival of eggs deposited early in the spawning season. The temperatures of early incubation (immediately after spawning) often determine ultimate embryo survival. There is abundant hatchery and experimental evidence that shows low embryo survival when initial incubation is above about $15^{\circ} \mathrm{C}\left(59^{\circ} \mathrm{F}\right)$. Both these incubation tests and experience holding female brood stock suggest that eggs experience lethal temperatures (either in the female or in the gravel) near $15^{\circ} \mathrm{C}\left(60^{\circ} \mathrm{F}\right)$. Egg and early embryo mortality is likely occurring in the Snake River.

Incubation through the winter also tends to be at higher temperatures than normal, which speeds incubation rates (the controlling role of temperature) and can have lasting effects on the quality and survival of alevins and fry. Heat retention in the reservoirs (especially Hells Canyon and Brownlee on the Snake River and Dworshak on the Clearwater above Lower Granite pool) causes winter temperatures at dam outlets to remain warm relative to normal winter water temperatures. Instead of occurring near the freezing point typical of a natural, east-side Northwest river, reservoir releases remain in the $4-10^{\circ} \mathrm{C}\left(40-50^{\circ} \mathrm{F}\right.$ range). This temperature range would seem to be nearly optimal for egg incubation, based on hatchery literature sources, which show optimal survival to hatch in the $5-13^{\circ} \mathrm{C}$ (about $40-55^{\circ} \mathrm{F}$ ) range. However, the condition of alevins at hatching is something else again. Maximum length and weight (implying vigor and 
ORNL 98-128295B/abh

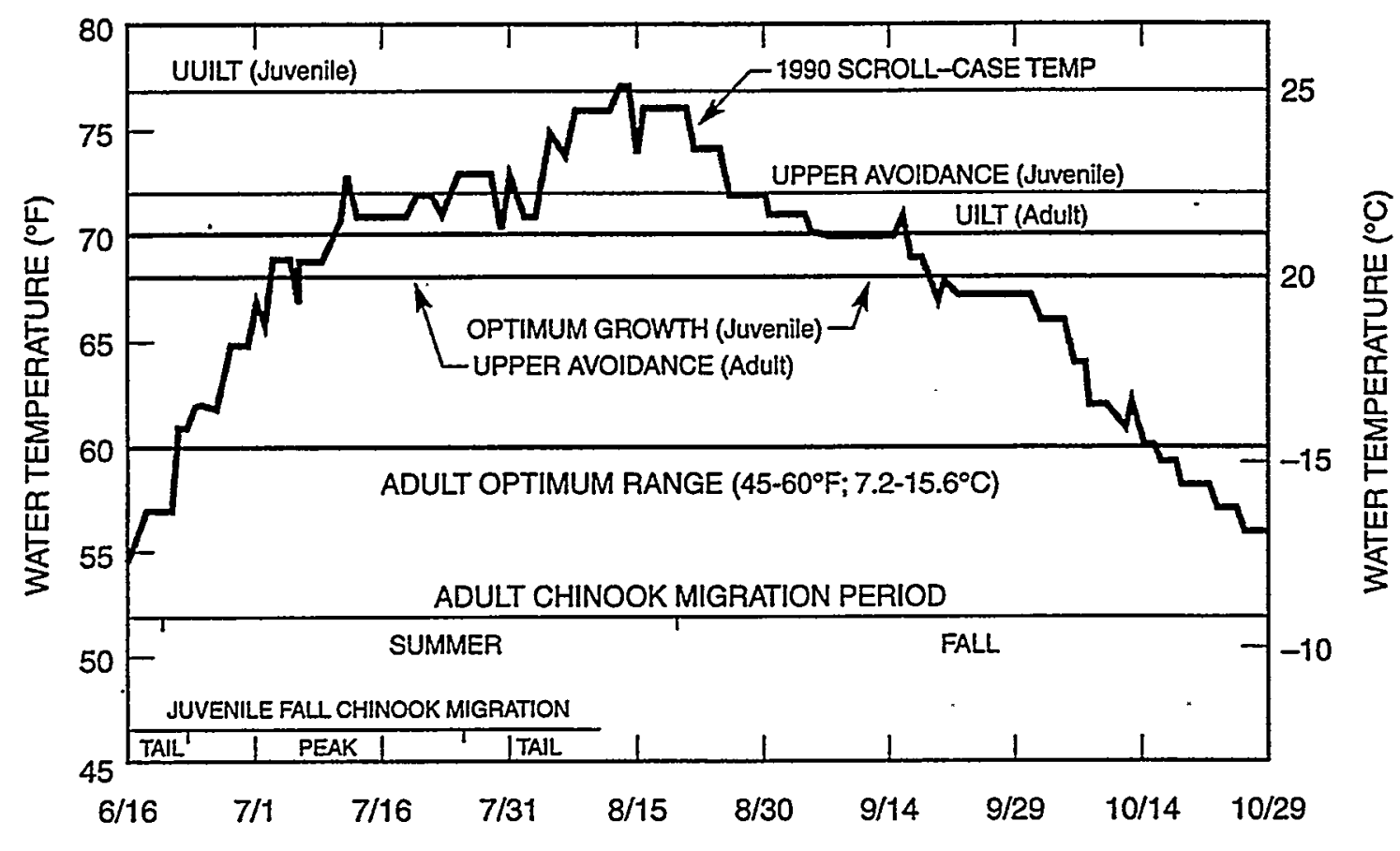

UILT - Upper Incipient Lethal Temperature

UUILT - Ultimate Upper Incipient Lethal Temperature

Fig. 18. Temperature requirements of juvenile and adult chinook salmon, compared with scroll-case temperatures of the mainstem Snake River at Lower Granite Dam in 1990. Normal adult and juvenile migration periods are shown near the bottom of the figure. Scroll-case temperatures represent the main channel flow, which is generally cooler in summer than shallow-water habitats normally occupied by juvenile salmon. 
survivability) occur in the lower end of the range, $5-8^{\circ} \mathrm{C}\left(40-46.4^{\circ} \mathrm{F}\right)$. At the higher end of the thermal range, rates of development are faster, energy reserves are used more rapidly, and smaller alevins result. Smaller fish at emergence likely means greater risk of predation.

At this point in the scenario, there is a reversal of water temperatures relative to normal. Winter storage of cold tributary water in the reservoirs causes dam discharges to begin to be colder than normal. The spring warming pulse typical of natural rivers is greatly delayed. Whereas the concern for salmonids in the Northwest is generally for adverse high temperatures, the concern now becomes for temperatures that are too cold. The cold temperatures slow normal rates of growth and development (the controlling role of sublethal temperatures).

Alevins and fry that normally hatch and emerge from gravels in March and April (but could emerge earlier in the Snake River because of warm incubation temperatures) find cold temperatures (usually near $4^{\circ} \mathrm{C} ; 39.2^{\circ} \mathrm{F}$ ) for their rearing period. Growth of juveniles is slow. Optimal growth for juvenile chinook salmon is generally in a broad range from about $12-17^{\circ} \mathrm{C}\left(54-62^{\circ} \mathrm{F}\right)$, based on numerous hatchery and experimental studies. Optimal growth temperatures are not achieved until after the time these underyearlings should have grown to migration size and left the system.

The cold temperatures also inhibit the physiological changes known as smoltification, which prepare the fish for saltwater residence and generally stimulate fall chinook juveniles to migrate downstream gradually as they rear and grow. There is emerging evidence that smoltification occurs at a larger fish size in fall chinook salmon reared in cold temperatures. This effect adds to the general slow growth of the fish in cold water to cause fish to move downriver later in the season than if reared in warmer (more normal temperature) water. Migrations normally occurring in May (as from the Hanford Reach on the Columbia River) now occur in June and July from the Snake River. The other anomaly is that these fish are larger and seemingly more robust than normal migrants when they begin to emigrate in earnest.

Late emigration can be disastrous for salmon migrating through warm Lower Snake River reservoirs. The immediate concern is again for warmer water. The upper limit of optimal growth rates (near $17-20^{\circ} \mathrm{C}$ or $62-68^{\circ} \mathrm{F}$ ) is exceeded by late June in the bulk flow of water passing through scroll cases of the Lower Snake River dams. In the shallow, sun-drenched shorelines where juvenile fall chinook normally feed and grow as they gradually move downstream, water temperatures exceed the upper avoidance temperature of about $20^{\circ} \mathrm{C}\left(68^{\circ} \mathrm{F}\right)$. Cut off from their normal feeding habitat and forced to reside in food-deficient water above their optimal growth temperatures (with high metabolic rates due to the high temperatures), the migrants suffer an imbalance between energy intake and energy expenditure, referred to as bioenergetic imbalance. Studies of migrants in Lower Granite Reservoir in the early 1990s showed that they existed, on average, at energetic levels just above that of starvation. On the positive side, fish actively avoided zones where temperatures exceeded the incipient lethal level of $23-25^{\circ} \mathrm{C}$ $\left(73.4-77^{\circ} \mathrm{F}\right)$. Lethal temperatures would be hard to avoid, however, when the main river (scroll case) temperature reaches $24.4^{\circ} \mathrm{C}\left(76^{\circ} \mathrm{F}\right)$, as it did at Little Goose Dam in 1991.

Smoltification is also affected by high temperatures. Normally, the migrants show signs of early smoltification at the time they initiate migration from the general area of 
their spawning. The indices of smoltification normally become stronger as the fish gradually move downstream. High temperatures experienced during migration, however, reduce the rate of smoltification, which some authors say is inhibited above about $15^{\circ} \mathrm{C}$ $\left(59^{\circ} \mathrm{F}\right)$, based on laboratory studies. The process of smoltification is actually reversed when some salmonid migrations are overly delayed.

Thus, large, robust (but late) juvenile fall chinook salmon arrive in the Lower Snake River reservoirs in June and July. They are energetically deprived there as a result of poor food supplies and temperature-controlled high rates of metabolism, but not killed outright by high temperatures. Survival estimates of PIT (passive integrated transponder)-tagged fish through the dams by the National Marine Fisheries Service show high survival. Nonetheless, the energetic deficit and gradually accumulating, physiologically limiting exposures to sublethal temperatures higher than optimal must take a toll. Some fish probably experience temperatures that would ultimately be lethal (with a week-long exposure).

In the Burbank Slough area of the mainstem Columbia, the Snake River migrants encounter another large area of shallow, warm water where the McNary pool has extended over the historical riverbank (as discussed in the first scenario). Temperatures rise further as the migrants pass these areas at the peak season of solar warming, and their high-temperature exposure continues. Their cousins, the Hanford fall chinook, have passed through the same area a month or more earlier without difficulty, probably because temperatures were cooler and nearly optimal then.

The ultimate demise of these Snake River juvenile fall chinook likely comes not from physiological heat death (as seen in laboratory tolerance tests) but as the result of predation. It is clearly established that the reservoir behind John Day Dam is a site of high predation rates on juvenile salmon, especially underyearling fall chinook. In this reach of river, fall chinook juveniles have been observed by the Smolt Monitoring Program in low flow years to be emaciated. Field observations show juveniles swimming in a disoriented way, often moving upstream instead of downstream. Predator stomachs are full of juvenile fall chinook salmon. Laboratory studies have clearly shown that increased susceptibility to predation occurs much sooner than direct heat death. Fish that are emaciated from experiencing a negative bioenergetic balance through much of their migration, and probably showing poor swimming performance and behavioral acuity, would be prime candidates to be eaten.

Although clearly there are other factors involved, the poor survival of fall chinook in the lower Snake River can be seen as a logical consequence of a series of temperature anomalies, mostly in the sublethal temperature range. These anomalies extend throughout the freshwater residence of the stock, from incoming adult to outgoing juvenile. Some involve the limiting effects of high temperature whereas others involve the effects of temperature on rates of physiological functions well within the tolerance range. The altered thermal conditions of the Lower Snake River have failed to match the life-cycle strategy of the fall chinook, which is to get into freshwater for reproduction after temperatures have fallen and get its juveniles out before temperatures rise to debilitating levels. Not only has the stock been squeezed by high temperatures at the traditional stress points of early fall and late spring, but its normal development has been put askew by an altered seasonal sequence of temperatures in between. 


\section{ISSUES IN THE DEVELOPMENT OF THERMAL STANDARDS}

How does the setting and enforcement of temperature standards in the Pacific Northwest logically fit into the complex ecological and physiological picture just described? Every locale probably has some site-specific scenario that suggests that temperature alterations have contributed to the decline (or perhaps rehabilitation) of salmonid populations and other valued components of the ecosystem. A single numerical upper temperature limit, which was the hallmark of the earliest temperature standards, does not seem sufficient to adequately protect all stages of aquatic life throughout a state or the entire region year-round. A single legal standard based on a limited range of biological criteria does not seem capable of accommodating the abundant, available information on environmental complexity or the physiological understanding of both lethal and sublethal responses to extreme or altered temperatures (unless the limit is so stringent as to preclude any other water uses). The more recent, seasonally adjusted limits based on physiology, behavior, and reproduction also seem to have limitations in matching organism responses to environmental complexity when applied over a wide and environmentally diverse area (such as a whole western state).

To be most realistic, it seems logical to focus on the biological and ecological relevance of temperatures in the local context (i.e., at scales appropriate for the functions being carried out), both to ensure adequate protection of valued biotic populations and communities there and to guard against being overly restrictive in places and times where it is not warranted. The scenarios of the previous section give a retrospective view-that is, deciphering where the environment has gone wrong thermally in both spatial and temporal dimensions for the life-cycle strategies of the fish. The challenge is to do likewise prospectively to establish what regulatory mechanism is needed to ensure that things go right.

To be fair to the physiological approach, it has not been applied adequately to be sure that it would not suffice. Maximum summer temperatures, limited excursions to higher temperatures, and seasonally staged monthly maximum temperatures of this approach, illustrated in Figure 1, may be sufficient in many or even most cases. The physiological approach should not be eliminated from consideration but evaluated along with all other possibilities. Simplest may actually be best.

The subsections that follow briefly discuss some of the considerations in establishing thermal standards for the Pacific Northwest. They are.organized in a sequence that caters to the flow of ideas rather than a listing of priority. They are not intended to recommend a course of action but to help establish and clarify the options. Both strong points and limitations are discussed. The section concludes with a suggested prioritization or sequence of steps, as an example of what must be done whatever the direction chosen, including the gathering of new information through research.

\subsection{BENEFICIAL USES}

The drafters of the Clean Water Act laid down a clear starting point. The Clean Water Act specifically requires the designation of beneficial uses of waters, which would set the stage for the level of water quality to be attained. In the present context, this 
requirement can be interpreted as the need to know how salmonids normally use a particular waterbody at a particular time. Recognizing that life-history functions partition river basins into areas for migration, spawning, rearing, and the like (each having different temperature requirements), "waters" must be given a spatial scale relevant to those functions. Current habitat use is probably not adequate for designating beneficial uses, considering the depressed condition of most salmonid populations. We must reach back in history (perhaps unreliable) or to the best scientific understanding of the probable uses and habitat conditions. These uses should be defined in the context of an environmental continuum with need for connectivity among habitats used sequentially by salmonids as well as function-specific designations, such as reaches used for spawning. In the wording of the Independent Scientific Group's report, Return to the River, we need to establish the "normative" condition for the reach. That is, the expected norm or standard of measure (more often based on the sum of scientific understanding about what should occur at such a site than a historical record of what actually did occur, although both can contribute).

In its most direct application, designation of beneficial uses for stream reaches or segments allows designation of critical temperatures for critical life stages occurring there. This would seem to be the logical intent of the Clean Water Act, and not a "new" approach. Physiological and behavioral data would be the foundation for designating the critical temperatures, with other constraints added based on particularly relevant ecological relationships. For example, a riverine reach may be used during a specific time period as a migratory corridor for one salmon species, a rearing habitat for another (or the same) species, and as a food production system for rearing juveniles. The most thermally sensitive life stage may be the migratory adults, which would then establish the standard for that reach over the period of their normal occurrence. A normative thermal pattern would emerge for the stream segment over a calendar year as this winnowing of

sensitive life stages occurs for each relevant time period. Actual life stages (e.g., adults) may not have been recorded for some time in this stream section, but local management plans indicate a desire to reestablish them. The local standard could be set in anticipation of attaining the desired use.

Defining beneficial uses for a stream reach is not easy or straightforward. Some difficulties are discussed in the following seven subsections.

\subsubsection{Social Decisions}

Designating beneficial uses in the present natural-cultural landscape involves social decisions as well as biological ones. Many different species are present at the same time in the same vicinity doing different things. The inhabitants may be competitors and valued differently. For example, juvenile salmon migrants and walleye coexist in places and times. Walleye are favored by higher temperatures and have an enthusiastic following among many anglers. Setting temperature standards to protect salmonids may be detrimental to walleye. Social choices must be made, for the normative standard for walleye will be different than for young salmon. The injection of human values becomes even more perplexing when alternative future management goals for species not now in the waterbody are included (e.g., restoring lost salmonid populations). Use designations 
may have to be decided through negotiations that include interested parties in the vicinity of the segment (although some will view such negotiations as an unjustified compromise).

\subsubsection{Biodiversity}

Maintaining biodiversity among salmonids, both in species and life-history types, may be a more pertinent concern than hypothetical shifts to warm-water communities. Temperature, in part, defines the distribution and life history diversity of the occupants (or potential occupants) of a waterbody. Alteration of the temperatures occurring annually and spatially can reduce the diversity of species or stocks that can be supported. This culling of diversity leaves the assemblage of remaining occupants more vulnerable to natural or human disturbances (it might be the previously culled stocks that would have been most able to cope with the new disturbance). We may also inadvertently affect diversity by managing for desired species. Our desire to propagate anadromous salmonids may impinge on the success of, for example, fluvial bull trout that occur (or might occur) in the same segments. Bull trout, generally, have even colder water temperature requirements than do most anadromous salmonids.

\subsubsection{Spatial Scale}

The appropriate spatial scale of beneficial-use designations is uncertain. In a rapidly changing landscape, such as the Pacific Northwest, where both geological and human

processes occur rather quickly, it would seem imprudent to limit the designated beneficial uses too narrowly in space and time. Historical uses of habitats by salmonids have undoubtedly changed in response to natural changes in habitat quality (by avalanches, floods, volcanoes, etc.). There must be latitude in available habitat quality for uses to shift in response to these and human alterations.

\subsubsection{Degraded Habitats}

Habitat constraints due to present degradation may preclude certain uses, either in the short term or a longer term. For example, a recently logged watershed may be so devastated that expectation of deep, cool pools and silt-free spawning gravels in the near future is unrealistic. Yet the presence of deep pools with cool water $<15^{\circ} \mathrm{C}$ in summer may be the most critical habitat feature for a species or stock, such as spring chinook salmon. Beneficial uses might be assigned as goals for restoration (as well as for preservation in areas presently having good habitat), with attainment of a temperature standard for pools tied to a timely schedule of habitat rehabilitation. Such refuge-specific standards are being implemented in some Southeast states to protect over-summering striped bass. A numerical criterion could thus be linked to a performance-based criterion in which compliance is measured as a progressive improvement leading to the normative goal (performance-based standards are discussed further in Section 7.2). 


\subsubsection{Utilization Potential}

Formal establishment of more detailed beneficial use designations, as already required in a broad context under the Clean Water Act, forces us to consider when a stream segment has attained its utilization potential (fish numbers versus habitat availability). With most stream reaches now having a multitude of cultural and biological uses, it may be unreasonable to expect the potential use for fisheries to match historical records or what might be ecologically possible if fish production were the only goal. Historical records often are anecdotal and record only the extreme high end of use, that is, a peak in harvest that may never have been sustainable. Currently, many historical spawning habitats are not "fully seeded" because of lack of spawning adults, not availability of high-quality habitat, as observed by detailed analyses by participants in the regional PATH process. Although it may be important for EPA to explicitly allow for designation of beneficial uses in anticipation of future return of salmonids, the amount of habitat designated for the future use should be considered carefully based on realistic measures of how the habitat might be used.

\subsubsection{How Many Segments?}

A drawback to basing thermal standards on reach-specific beneficial uses is that there could be hundreds of unique reaches in each state, each with different uses and potentially with different thermal standards. Establishing and administering such a large list could be chaotic. An extreme example would be designation of distinctive thermal standards for cold pools used as thermal refuges. At the other end of the spectrum would be so few specific reaches that a single state standard might as well be adopted. If standards are to be adopted based on beneficial uses, how many unique segments is realistic and workable? Although surely this must be a decision based on the ecology of the state's waters, a reasonable list might include a dozen or so typical sets of multiple uses. For example, a stream reach could be designated as salmon spawning and rearing habitat from October until April where these functions occur. Another designation could be salmon migration from October to December and March to May, where adults are transients in the fall and juveniles are transients in spring. The state's waters could be classified among these sets. Although lumpers would argue for fewer categories and splitters would argue for more, a manageable list should be possible.

\subsubsection{A Big Job}

Beneficial use designations that adequately match biological functions still need to be established for many waters of the Northwest, despite considerable progress (some current designations are of little practical use, such as designating whole streams for "fish and wildlife" uses). For many river and stream reaches, there is limited knowledge of habitat use and fish movements. However, a clear vision of what we want from our environment is essential for the setting of protective standards. Setting of reach-specific beneficial uses tied to the biological functions expected to occur there ought to be high priority, regardless of whether we are doing so to revise temperature standards. EPA 
guidance for the establishment of beneficial uses may be as important as the setting of a temperature standard to attain those uses.

Modern technologies can help with designation of beneficial uses and enforcement of the standards that are selected. There is already progress in many states at designation of beneficial uses by stream segment (e.g., inclusive river miles). These segments are then the basis for segment-specific water quality standards and enforcement. Modern mapping techniques, such as Geographic Information Systems (GIS), have made seemingly intractable documentation tasks routine. Likewise, nearly continuous monitoring of water temperature has become cheap, reliable, and automated. Segment-specific monitoring is both technically and economically feasible and should not be a constraint to designating segment-specific beneficial uses and standards.

\subsection{TEMPERATURE REQUIREMENTS}

Assignment of temperature limits to beneficial uses requires reliable biological data for the life stage or function to be protected. However, this fact has been recognized for many years and the most relevant physiological, behavioral, and reproductive data for salmonids have generally been acquired. There are adequate compilations of important scientific literature and relevant experience from the operation of hatcheries (e.g., McCollough 1999). With rare exceptions, it is not necessary to test the thermal requirements of the inhabitants of each stream segment for which the beneficial uses are established (or even for the entire river basin). Thermal requirements are generally species and life-stage specific, unless there is good reason to expect that a stock has been so isolated that it may have evolved unique characteristics. Most anadromous salmonids have similar thermal requirements. The challenge is to make intelligent syntheses, use existing data, and selectively identify (and fill) the few needed information points.

One disconcerting feature of the literature record is a lack of complete agreement in numbers presented. A search for the lethal temperature for chinook salmon, for example, will yield a range covering a few degrees. These differences are probably all functions of the studies more than of the inherent capacities of the fish. Each author has interpreted his or her data or experience somewhat differently. Experimental designs differ, fish are in different physical conditions during tests, endpoints for survival differ, and there is always individual variability among fish specimens tested. The lesson is that we should not argue about decimal points but be content with a weight of evidence for each critical temperature being summarized. There may be some value in selecting the most stringent of the alternatives, but we should recognize that errors can occur in both directions from the true value (a colder value may not be any better representation of the true value than a warmer one).

The rarer a species or stock, the less likely there will be definitive data on its thermal requirements. Obtaining such data may not be possible for species or stocks listed under the Endangered Species Act. For these species or stocks, estimation from closely related or environmentally associated species may be necessary, with a sufficient margin of safety applied. 


\subsection{REQUIREMENTS FOR SALMONIDS VERSUS REQUIREMENTS FOR ALL BIOTA}

It is usually assumed that temperature standards established on the basis of thermal requirements of salmonids will be protective of other biotic components of the ecosystem (e.g., aquatic invertebrates important as fish food items or in their own right). It is important to recognize that this is a belief, not necessarily a proven fact. There is a valuable literature on topics (largely temperature dependent) such as altitudinal zonation in mayflies, seasonal patterns in the timing of growth and emergence in aquatic insects, and thermal tolerance of some species and life stages of invertebrates. Some of this information suggests thermal guilds of organisms (i.e., groups of species and life stages associated with certain temperatures or temperature regimes). These data are too sparse and unsynthesized, however, to form the basis for regional standards. In reality, however, it takes an ecosystem to support a salmonid, and it is the ecosystem that we wish to protect or rehabilitate.

It seems reasonable to use the thermal requirements of salmonid life stages as keystone indicators of the seasonal thermal requirements of stream segments. They help define what is thermally "normative" for the segment. The approach is consistent with the "Representative and Important Species (RIS)" approach used in other sections of the Clean Water Act. Further research on invertebrates may ultimately allow some of them to be included as RIS. In the meantime, attainment of the needs of salmonids should allow conditions suitable for most invertebrate co-inhabitants. Proponents of invertebrates who believe otherwise have the opportunity to bring supporting data to periodic discussions leading to revisions in both beneficial use designations and thermal standards.

\subsection{AMBIENT AS BASELINE}

Many existing temperature standards refer to an allowable deviation from the natural or ambient temperature. This is a useful approach for regulating the heat output of a simple, point-source discharge, where the temperature elevation of the waterbody caused by the effluent is at issue. It is less relevant to protecting the viability of aquatic life in a broader context of a whole waterbody and as a result of the multiple causes of temperature change (both natural and anthropogenic). The assumption behind ambientbased standards is that the current ambient is acceptable for the beneficial uses, which may not be true. Habitats are already highly modified such that the current temperature may be a poor reflection of the conditions needed to sustain viable salmonid populations. It is far better to base standards on desired beneficial uses and the temperatures needed to attain those uses.

Definition of an ambient temperature is technically difficult in a thermally heterogeneous environment with daily and seasonal fluctuations and large spatial variations caused by both natural events and human activities. A temperature recorded at a bridge piling in a large river, for example, is the culmination of continuous but variable heat transfer processes occurring over several days in the watershed upstream of that 
point. Even the long-term average ambient is changing as climate warms. It seems unwise to base firm standards enforcement on such a fragile base.

One of the main reasons historically for regulating on the basis of ambient was to preserve an annual temperature cycle. Numerical temperature standards tend to be directed at just the summer season and provide mostly a maximum temperature cap. Several states have adopted seasonal or monthly maxima. Where power station cooling water was the main concern, winter maxima were often specified to prevent damaging cold shock from abrupt termination of an abnormally warm thermal discharge where fish have been residing.

An annual temperature cycle can be preserved far more rationally than by matching an ambiguous "ambient." It is accomplished by assembling the critical temperatures for beneficial biological uses for a stream segment (Figure 1). These biologically based critical temperatures can be used alone to create an acceptable annual thermal cycle. This has been the rationale behind temperature standards based on physiological, behavioral, and reproductive requirements, as recommended by the National Academy of Saevel/National Academy of Engineering review in the 1970s. Biological criteria are perhaps best used, however, in conjunction with a historical record of temperatures and their variability in a stream segment (although such records are rarely available from predevelopment years that would best represent the natural condition). The historical record provides a smoothing function among critical life-stage temperatures, which otherwise could create step-wise temperature changes. Where long time series of temperatures are available, the data may provide meaningful statistical information as a representation of the normal temperatures (including variability) for a site.

\subsection{REGIONAL DIFFERENCES IN THERMAL REQUIREMENTS}

It is often claimed that different thermal standards should apply in the two main physiographic regions of the Pacific Northwest, the cool and forested west side of the Cascade Mountains (and similar habitats at high elevations along the west side of other mountain chains) and the arid interior basin. The logic is intuitive-it is much hotter and sunnier in the arid basin, so the temperature standards should allow stream temperatures to rise higher in summer there than in the wetter and cloudier locations.

It has yet to be adequately demonstrated that the thermal requirements of salmonids differ geographically to the extent that would warrant separate measures for arid and wet locations in the Northwest. That is not to say that it could not occur. Future research may justify such designation, and interested parties should be encouraged to document their beliefs for use in subsequent evaluations of thermal standards.

Most thermal requirements appear to be species specific. In fact, similar thermal requirements can often be recognized in groups of species (thermal guilds, as presented by K. E. F. Hokanson). Many salmonid species, for example, have quite similar temperature requirements for equivalent life stages. Considerable research to detect. geographic differences in thermal requirements of largemouth bass, which is widely distributed from Florida to southern Canada, failed to demonstrate any significant differences, except for the Florida strain that was already recognized as a distinct subspecies. 
The main reason for considering different thermal requirements in separate geographic or temporal (e.g., migrating at different times) stocks is the potential for geographic or temporal isolation and differing annual thermal regimes in localized habitats to have led to evolution of differences. The presence of locally adapted stocks with respect to other biological features suggests that local adaptation to temperatures could have occurred. Local adaptation is perhaps most likely in non-anadromous species that have no opportunity for genetic mixing (anadromous species usually stray geographically and overlap temporally). Warm locations with isolated resident stocks, such as the upper Klamath basin's rainbow trout or several stocks of redband trout, may show geographic differences in thermal tolerances. Although suggested in the past, the definitive experiments to demonstrate this have not yet been done.

More likely than regional differences in thermal requirements is the probability that stream segments with similar beneficial uses will have animal communities with similar thermal requirements wherever they occur. For example, it is likely that spring chinook salmon spawning habitats will be thermally similar in locations as diverse as the upper Willamette River basin, the upper Yakima River basin, the Grande Ronde River basin, and the upper Salmon River. Rather than having to create unique thermal standards for each stream segment, experience may allow an aggregation of suitable annual temperature cycles by categories of beneficial uses. In essence, there could be useful beneficial-use "guilds" in which the same temperature standards could be applied. Thus, of perhaps hundreds of stream segments in a state with identified beneficial uses, a much lesser number of typical or characteristic uses (perhaps a dozen, as suggested above) might be identified. The state could thus designate thermal standards for each of the (perhaps) 12 use types, and indicate which use type applies to each segment.

\subsection{FULLY PROTECT}

It is a general goal of water quality standards to "fully protect" aquatic life. By this we usually mean that we want to have a high degree of certainty that the standard we select will maintain populations of desired organisms (including genetic stocks and preserving life-history diversity), including some latitude for sport, commercial, or subsistence harvest. However, it is worth dissecting what we really mean by this statement lest we get drawn into situations not intended. In the extreme, does "fully protect" mean that we object to one fish being killed? There are some in the public, such as those associated with organizations that are nominally promoting the ethical treatment of animals, that would like to see this strict interpretation.

Unlike our concern for ourselves, we generally view animals as populations to be sustained, not individuals to be protected. A possible exception would be species on the endangered species list, for which stricter limitations of "take" are appropriate. We justify harvest, both commercial and sport, on the basis of a capacity of a population to sustain some losses and still maintain healthy numbers. In nature, most populations have many well-documented mechanisms available to compensate for losses of a few individuals, such as enhanced growth rates or lower mortality rates of survivors. "Fully protect" in this instance means protection of the population and a justifiable removal of some individuals. 
Assay data used to establish the temperature requirements of aquatic organisms exhibit both individual and "population" responses. Typically, some individuals are more susceptible than others to stress and die (or show other symptoms) more quickly or at a lower temperature. Other individuals are hardy and persist longer in the test or at higher temperatures. The responses of a group of tested individuals is usually summarized statistically as an estimate of the response of the population represented by the sample [e.g., a median (50\%) response time with a measure of variance]. These generalizations are true whether the stress is at lethal or sublethal levels. The difference in temperature between the first fish to show a response and the median or last fish to show it can be large. Data reported in the literature are usually the median response for a test population, as shown in Figures 14-16. Safety factors have been included in some thermal regulations to adjust median response data to reflect protection of most of the population.

It is important to be clear about what we mean by "fully protect." Are the standards being set to fully protect the viability of populations or the protection of all individuals? It is most appropriate ecologically to protect the populations. If there are special situations, such as ESA status, genetic diversity, or life-history types of sub-populations, these issues should be evaluated explicitly to see how protection of populations affect these parameters. This point may be debated for a particular situation (e.g., where loss of even one migrating adult salmon is unacceptable), but there is need for explicit understanding of the outcome of the debate.

\subsection{LOW-TEMPERATURE STANDARDS}

We conventionally think of temperature standards as being established to protect from too high temperatures. However, as the previous discussion indicated, temperatures that are too low can be equally as damaging to fish populations under certain conditions. Minimum standards for acceptable temperature may need to be established seasonally for locations such as tailwaters of storage reservoirs in summer. There, deepwater discharges often leave tailwaters unseasonably cold and aquatic populations unable to carry out normal seasonal functions. Recognition of the importance of too low temperatures is a stimulus to develop annual temperature cycles as standards.

\subsection{RATE-OF-CHANGE LIMITS}

There are some suggestions in the literature that rapid rates of temperature change can be too great to be tolerated even though the temperatures themselves are within the established tolerance range. For example, an instantaneous $10^{\circ} \mathrm{C}$ thermal rise may be detrimental from 5 to $15^{\circ} \mathrm{C}$, even though 15 is about optimal over the long term. Clearly, this "thermal shock" aspect of thermal tolerance should be considered.

Most thermal mortality studies actually include thermal shock as part of the experimental treatment, however. Nearly instantaneous temperature changes (the most rapid rate possible) were incorporated in the conceptual foundation of "resistance times" at changed temperatures and "incipient lethal temperature" at both high- and lowtemperature ends of the scale by F. E. J. Fry and colleagues in the 1940s. J. R. Brett 
established that the hatchery practice of "tempering" fish when temperatures were changed actually made little difference to survival so long as the change was within tolerable limits. The concepts of Fry were exemplified for salmon by the doctoral dissertation research by Brett in the 1950s, from which we obtained much of the basic thermal tolerance (survival) data still used today.

Sublethal effects that influence mortality rates (e.g., through predation) or growth are still possible with rapid temperature changes, however, and have not been investigated thoroughly. Although effects have been speculated, we lack good information on possible effects of different amplitudes of daily fluctuations on Northwest fishes.

Current evidence does not support a limitation on rate of change in temperature as a formal part of a thermal standard. More quantitative physiological data on this aspect of thermal tolerance may be useful for subsequent evaluations of potential thermal limits. Rates of change actually experienced by fish in the environment should be investigated.

\subsection{SPATIAL CONTINUITY OF STANDARDS}

Biota that move around a lot need to have all of the locations they occupy protected from detrimental temperatures at times when they are there. In the current jargon, habitats need "connectivity" and should not be fragmented by adverse temperature conditions. One lethal location in the life cycle can bring down the entire yield of other suitable habitats. For example, pristine environments of a wilderness area can be negated for fish production if the lower reaches of streams outside the wilderness are unsuitable. Although the example of an anadromous salmon migrating sequentially through mainstem, lower tributaries, and upper tributaries is most evident, the same holds true for so-called resident fish, which often migrate large distances in freshwater between spawning areas and habitat occupied during the rest of the year (e.g., bull trout or sturgeon).

Both selection of beneficial uses and establishment of the thermal standards for those uses need to consider physical and temporal continuity among habitats. This can be more easily said than done when there are competing water uses. Each site will be different, but the principle of maintaining continuity needs to be upheld.

\subsection{WHAT TEMPERATURE TO REGULATE?}

In a spatial and temporal continuum of temperatures, and species and stocks that move about a great deal in their life cycles, what attribute of temperature should be selected to regulate? Oregon, for example, has selected a 7-day moving average of the daily temperature maxima, keyed to the thermal requirements for rearing and growth of juvenile salmonids (with special conditions for spawning and incubation). Current EPA guidance suggests a maximum weekly average as an upper limiting temperature, keyed to the growth responses of representative, and important species. Averaging, however it is done, acknowledges that organisms generally respond to cumulative temperature exposures over extended periods of time, assuming that the level is not within the lethal range (for which shorter term criteria must be applied). 
A week may not be the correct time period for averaging. Organisms respond to the cumulative history of thermal exposures in both the lethal and sublethal ranges. As noted in the discussion of physiological responses, both the lethal effects and sublethal limiting factors can be accumulated over time. Physiological repair mechanisms are also taking place. It is logical that these negative and positive responses could be modeled to establish the exact time over which damages would be expressed (as is currently done for directly lethal responses). Although the idea is appealing, the capability is not there to do it. One week may be arbitrary, but it is reasonable.

A functional temperature related directly to the designated beneficial use is the most biologically relevant temperature to measure for regulation. For example, if fall chinook salmon spawning is the critical beneficial use for a stream segment between October 15 and December 1, then the temperature to be regulated should not exceed the limits suitable for such spawning and early egg survival. There is fairly broad consensus that although adults can survive temperatures of near $72^{\circ} \mathrm{F}\left(21^{\circ} \mathrm{C}\right)$ for a week, they are able to hold before spawning without excessive mortality or disease and produce more than $50 \%$ viable eggs only at $60^{\circ} \mathrm{F}\left(15.6^{\circ} \mathrm{C}\right)$ and below. It seems reasonable that a maximum temperature of $60^{\circ} \mathrm{F}$ (any day) would be a functional temperature to regulate on chinook salmon spawning grounds. Temperature requirements for initial incubation are not greatly different, but maximum egg and early embryo survival appears to be at slightly lower temperatures, near $58^{\circ} \mathrm{F}\left(14.4^{\circ} \mathrm{C}\right)$. A reasonable temperature limit for longer term egg exposure would be a 7-day running average not exceeding $58^{\circ} \mathrm{F}\left(14.4^{\circ} \mathrm{C}\right)$. Later incubation (winter) requires cooler temperatures, with highest survival near $55^{\circ} \mathrm{F}$ $\left(12.8^{\circ} \mathrm{C}\right)$; therefore, the limit should be phased gradually into an average temperature that meets this level after the spawning period. These temperature limits would apply to the entire stream segment for the duration of time in which fall chinook salmon spawning is the designated beneficial use. Other beneficial uses (and associated thermal limits) would apply to the segment at other times (perhaps other species and life stages). Other stream segments would likely have other beneficial uses (no fall chinook spawning, but perhaps bull trout), and the temperature limits for those uses would be the most relevant. The example of fall chinook salmon does not imply any particular preference for this species as a surrogate for others; this determination must be made for each beneficial-use segment.

Much of the debate over alternative temperatures to measure and regulate revolves around the selection of surrogate temperatures for the more functional temperatures that are the primary concern in a stream segment. Regulators and technical support staff have sought to find summary descriptions of water temperature in the environment that could have wide application to species and locations. The 7-day running average in the Oregon standard is one example. A weekly average of daily maximums is another. Often, there is almost a trial-and-error approach to selecting the surrogate summary descriptions (although each has pros and cons from the standpoint of biology). Surrogates may ultimately be useful and necessary, but a biological perspective says that they should be developed on the basis of the requirements that match the beneficial uses at the particular location.

The 1973 National Academy of Sciences/National Adacemy of Engineering report on water quality criteria for EPA concentrated on four main features of temperature as 
appropriate for application to species- and location-specific standards, as illustrated in Figure 1: (1) long-term, average temperatures for maintaining adequate growth rates of key species (as an integrator of all physiological functions), for which the maximum weekly average temperature was selected as the indicator (surrogate) for a hightemperature limit; (2) short-term exposures to temperatures potentially above the longterm lethal temperature at all times of year for protecting short-term survival, for which the laboratory data on median survival times at various acclimation (ambient) and exposure temperatures plus a safety factor of $2^{\circ} \mathrm{C}$ were selected; (3) winter criteria that would allow nearly instantaneous cooling to ambient without mortality, for which laboratory data on cold shock survival data for different holding (acclimation) temperatures above ambient were used; and (4) site-specific requirements for reproduction applied whenever they were relevant, which generally imposed a nearnormal seasonal cycle of temperatures. Thermal effects of steam-electric power stations were a major concern during the writing of those criteria. At the time, they introduced a higher degree of biological and ecological site specificity to thermal effects analyses; in today's perspective, they may not be sufficiently oriented to all of the potential beneficial uses in natural environments. From a physiological and behavioral perspective, the National Academy criteria protected species and life stages occurring at a site (or expected to occur) from several levels of effects. These were: (1) lethal effects (by ensuring survivability of direct thermal exposures to high and low temperatures), (2) sublethal effects (by maintaining growth performance), (3) habitat exclusion (by maintaining temperatures generally below upper avoidance temperatures, which are slightly above optimal growth temperatures), and (4) reproductive continuity (by special reproductive limitations according to season). When sensitive stages of the inhabiting organisms were used, protection of aquatic communities seemed likely.

Adequate representation of temperature variability, especially daily cycles, in surrogate thermal limitations has been of considerable concern. Simple temperature averages over an arbitrary length of time do not fully protect organisms from transient elevations well above the average (which could potentially be lethal or otherwise severely stressing). The National Academy criteria and current EPA guidance, however, accommodate these transients by specifying a separate criterion for the duration and magnitude of short-term excursions into the potentially lethal range. This approach still seems appropriate. Regulation by averaging maximums does not fully account for the amplitude of daily cycles, which may in itself be detrimental (although the data on this subject are sparse and contradictory). The same 7-day average of daily maxima can, for example, represent many sequences of temperature exposures and average temperatures. From a biological perspective, it would seem important to evaluate temperature variability over time in a stream segment in the context of the particular beneficial uses. Different uses may have different sensitivities to variability. From this analysis one could establish limitations on variability as well as on other summary features of temperature.

This perspective piece will not resolve this question. At this point the matter still needs further discussion, analysis, and development of consensus among both regulators and biologists. Likely, there will need to be several temperature measures in a watershed tailored to the beneficial uses of specific habitats. Following selection of these measures, 
it may be fruitful to aggregate similar beneficial-use requirements statewide into a few more broadly (geographically) applicable measures. Any broadly applicable measurement approach would thus have the benefit of a solid foundation in matching the site-specific beneficial úses.

\subsection{SITE-SPECIFIC LIMITS (VARIANCES)}

It is unrealistic to expect a state water quality agency, department of fish and wildlife(which usually advises the water quality agency on beneficial uses and thermal requirements), or EPA to anticipate every thermal characteristic of the environment that would affect biota and to incorporate the scenario explicitly in the water-quality regulations. It is also unrealistic that temperature monitoring will be so all-encompassing that every situation of specific interest will be covered. Despite a large literature on thermal effects, it is highly likely that the most relevant thermal-requirements data may not be sufficient for clearly answering the questions raised for a specific situation (although in the majority of cases, the present data are adequate and persuasive). As a result, there could be overly conservative application of beneficial-use designations or the specific thermal standards (overall or at a certain time of year). There also could be instances of overly lax standards to protect a specific local use.

To cover such instances, most state regulations include sections allowing site-specific standards and variances (usually as a way of locally relaxing stringent standards). For temperature, there are sections specifically allowing thermal variances in accord with Section 316(a) of the Clean Water Act. There is also a requirement in the recent Clean Water Act amendments for Total Maximum Daily Load (TMDL) assessments for watersheds, which result in watershed-specific regulations concerning quantities of pollutants that can be discharged (although this has only recently been applied to temperature).

A provision for site-specific standards or local variances based on detailed studies at the site would be a reasonable inclusion in water temperature regulations. This provision might be applied at a more local scale than the normal beneficial-use designations of stream segments. The exact spatial scale would have to be defined. The 316(a) process for steam-electric power stations is an appropriate model, because it is specifically provided for in the Clean Water Act. In that case, the discharger is provided an opportunity to submit a "316(a) Demonstration" to the regulatory agencies for the purpose of making a site-specific case that the local thermal standards are too stringent and that proposed alternative standards should apply. Such decisions are reviewed periodically, usually every 5 years. A similar opportunity would seem appropriate, for example, for an irrigation district that discharges warm irrigation return water or for a watershed association that believes portions of its watershed do not need to maintain the general reach standard. The variance process would need EPA oversight and guidance, similar to that provided for the 316 (a) process.

Such variances may be useful in the short term before the goal of the segment-specific beneficial use can be attained, such as during times of habitat restoration. Variances could be granted for a specific time period ( 5 years is the usual length of time for 316(a) variances), with progressively more stringent alternative thermal limitations established 
in each variance period. This would ensure a gradual improvement leading to the full attainment goal for the segment. If the desired temperature standard after full restoration is implemented immediately, violations during the process of habitat restoration are assured (with many negative repercussions). Such a system would provide site-specific numerical standards for the performance-based standard discussed in Section 7.2.

It would be important for the state agency or EPA to outline the minimum amount of information that would qualify for a site-specific standard or variance. From a biological perspective, the following may be needed for the state to make an informed judgment (including EPA and other agencies when consultation is required, as for the Endangered Species Act):

1. The "site" proposed for alternative use designation or thermal limitations would have to be defined geographically. This would probably consist of a certain reach of stream between designated stream length markers (between stream miles $\mathrm{X}$ and $\mathrm{Y}$ ). The site would have to be considered in the context of a larger setting, including implications for the connectivity among upstream and downstream habitats (e.g., migration routes).

2. Key species and life stages present at the site at representative times of year (or expected to be there, if future use of the segment is the basis for the standard) and their relative abundances should be identified. The "key" species could be identified using criteria adopted by EPA for Representative and Important Species (RIS) for thermal 316(a) demonstrations. Other criteria may be appropriate for a particular site (for example, undesirable introduced species or assemblages would not be included just because of presence). Major, moderate, and occasional abundance periods should be identified. Generally available occurrence data would likely not be sufficient for a difficult decision, and site-specific occurrence and abundance data from on-site studies would have to be obtained and presented by the applicant. Species or life stages that are selected particularly as surrogates for other species should be identified and the logic explained (e.g., if bull trout are protected, temperatures will be fine for juvenile cutthroat trout, which have less stringent thermal requirements).

3. The spatial extent of affected biological resources would also need to be identified (zone of influence), as the affected biota probably would extend beyond the actual site of the proposed site-specific alternative limitation (e.g., anadromous species). Therefore, the spatial scales of both the site specificity and the ecological analyses would need to be specified.

4. The alternative thermal limitations would have to be proposed. This would include proposed locations and types of measurement and appropriate statistics (averages, etc.) as well as temperatures. The rationales for the proposal should be presented.

5. Critical temperatures for the species and life stages would be needed with predictions of the effects of the proposed alternative thermal limitations. The analysis probably would require more information than is available in current literature reviews. For example, if it is contended that the local stock of a species is more temperature tolerant than is represented in the literature, the applicant for a variance would need to provide persuasive laboratory experiments and field data to document this difference and the suitability of the proposed alternative limit for protecting the stock.

6. Detailed temperature records appropriate to the site would be needed. These records would include, at a minimum, one full year of nearly continuous records at the 
site. The degree to which the year of data represents the typical condition would need to be verified by reference to historical climate records (Was the year a particularly dry, wet, warm, or cool year based on data from nearby weather stations?). Comparisons with records for other years at surrogate sites with similar habitat characteristics may be needed, also.

7. The applicant would need to evaluate the mechanisms controlling temperature at the site and how temperatures at the site affect temperatures in other segments. This would include identification of the processes affecting temperatures and alterations in those processes through anthropogenic changes. The analysis would have to ensure that there are no significant system-wide consequences of a local decision. Depending on the complexity of the situation, thermal-hydraulic modeling may be needed.

8. If it is argued that current conditions, which are not in compliance with the thermal standard, are sufficiently protective of a desired biotic community, then a "no prior appreciable harm" evaluation (similar to its use in a 316(a) demonstration) would have to be presented. The criterion for lack of harm could be, for example, no diminishment from the desired production level of juvenile salmon, as based on resource-agency goals (assuming that these goals have some technical relationship to stream carrying capacity). Field records of production over several years would be needed to sustain this example. Production of important resident species would be another example.

9. The demonstration should integrate other closely related stressors or habitat features. The cumulative effects of all influences on biological populations at a site should be evaluated in the context of the proposed alternative thermal limitation.

10. There should be a provision for thermal and biological monitoring and assessment (and reporting to the regulatory agencies) to see if the alternative use designations or standards are working as expected. This should include both local and system components, as the effects may be manifested at a distance from the site.

Presentation and review of cases for site-specific beneficial uses, variances, or standards could administratively be made in a tiered fashion, based on the estimated biological consequences. An initial screening tier might consist of an applicant demonstrating, with state fish and wildlife agency concurrence, that salmon or resident fish production goals are currently being met and that the current situation warrants a "no prior appreciable harm" designation. There may be no point in requiring the full-scale presentation of data in such a case. Where this simple demonstration is doubtful, a second tier demonstration/evaluation for the alternative limitation could consist of a persuasive predictive analysis by the applicant based on available biological and thermal data (e.g., from data sources such as StreamNet or the state's water quality monitoring program). Where available data are insufficient for a decision, the applicant may need a third tier demonstration consisting of new laboratory and site-specific biological and physical data. Consultations between the applicant and the state (most likely including other resource agencies, as well) would be needed to help define the tier most appropriate to the site and situation. 


\subsection{STEPS IN SETTING REACH-SPECIFIC STANDARDS}

The following steps are suggested as being necessary for setting reach-specific temperature standards for the Pacific Northwest from a biological/ecological perspective. Reach-specific standards are not the only valid approach to standards-setting. However, the complexities of developing standards with any approach should be understood and debated before a commitment to proceed. This approach provides an example.

1. Establish segment-specific beneficial uses for specific times over an annual calendar.

Waters of the Pacific Northwest would be segmented into reaches with definable uses at particular times. Each segment should reflect the species and life stages that use the segment now, historically, and as intended for the future based on resource agency analyses and consultation among users of the segment. Segments would vary in length depending on the uses. Because of an emphasis on protecting anadromous salmonids, continuity of segments should be maintained to ensure that the life stages can be properly sequenced in suitable habitat (i.e., adult migration, pre-spawning holding, spawning, egg incubation, fry emergence and initial feeding, juvenile rearing, juvenile outmigration). This task would likely be coordinated by the state water quality agency and should be carried out with assistance of the state fish and wildlife department; relevant tribal fisheries resource agencies; relevant federal fish and wildlife agencies; and state, tribal, and federal agencies most involved with resource development and land use management.

\section{Use thermal-effects literature to establish the critical temperature limitations for the beneficial uses, including proper timing of the sequence of life stages.}

Physiological, behavioral, and ecological information for setting these limits have been summarized in recent reviews. Survival is important over short time frames. Maintaining acceptable development and growth rates are important over the long term. Behavioral factors, such as spawning and migration, are important over specific time ranges. Both upper and lower limits should be included. Full protection should be defined as maintenance of the populations and communities rather than protection of every individual, except under special circumstances. Additional emphasis should be placed on sequencing of temperatures for life-cycle continuity.

\section{Summarize available historical temperature data for each segment or a reliable} surrogate.

Reliable historical data are invaluable, when available, for establishing the normal annual sequence of temperatures in a stream segment, as defined by daily averages, daily maximums, and daily minimums (or reasonable approximations). These data would be used to ensure that a normal annual temperature cycle is maintained, while ensuring timely sequencing of critical temperatures for life stages. The cycle, however, does not become a numerical "ambient" for setting an allowable deviation as the standard (the critical temperatures for specific life functions would set the numerical standard). 
4. Identify unique thermal attributes of a segment, such as summer or winter thermal refuges, that require protection.

Microhabitats are particularly important for maintaining life cycle integrity in many situations. They may outweigh the dominant temperatures of the segment, as in summer thermal refuges for spring chinook salmon. The standard for the segment should protect these areas.

5. Construct a diagram of the critical temperature cycle for biota in the stream segment from the critical life-stage temperatures and smoothed by the annual temperature cycle.

Critical temperatures for multiple species in a segment are aggregated as upper and lower temperature limits for each day of the year. Each day will have allowable upper and lower bounds (e.g., cool enough to prevent loss of productivity due to high temperatures and warm enough to ensure adequate growth and development). Many stream segments may be similar in both beneficial uses and resultant critical temperature diagram.

6. Diagram the temperature limits encountered by a species over a life cycle in fresh water.

As a check of the adequacy of segment-specific thermal limits, the continuity of temperatures experienced by a species as it moves from segment to segment over its life cycle in fresh water should be diagramed or tabulated. For example, would proposed segment-specific temperature standards ensure successful completion of the freshwater life stages of fall chinook salmon as recounted in the second scenario presented?

7. From the segment-specific annual curves for temperature limits, aggregate several sets based on commonalties.

It is unlikely that all beneficial use segments will be unique. Characteristic annual cycles of limiting temperatures may be developed that apply broadly to beneficial-use categories. Of hundreds of stream segments in a state that are defined by beneficial uses, many fewer (perhaps a dozen) typical, characteristic types (and thermal standards) can be applied.

8. Specify the locations where the standards for each stream (or lake) segment apply.

Although the general intent would be for a standard to apply to the entire stream segment, this may not be the most protective or a reasonable fit to the environmental situation. The limiting thermal standards may be in isolated thermal refuges in streams rather than the segment as a whole, or in particular lake strata rather than at the surface. Yet it often would be unrealistic to expect a whole lake or a whole stream to meet conditions that are required in particular zones of naturally stratified waters. There should be consideration of whether maintaining standards in the specific location will be protective of the segment as a whole (e.g., will attainment of a cold temperature standard in a thermal refuge excuse raising temperatures to lethal levels in other stream reaches?). More than one set of standards may be needed for a single segment. The issues discussed earlier in this paper would need to be considered. 
9. Establish the basis for allowing exceedances of temperature standards, based on historical temperature data (analogous to the 7Q10 provisions of other water quality standards) and the vulnerability of biological resources.

Exceedances of water temperature standards may occur for brief periods, and it is important to specify the conditions under which such exceedances are permissible. There is precedent in the use of historical hydrological streamflow data for other water pollutants. An analog for temperature is desirable. However, this approach must be tempered by understanding of the vulnerabilities of local populations and communities and the effects of current conditions in causing undesirable biological effects.

\section{Include provisions for mixing zones.}

Mixing zones are important for industrial effluents, natural stream confluences, and the boundaries of stream segments with different thermal standards. They should be recognized in the regulations.

\section{Establish a process for allowing site-specific temperature limitations based on demonstrations of need.}

In a process analogous to Section 316(a) of the Clean Water Act, a mechanism should be put in place for demonstration of the adequacy of alternative thermal limitations for protecting beneficial uses. This allows for detailed data collection and presentation of evidence for specific locations. It specifically allows for exceptions (variances) when more broadly based standards are deemed overly protective or otherwise inappropriate. A criterion for minimum acceptable data should be established.

\section{Consider performance-based standards for selected situations as a way to work} progressively toward meeting biological requirements.

Where it is unrealistic ecologically to expect rapid attainment of the desired thermal standard because of massive habitat alteration, it is still biologically valuable to move toward attainment of the desired standard to the degree possible. From the biological perspective, it would be desirable to consider the use of performance-based interim standards (or compliance stages) that eventually attain the temperature goal for the stream segment. Such interim standards would provide short-term protection measures. The interim standards would allow for realistic time frames for changes in land-use and watermanagement practices and designate a trajectory for recovery. Performance-based standards are discussed under Issues in Compliance. This administrative decision would need to be coordinated with planning by land and water management agencies, watershed management associations, and other relevant groups.

\subsection{RESEARCH/ANALYSIS NEEDS FOR REACH-SPECIFIC STANDARDS}

A number of types of research are necessary in order to undertake setting of water temperature standards using any particular approach. The list that follows continues the example of establishing standards for specific reaches based on identified beneficial uses. More needs will undoubtedly become apparent if this approach is carried out. Similar lists would need to be compiled for other standards-setting approaches. 
1. Identification of beneficial uses for stream segments. Not all streams and other waters have been inventoried sufficiently to record where beneficial uses occur. Mapping using GIS technology is practical.

2. Identification of thermal refuges or other special temperature habitats. Although the principle of thermal refuges has been well proven for many species, the actual locations of refuges for salmonids in the Pacific Northwest's streams remains uncertain.

3. Temperature monitoring. Long-term temperature records must be maintained (e.g., stations operated by the U.S. Geological Survey or other water quality networks), and new stations established in beneficial-use segments. New technology for small, in situ temperature recorders makes this task tractable.

4. Temperature analyses. Available historical temperature records should be analyzed for use in establishing normal conditions for beneficial-use segments. This would include records actually within segments and selection of appropriate surrogate records where none exist or recent segment temperatures are known to be abnormal because of habitat degradation.

5. Monitoring of temperatures actually experienced by fish or other aquatic life. Radiotelemetry transmitters and implantable miniature temperature recorders allow detailed information to be gathered about actual temperatures experienced by fish. Although temperature telemetry has a decades-long and fruitful history, little use has been made of implantable temperature recorders. The number of studies with salmonids, such as work by $\mathrm{C}$. Berman with spring chinook salmon, have revealed important information about thermal habitation. More information is needed (e.g., what temperatures are experienced by migrating salmon, both adults and juveniles, when they encounter thermally heterogeneous habitats).

6. Establish a uniform temperature analog to the hydrological $7 Q 10$. This is needed as a basis for establishing allowable exceedances consistent with current $7 \mathrm{Q} 10$ practice for water quality standards.

7. Seek commonalties among beneficial uses and critical temperature patterns that can form the basis for a set of broadly applicable standards (beneficial-use "guilds"). For example, all spring chinook salmon spawning areas may be essentially similar wherever they are located. A common standard for an annual temperature cycle for this beneficial use may be possible.

8. Establish a process for allowing site-specific temperature limitations based on demonstrations of need. The technical aspect of this need is establishment of guidelines for making a sufficient case for proposing alternative thermal limitations (e.g., kinds, amount, and quality of information). EPA guidelines for 316(a) demonstrations for thermal power stations may be helpful. 


\section{ISSUES IN COMPLIANCE}

The setting of standards and methods of compliance need to go hand in hand, but it is useful to separate them as separate thought processes. No standard makes sense if there is no way to measure compliance, just as no strict enforcement make sense if there is no firm endpoint to enforce.

\subsection{WHERE TO MEASURE TEMPERATURES FOR COMPLIANCE}

Inherent in the concept of thermal regulation by designated beneficial uses is the necessity to monitor temperatures for compliance at locations and times relevant to the use. If salmonid spawning and incubation are the designated uses, then the most relevant temperatures would be at spawning sites and applicable during the period of spawning through fry emergence. If adult migration is the only beneficial use in a certain time period, then temperatures of the main streamflow may be most relevant. An index of the bulk streamflow temperature will not be adequate if the critical habitat is, for example, a summer thermal refuge with a temperature considerably below that of the main flow. Cool thermal refuges for over-summering adults may be the most germane habitat features for monitoring in some stream segments in summer.

It seems appropriate for EPA to require designation of a monitoring location for each stream segment and time period given a specific beneficial use. For example, a segment designated as refuge for over-summering adults would be regulated between June and September on the basis of maximum temperatures monitored in one or more representative refuges. The monitoring itself would not answer questions about adequacy of numbers of refuges, their size or frequency of use to support a fish population. But typical refuges could be selected for monitoring after these factors have been analyzed. The monitoring location would be established by the state water quality agency in conjunction with the fish and wildlife department, as is the usual practice for establishing beneficial uses.

In parallel with the distinction made between functional and surrogate temperature measurements, there may be both functional and surrogate locations. The functional location would be at the exact site of a beneficial use. However, some surrogate location may adequately represent the functional location. For example, the most functional location for egg incubation temperature is in the salmon redd or nest itself. This measurement site may be impractical, and a surrogate measurement site might be selected at a convenient highway bridge piling in the main stream channel. Bridge sites are commonly used as temperature monitoring stations for compliance. The bridge location would be far easier to handle logistically. Once the relationships between temperatures (including variability) at the actual spawning sites and the bridge piling location are known sufficiently, the bridge piling may constitute an excellent surrogate monitoring site.

Lakes provide a special case for temperature monitoring to match biological requirements. The stratified thermal structure of lakes establishes thermal habitats that are not represented by typical near-surface monitoring stations. Habitats needed for 
salmonids often lie in mid-depth or below in summer. Temperatures at those depths (and the accompanying dissolved oxygen levels) are critical and there is where temperature monitoring should take place.

\subsection{PERFORMANCE-BASED STANDARDS}

The desired thermal standard for a segment may not be attainable in the short term because stream temperatures experienced by salmonids are so dependent on other habitat features in a watershed. Clear habitat limitations often take a long time to rectify. From a biological perspective, it seems logical, still, to seek progressive improvement toward eventually attaining the desired standard. The habitat-related processes affecting temperatures are known, as described in Section 3.1, and remedial measures can be developed and implemented. With good environmental planning and an active implementation schedule, temperature conditions matching the attainment standard can probably be achieved over some period of time. The "standard" to be met at any one time could be the performance record of actions on the schedule of improvement toward reaching the goal. A series of interim temperature standards may be a suitable way of ensuring habitat improvements. A local venue for this development and implementation is often best, with encouragement, guidance, and assistance from the state and federal regulatory bodies and resource management agencies.

Use of performance-based standards or interim standards is clearly an administrative decision, but it has a sound biological rationale in progressive environmental improvement. See Sections $6.11,6.12$, and 6.13 on site-specific standards and variances for further discussion of justification and mechanisms to accomplish attainment of desired standards.

In this context, a performance-based approach still requires a goal, most likely in the form of a temperature standard. Thus, the performance basis for enforcement of a standard does not take us away from the need for the final thermal standard as a goal.

\subsection{ALLOWABLE EXCEEDANCES}

Generally, water quality standards are established under the specific assumption that they pertain within the "typical" flow conditions of a stream. They generally do not apply when flows fall below the historical once-in-10-year, 7-day low flow (7Q10), based on long-term hydrological records. Most state standards for water pollutants include a 7Q10 provision. For temperature, we must question whether this is a reasonable way to account for natural temporal variability, when that variability may be caused by many factors in addition to flow. Unlike the addition of a chemical effluent for which concentration in a waterbody is largely a function of dilution flow, temperatures change naturally as a feature of habitat modification, climate, local weather, etc., as discussed in Section 3.1. Temperature variations may bear little direct relationship to flows, although high temperatures in Pacific Northwest streams are often exacerbated by low flows.

Assuming the general 7Q10 concept of allowing exceedances based on atypical (less frequent) conditions is supported, it seems logical to decouple allowable exceedances in temperature standards from flows. Temperature itself may need an analog to $7 \mathrm{Q} 10$ based 
on long-term historical temperature records, such as a 7T10 (the once-in-10-year, 7-day sustained high temperature). In other words, there could be an acceptable (albeit infrequent) exceedance frequency based on temperature alone. Assuming that we also are concerned about low temperatures, there could be a $7 \mathrm{~T} 10$ for low temperatures, as well. To require otherwise would fly in the face of a major assumption about historical frequencies that are fundamental to compliance with other water quality standards.

There are several difficulties for establishing a $7 \mathrm{~T} 10$, or its reasonable analog perhaps with a different statistical periodicity. Historical temperature records, especially recent ones, include those very anthropogenic changes from which we seek to recover. The exceedances often occur in groups of years, rather than the ideal once-in-10-year recurrence interval (there are often strings of exceptionally warm years). This could cause major population losses for anadromous salmonids that must maintain a reasonably unbroken chain of reproductive years over a 3-5-year cycle. Because the myriad of human temperature alterations occur on top of natural variability, the regulatory activity to control temperature may be more urgent during the statistically infrequent warm (or cold) years than during the statistically more common situations. All-in-all, allowable exceedances for temperature need to be thought through carefully. In doing so, we may question the validity of all 7Q10 assumptions in water quality compliance.

\subsection{MIXING ZONES}

The concept of a mixing zone is well established in the history of water quality. It assumes that an effluent from a discharger requires a certain zone for mixing with the general water body. Traditionally, the mixing zone has been considered a zone in which the receiving-water standards do not apply. Specific constraints are usually placed on the size and shape of mixing zones to ensure that they do not occupy the whole crosssectional volume (thus allowing a zone of passage for mobile organisms in water that does meet the standard and restricting the size of any local adverse impact). Mixing-zone regulations for temperature are routinely imposed on operators of steam electric power stations for the discharge of heated condenser cooling water.

An extension of the mixing-zone concept may be needed for the mouths of tributaries that enter a stream segment when the tributary temperature does not meet the standard for the receiving stream segment. This is especially germane if segment-specific standards are adopted based on segment-specific beneficial uses. Because it is not subject to manipulation and control, the zone downstream of the tributary mouth may need some specific exemption from the standard of the receiving segment. Two general cases can be envisaged, one in which the tributary meets its segment-specific temperature standard (which is different than the receiving water) and another in which the tributary does not meet its standard. In the first case, a natural mixing zone may be specifically recognized. In the second case, it seems reasonable to consider the zone of mixing as an extension of the zone of noncompliance for the tributary (subject to remedial measures to meet standards in the tributary).

A similar situation would occur when a single stream is segmented into reaches with different segment-specific standards. There would have to be a transition between the two different standards. The upper segment would need a "mixing zone" as it enters the 
downstream segment. This zone would have to be small relative to the lower segment or. it would defeat the purpose of segment-specific standards.

As a general rule, salmonids are better protected if abrupt thermal gradients are avoided. The critical time documented in the literature appears to be during upstream migration of adults in summer, although there may be other instances that need exploration. Adult salmonids often will not enter tributary streams when the temperature is high $\left(>70^{\circ} \mathrm{C}\right.$ ), or the differential too great (mostly anecdotal evidence, usually when the tributary is at the high end of the tolerable temperature range). As segment-specific temperature standards are considered for both tributaries and receiving segments, the details of possible thermal gradients in the zone of mixing need to be considered carefully. Creation of special cases for zones of mixing should not be used to justify broader exemptions. 


\section{DEVELOPMENT OF ALTERNATIVE TEMPERATURE-REGULATING MECHANISMS}

The setting and enforcement of in-stream temperature standards is only one way that water temperatures may be improved for aquatic life by regulatory actions. There are other avenues, some that may be appropriate under the Clean Water Act.

\subsection{REGULATION OF LAND AND WATER MANAGEMENT PRACTICES AFFECTING TEMPERATURE}

An overwhelming impression comes from the discussion of stream temperatures in the Northwest at the beginning of this perspective piece. That is a realization that land use practices and the development of watersheds for hydropower, irrigation, and timber production are the major factors in altering stream temperatures. These are features of regional development that have affected temperatures over large spatial scales. Ultimately, no set of stream or lake temperature standards matched to the needs of coldwater biota will be met unless such land-use practices change. The logical question then is whether stream temperatures themselves should be regulated or whether there should be heightened regulatory efforts to rectify habitat-damaging practices. A standard might be developed, for example, for the percentage of streambank that can be denuded of riparian vegetation.

It seems most reasonable that the two efforts-temperature standards and land-use regulation-should go hand in hand. Temperature standards provide the goal, based on the needs of desirable salmonids and other cold-water biota (or other biota at certain locations, depending on the beneficial uses selected). Habitat protection is essential and restoration is the most likely remedial measure when standards are exceeded. Yet it is unclear how much restoration is needed for a particular stream segment. A program of habitat restoration aimed at (among other things) returning temperatures to acceptable levels could have a measure of performance based on temperature monitoring.

\subsection{REGULATION OF NON-POINT-SOURCE INDUSTRIES FOR TEMPERATURE CHANGES}

Land-use changes and water management practices affecting stream temperatures are as clearly tied to particular industries as are pipeline effluent discharges. Thus, there is logic to regulation of individual companies' activities based on technology standards for their industries. Designation of industry-specific Best Available Technologies for reduction of point-source pollution was a notable innovation of the 1972 Clean Water Act. It can provide a mechanism for handling industry-specific non-point sources, as well. Management programs would be tied to industrial sectors, which would be tied, in turn, to temperature standards.

Several industry-specific practices that affect stream temperatures have been discussed earlier. They include the following. 


\section{Timber Industry}

a. clearcutting of forest tracts, with soil warming and warm runoff during warmseason precipitation;

b. logging of riparian zones, with opening of the canopy and increased solar warming of streams;

Agriculture

a. water diversions from cold-water streams, reducing cold-water flows;

b. summer flood irrigation, with warming of groundwater reaching streams;

c. warm irrigation return flows and runoff, with direct warming of streams;

d. stripping of riparian zones for crop production to the water's edge, with opening of the canopy and increased solar warming of streams;

e. cattle grazing to the water's edge, with trampling of riparian vegetation and modification of stream channels to allow wider, shallower streams with more solar heating.

Hydropower

a. abnormally cold or warm dam discharges, with alteration of seasonal temperature cycles;

b. daily power peaking cycles, which periodically floods and dries river channels stranding fish and exposing them to solar heating in residual pools;

c. reservoirs with broad, shallow expanses of water, with solar heating.

The intent of regulatory action would be for some historical and current technology practices to cease and be replaced by other activities that are more appropriate for protecting stream temperatures and aquatic resources. This intent is analogous to Clean Water Act intent for point sources. The EPA could develop standard approaches for industrial categories (e.g., timber, agriculture, hydropower) just as it did for industrial categories of point sources (e.g., steam-electric power Industry, textile Industry, etc.). Alternative activities (such as providing proper buffer strips of unlogged timber along streams) would be subject of negotiations between the regulatory agency and the company, as it is for point-source Best Available Technology (some practices, for example riparian buffers, are already part of state "standards" under auspices of other programs, such as Best Forest Practices).

This approach would be novel for regulation of temperature from non-point sources, but it fits the general context of the Clean Water Act. Specific legislation might be required for its implementation.

\subsection{FLEXIBLE REGULATIONS/FREE-MARKET COMPLIANCE}

The story of U.S. acid rain control offers a case study in the successful regulation of a wide-ranging pollutant. In the 1970 s, sulfuric acid seemed to be consuming the environment. But today, after 20 years of control, acid rain is on the mend. Perhaps most surprisingly, it has been a bargain: Cost estimates are about $\$ 1$ billion per year compared with earlier forecasts of $\$ 10$ billion or more. Economists are still trying to understand why control is proving to be so cheap, but they agree that at least partial credit must go to unusually flexible regulations and their use in the free market. In the 1990 Clean Air Act Amendments, Congress told power plant operators how much to cut emissions but not 
how to do it and established an emissions trading system in which power plants could buy and sell rights to pollute. Innovation replaced rote site-specific compliance. It was a radically different way to carry out environmental regulation, and the lessons learned are impressive. A flexible system of emissions trading also serves as the crux of U.S. proposals for controlling climate change from greenhouse warming. It is inescapable that we examine this prototype for its potential applicability for temperature control in Pacific Northwest waters.

The exact steps in acid rain control do not, of course, fit the temperature situation. Sulfur discharges were largely point sources, and there were definable power stations with emissions. Historical regulatory actions went the usual route of "command and control" with specific control technologies (scrubbers on stacks) specified. As these standard steps were taken and additional control was necessary, the 1990 amendments established phased emissions reductions based on the heat output of each fossil-fueled power station. But the crucial step seems to have been the authorization of emission allowances, "right-to-pollute" coupons that could be bought, sold, or saved. Such trading within a cap on total releases meant emitters were strictly accountable for the end result but had flexibility in how they got there.

So, how could this experience apply to temperature in Pacific Northwest waters? Because the key is to capture the innovative talents of those regulated, it is not appropriate to fully specify such a system. But an outline needs to be apparent if such a system is to be adopted. These are preliminary thoughts in need of discussion by all parties.

We have seen that water temperature is a product of a landscape that is much altered from the pristine condition that fostered successful salmonid fishery resources. This landscape is not unlike the airscape and landscape that fashions the sulfur emissions of power stations into the acid-caused destruction of water resources. Instead of a clear Industry leader in emissions, however, we have a multitude of temperature-altering activities-hydropower dams, storage dams, irrigation, pasturing, logging, etc. On the other hand, "water-scapes" are more distinct than "air-scapes" in having clear watershed boundaries in which the multiple sources of temperature change can be identified.

The factors and processes affecting stream temperatures can be separated within a watershed. Each watershed will have its own "cast of characters" that cause water temperature to deviate from what would produce sustainable and harvestable populations of salmonid fishes. Some in this cast will tend to warm waters, others to cool them. The relationships may change from season to season. Actions of one player may cancel the actions of another, such as warming by deforestation in one reach that may be nullified by cooling through additional shading in another reach. In essence, a watershed will have its own characteristic Total Maximum Daily Load (TMDL) of heat, which can be added to or subtracted from by water- and land-management practices that alter the heat flux factors discussed earlier. A scheme of non-point-source "trading" within the TMDL seems feasible as an analog to sulfur emissions trading.

Temperature standards can be established and temperatures can be measured at discrete places in a watershed, which would serve as index points for overall compliance. The points would be chosen according to the geographical and developmental characteristics of the watershed and its expected uses by salmonids, but not to verify that 
each habitat segment in the watershed is in compliance with physiological needs of salmonids. Undoubtedly, the standard at each index site would vary in a seasonal cycle. Selection of these index points for standards and monitoring would need considerable input from water quality agencies, fisheries managers, land owners, and watershed users.

The analog of sulfur emissions coupons and trading could be heat-based debits and credits within a watershed upstream of the agreed-upon monitoring station. Thermal modeling could establish background (undeveloped) levels of heat balance for stream reaches and the current heat balance under present development. Further development of current models for stream temperatures, such as those used by S. W. Hostetler in 1991 for the Steamboat Creek basin, Oregon, would undoubtedly be needed but would be stimulated by the free-market process (just as improvement in air quality models was stimulated). The TMDL for heat could thus be established. Landowners could be assessed levies (paper fines) based on their excess heat input. A clear-cut reach of streambank in a zone of timber management, for example, may have a present excess heat input of a certain number of heat units per summer and incur a certain levy. An irrigated agriculture return flow would have its own characteristic excess heat input and levy. In contrast, a revegetated riparian zone could have a net reduction in heat units added (and incur a credit). There would be a watershed accounting of debits and credits. A logging operation with adequate streamside buffer forest would add less heat to the stream (and incur fewer heat debits, thus showing a quantitative benefit to operations based on a reduced levy). An allowance for any unavoidable additional heat input might be obtained from a downstream land-water user for example, by buying heat credits from the downstream riparian owner who agrees to revegetate his streambank as it passes through pastureland. Depending on the needs of the salmonid populations, heat credits might be accrued (and sold) by establishing thermal refuges in areas currently devoid of such habitat features (e.g., by directing cool groundwater to sloughs and side channels where fish can congregate). Irrigators that agree, for example, to flood irrigated pastures in winter to recharge floodplain groundwater with cold winter water could accrue saleable credits for the summer months when the floodplain under their pastures drains cool groundwater into steams.

The accounting for thermal credits and debits would seem to be most effective if done by local watershed occupants organized in watershed councils and overseen by the state water quality and fisheries agencies (under overall guidance from EPA). The watershed council would be accountable for maintaining the temperature standard at one or more index monitoring points. Noncompliance could presumably be penalized in standard fashions through the watershed councils to the most offending parties or the groups as a whole. It seems reasonable to believe that a common overall scheme could be applied to tributary watersheds of different sizes and developmental complexity. It should also work for the mainstem. Each watershed would clearly require individual attention for all stages of implementation.

A beneficial side effect of heat-based debits and credits should be to help prioritize regional (watershed) actions quantitatively by actual effects on the system. It is highly likely that the market forces for heat debits and credits in a watershed would tend to stimulate mitigative actions where they would do the most good. 
The point of this brief discussion is not to be prescriptive but to initiate a process of thinking. It is based loosely on the concept of emissions credits, debits, and trading in acid rain control. Although the analogy is not perfect, it deserves serious attention as a means of stimulating actions that reduce unnatural temperature alterations and mitigate against those temperature-altering activities already in place. Information and analytical tools now not available could be augmented dramatically if there is an economic incentive on the part of landowners to further develop them. The concept allows for (and encourages) a trading of debits and credits among entities that alter temperature, so that the end result for a watershed unit is a thermal habitat suitable for salmonids.

\subsection{FISHERIES MANAGEMENT TOOLS}

The interactions of fish populations and temperature conditions (adverse or favorable) can be influenced directly by fishery management decisions. Although relevant to both setting of standards and obtaining compliance, the fish management options may be considered as "alternative temperature regulating mechanisms" by virtue of the beneficial uses they establish. The fish management community has many tools other than water quality standards that it can apply to protect fish populations. Some of these tools can be used to great advantage both alone and in conjunction with thermal standards. When revisions of temperature standards and their enforcement are discussed in state water quality agencies, it seems wise to include participation by fisheries managers. High synergism can result, for the benefit of the resources we seek to protect.

For example, the importance of cool thermal refuges to oversummering salmonids has been discussed previously. Refuges provide necessary cold temperatures when the remainder of the habitat is too warm for survival. Although physiologically advantageous, refuges can be disastrous for a fish population when coupled with intense fishing. Anglers soon recognize a refuge, not for its ecological function, but for the abundance of fish, often ones that are hungry (and catchable). Overfishing is a common result.

Fishery management agencies in other regions of the United States recognize that protection of thermal refuges is a high fish management priority as well as a water quality priority. The management agencies have adopted a two-pronged approach: (1) identification and protection of refuges from development (development that ranges from proposed submergence in reservoirs to overpumping of groundwater needed for cool springs), and (2) restriction of fishing at refuge locations during time periods when fish are concentrated in the refuges (known from site-specific studies and general recognition of the ambient temperatures that force fish into refuges). The water quality agency does not limit temperatures of the entire water body to a standard based on the thermal refuge temperatures. Rather, the protection of the refuge is ensured by fishery management actions.

A corollary to the protection of thermal refuges, and a potential drawback if used in the extreme, is the acceptance of a "degraded condition" for the remainder of the habitat. It may be assumed (incorrectly) that all is well for the species when only a few selected locations (refuges) are protected. To this objection one can say only that knowledge of local situations is essential. If both temperature standards and fish management are 
undertaken in the context of the locality and the local fish stocks, then questions of the sizes of refuges, connectivity among refuges, seasonal duration of isolation in refuges, and related matters can be taken into account as local fish management actions are set. The presence and use of thermal refuges is perhaps one of the strongest arguments for reach-specific standards (and associated fish management). 


\section{ACTIONS TO CONTROL WATER TEMPERATURES}

Human modifications of the landscape have had more effect on water temperatures in salmonid streams and rivers than point discharges of thermal effluents. Whereas the primary concern over high temperatures in the 1960s and 1970s was over thermal (heated) discharges from condenser cooling of new steam-electric power stations proposed for the Northwest, either nuclear or fossil-fueled, the recent concern has shifted to the more pervasive warming by a broad spectrum of land-use changes. Power stations were subjected to stiff environmental review [such as under the National Environmental Policy Act, NEPA], and generally not built, in part because of the projected heating of Northwest waters. Landscape changes, including construction of dams and reservoirs, diversion of water for irrigation, and removal of riparian (streamside) vegetation, have been less easily avoided or remedied. Nonetheless, actions are possible and desirable to return the Northwest's waters to their traditional cool condition suitable for salmonids. A flexible, free-market-trading system of thermal debits and credits might stimulate remedial actions.

Some options are discussed here. Many of them were raised and discussed at a temperature workshop sponsored by U.S. EPA in Portland, in November 1997. These actions should be viewed as possible means for attaining the goals of temperature standards, not as substitutes for establishing and enforcing standards.

\subsection{SELECTIVE DEPTH WITHDRAWALS FROM DAMS}

Temperatures of water discharged from reservoirs at dams often can be controlled by selecting the depth from which water is withdrawn. Warm-season stratification (warmer water at the top) creates a suite of possible release temperatures, depending on the size and mixing characteristics of the reservoir and prior water releases (which can deplete water of desired temperatures). Engineering devices for selective withdrawal are available and have been added to some Northwest dams (e.g., Libby Dam). Selective withdrawal can recreate more normal seasonal temperatures in dam tailwaters, within limits of the stratification characteristics and volumes of the reservoir. Such devices are costly to install and take long construction times, especially to add (or "retrofit") to an existing dam, and are useful only if reservoir releases are managed continually after installation. Considering the large magnitude of thermal effects below large storage dams, however, selective withdrawal is often seen as an important measure.

\subsection{COLD-WATER DISCHARGES FROM DAMS IN SUMMER}

The pervasive overheating of rivers by shallow (sun-exposed) reservoirs can be ameliorated somewhat by discharges of cold water from upstream storage reservoirs in summer. Water from deep in reservoirs tends to be cold in summer, due to stratification and storage of cold winter water. This water can be released (and often is) in summer to the downstream river-reservoir system. The U.S. Army Corps of Engineers has conducted experimental cooling of the lower Snake River since 1991, using cold discharges from Dworshak Reservoir on the tributary Clearwater River. Cooling has 
been detected through all lower Snake River reservoirs to Ice Harbor Dam, and the amount of cooling is believed to be beneficial to upstream-migrating fall chinook salmon.

\subsection{REPLANT RIPARIAN VEGETATION}

Tributary streams and the shallow shorelines of mainstems once were shaded by streamside (riparian) vegetation, and this vegetation can be restored. An assortment of native willows, cottonwoods, and other species of trees and bushes provided nearly complete canopies over small streams and extended far out over larger streams. In forested areas, large trees extended to and over the water. The rootmasses of such vegetation, especially the large trees, provided stabilization for streambank soil and caused water flows to cut deep pools and undercut streambanks. Solar radiation that might have reached the stream surface and warmed the water was intercepted by leaves, branches, roots, and overhanging soil. This riparian landscape can be recreated by fencing of cattle from streamsides (to avoid trampling and feeding on vegetation), replanting with native vegetation, or creating (and enforcing) buffer zones for logging. Similarly, shading should be provided for artificial systems (e.g., raceways, ponds, fish ladders).

\subsection{REDUCE OVERBANK EXTENSIONS OF RESERVOIRS}

Reservoirs tend to increase the heating of river water by exposing a larger surface area to solar radiation than occurred prior to impoundment. Much of this increase in surface area occurs in what is known as the "overbank" zones, places where the impounded water extends over the old riverbank and onto the flat floodplain. Overbank areas are usually shallow and broad solar collectors. The water heated in overbank areas generally rejoins the main river and contributes its heat to the mixed channel flow. The Burbank Slough area of the mainstem Columbia River (McNary Reservoir) downstream of the Snake River confluence is an example. Overbank zones can be enticing habitats, with the exception of high temperatures, for juvenile fall chinook salmon. Reservoirs can be designed to minimize overbank coverage, elevations can be lowered in summer to seasonally reduce overbank zones, or the overbank zones can be isolated from the main river flow through diking (in essence, creating standing lakes that will develop warmwater ecosystems in isolation from the main river-reservoir system). Juvenile salmon should be excluded from these habitats in midsummer.

\subsection{CREATE/PROTECT THERMAL REFUGES}

High spatial variability of temperature was probably common in the undeveloped basin and can be protected where it still occurs or be reestablished. Springs, seeps, deep holes, shaded zones, and the like probably offered spatially discrete refuges of cooler water spaced between warmer zones. Cold-water fish generally use such refuges for weathering the warmest seasons. The annual productivity of some waters can be controlled by the seasonal availability of such refuges. Once identified, such refuges 
should be protected. Opportunities may occur to reestablish cool holding areas or refuges.

\subsection{FLOW AUGMENTATION}

Increasing flow rates of streams (e.g., from upstream storage reservoirs) may serve to cool (or reduce warming) of streams and rivers, although this often-accepted belief has limits and may not be effective in all situations. Considering the general shortage of water supplies in much of the Northwest, this action should not be taken without careful consideration of the actual causes of warming in the affected reach and the effects (both local and regional) of augmenting flows.

\subsection{REDUCE AGRICULTURAL RUNOFF}

Return flows from agriculture are often warm (as well as containing other materials detrimental to aquatic life, such as pesticides and silt) and their control can aid in maintaining cool stream temperatures. Measures ranging from better use of water at the field to engineering of holding basins at the discharge end can be used effectively.

\subsection{PHASE OUT FLOOD IRRIGATION}

Flood irrigation, which may use warm water, exposes water to solar heating, adds large volumes of warm water to the subsurface through infiltration, and often results in high runoff of warm water to streams, can be replaced with sprinkler or drip irrigation. Several thermally damaging effects of agriculture on salmonids can be reduced or eliminated by fundamental changes in agricultural practices that are beneficial to the agricultural interests as well (e. g., less water use). Although such changes in irrigation practices are technically feasible and becoming more prevalent, old-style practices persist in a high percentage of agricultural lands of the Northwest.

\subsection{WINTER GROUNDWATER RECHARGE}

Irrigation water applied to agricultural lands in winter can recharge aquifers with cold water that often will reach streams through the subsurface in summer and benefit salmonids. Summer irrigation, especially if done in excess, tends to add warm water, both charging the subsurface with warm water and heating the gravel substrate. Groundwater seeps and springs entering a nearby stream are thus unnaturally warm. Irrigation usually ceases in autumn, although water sources are generally both cold and more available in winter. Winter recharge would cool the substrate and build a volume of cool subsurface water that would seep to the stream in the warm season. Winter recharge could be extended into spring in some areas by storing water in ice (ice mounds created by winter spraying, such as is done by snow machines on ski slopes). Winter aquifer recharge, usually through shallow basins to which river water is diverted in winter, is a common feature of water management in the Central Valley of California. 


\subsection{REESTABLISH SPRING FLOOD PEAKS FOR GROUNDWATER RECHARGE}

Spring flood peaks that historically pushed cold water laterally into floodplain gravels and recharged subsurface aquifers for summer return flows as cool seeps and springs could be reestablished through flow management.

\subsection{BREACH LEVEES AND ALLOW FLOODPLAIN FLOODING}

Levees currently used to prevent seasonal flooding of floodplains, usually in winter or spring, could be breached to aid groundwater recharge and subsequent infiltration of cold water to streams. This would be feasible only where the levees are "protecting" agricultural lands. Floodplain management would be necessary, including relocation of some dwellings that would be put at risk.

\subsection{REDUCE FISH EXPOSURE TIMES IN DAM FOREBAYS}

The length of time juvenile and adult salmon migrants spend in warm dam forebays could be reduced by use of attraction flows or other fish guidance measures. The temperatures may not change, but the duration of exposure to warm temperatures (important for causing damage) would be reduced. Although most mainstem reservoirs are fairly well mixed, zones of the immediate forebays (just upstream of each dam) are often $2-3^{\circ} \mathrm{C}$ warmer than the main river flow in summer. Also, there is a strong tendency for migration to be delayed in these zones by several hours to days, based on radiotelemetry studies of both juveniles and adults. Adult migration delay is often accompanied by "fallback," the passage of the presumably disoriented fish back downstream through spillways or turbines resulting in damage during passage and the necessity to reclimb fishways. Artificial attraction flows can guide fish through forebays to dam bypasses (juveniles) or upstream from fishway exits (adults). 


\section{CONCLUDING THOUGHTS}

The temperature variations in space and time that characterize the natural environment (and the human-modified one, as well) and the relationships of these variations to the full use of historical (and potentially recoverable) habitats by cold-water fish do not make setting and enforcement of temperature standards an easy task. Complexity begets complexity until just about any standards-setting and compliance scheme soon becomes intractable.

The current approach to thermal criteria, although now more than 25 years old, has the benefit of simplicity and tight connection to the physiological requirements of the organisms we want to protect. Annual and monthly caps are placed on temperatures so that a seasonal cycle is preserved. These caps reflect conditions in which the sensitive species can both survive and grow at nearly maximal rates. Seasonality of the standards preserves normal reproductive cycles, which often occur in periods of increasing or declining temperatures. Short-term excursions are allowed based on known survival capabilities plus a protective safety factor. Within this overall framework, each state sets its own standards based on the biota present (or desired) and their physiological thermal requirements. Even this scheme has yet to be fully adopted and enforced.

Designation of segment-specific standards makes sense as a refinement of the current approach. In environments as diverse as those in the Pacific Northwest, a single statewide standard, or even a few broad ones, would not cover the range of habitat variability. Evaluation of each stream for segments with differing uses (whether current or past that we desire to recover) seems appropriate for matching uses to organism temperature requirements and regulatory standards. Such a resource inventory and classification seems valuable whether thermal standards are the objective or not. The effects of any number of environmental alterations (from housing and road development to logging and industrialization) should be evaluated with an understanding of the beneficial uses of the affected stream reaches. Thermal standards could logically tier on these broader resource inventories and water resource goal-setting.

The emerging recognition that cool thermal refuges play a large part in sustaining many cold-water fish populations provides both an asset and a liability for standardssetting. We are unsure whether these features reflect historical significance or a symptom of the current damaged landscape. To what degree do we allow the presence of a few physiologically suitable refuges to permit the remainder of the stream to be degraded? How do we protect needed refuges within a standards framework? Do we have stream segments so small that they encompass just one refuge? Probably we can't protect refuges under water temperature standards but must do so anyway using other mechanisms.

The importance of subsurface water in maintaining suitable stream/river temperatures in the environment has been raised in our consciousness only recently. The fluxes of water into and out of these underground reservoirs, on daily and seasonal cycles, both sustain the cool microhabitats used by salmonids and cool the main channel flow. How we alter the subsurface flow in floodplains through agriculture and damming is now recognized as having effects on habitat suitability far greater than all the thermal effluents 
ever contemplated for the region. Ways to fix these alterations are emerging and wait testing and implementation.

In many ways, the potential fixes for thermal problems are getting ahead of our ability to easily regulate temperatures. We know we should leave forested streamside buffers, revegetate riparian areas denuded by grazing, reestablish side channels and seeps for groundwater, foster deep pools in streams now clogged with erosion-derived gravel and silt, and so forth. What is lacking is a coherent incentive to do these worthwhile things.

Simple, stringent standards applied at index locations based on general beneficial uses, followed by flexibility in how the standards are met, may be the best incentive. The focus would be shifted from complexity of a standard (and complexity in monitoring and compliance) to the range of alternatives for making a difference in stream temperatures. Let the complexity of the environment be reflected in the range of opportunities for improving thermal habitat, not in the complexity of temperature regulation. Although specific recommendations are not the role of this report, the success for acid rain control of a firm emissions-reduction goal and flexibility in meeting that goal bear some serious further consideration in water temperature regulation. Heat debits, credits, and trading within an appropriately sized watershed could let market forces find the most bang for the buck in getting temperatures to levels and at times and places that encourage fish to thrive. 


\section{READING LIST}

\section{Section 1}

Benke, A. C. 1990. A perspective on America's vanishing streams. Journal of the North American Benthological Society 9:77-88.

Beschta, R. L., R. E. Bilby, G. W. Brown, L. B. Holtby, and T. D. Hofstra. 1987. Stream temperature and aquatic habitat: Fisheries and forestry applications. pp. 191-232. In E. O. Salo and T. W. Cundy (eds.). Streamside management: Forestry and fishery interactions. University of Washington, Seattle, Washington., USA.

Bisson, P. A., T. P. Quinn, G. H. Reeves, and S. V. Gregory. 1992. Best management practices, cumulative effects, and long-term trends in fish abundance in Pacific Northwest river systems. pp. 189-232. In R. J. Naiman (ed.). Watershed management: Balancing sustainability with environmental change. Springer-Verlag, New York, New York, USA.

EPA (U.S. Environmental Protection Agency). 1998. Columbia/Snake River Mainstem Water Temperature Workshop. Portland, Oregon, December 3-4, 1998.

Grossman, G. D., J. Hill, and J. T. Petty. 1995. Observations on habitat structure, population regulation, and habitat use with respect to evolutionarily significant units: A landscape perspective for lotic systems. pp. 381-91. In J. L. Nielsen (ed.). Evolution and the aquatic ecosystem: Defining unique units in population conservation. American Fisheries Society Symposium 17, Bethesda, Maryland, USA.

Independent Scientific Group. 1996. Return to the River: Restoration of Salmonid Fishes in the Columbia River Ecosystem. Northwest Power Planning Council, Portland, Oregon.

Lichatowich, J. A. and L. E. Mobrand. 1995. Analysis of chinook salmon in the Columbia River from an ecosystem perspective. DOE/BP-25105-2. U.S. Department of Energy Bonneville Power Administration, Environment Fish and Wildlife. Portland, Oregon.

McCollough, D. A. 1999. A review and synthesis of effects of alterations to the water temperature regime of freshwater life stages of salmonids, with special reference to chinook salmon. Prepared for the U.S. Environmental Protection Agency, Region 10, Seattle, Washington.

Naiman, R. J., T. J. Beechie, L. E. Benda, D. R. Berg, P. A. Bisson, L. H. MacDonald, M. D. O'Connor, P. L. Olson, and E. A. Steel. 1992. Fundamental elements of ecologically healthy watersheds in the Pacific Northwest coastal ecoregion. pp. 127-88. In R. J. Naiman (ed.). Watershed management: Balancing sustainability and environmental change. Springer-Verlag, New York, New York, USA. 
National Academy of Sciences/National Academy of Engineering. 1973. Water Quality Criteria 1972. Report EPA.R3.73.033, U.S. Environmental Protection Agency, Washington, D.C.

Nehlsen, W., J. E. Williams, and J. A. Lichatowich. 1991. Pacific salmon at the crossroads: Stocks at risk from California, Oregon, Idaho, and Washington. Fisheries 16(2):4-21.

Meehan, W. R. (ed). 1991. Influences of forest and rangeland management on salmonid fishes and their habitats. American Fisheries Society Special Publication 19.

Schlosser, I. J. 1991. Stream fish ecology: A landscape perspective. Bioscience 41:704712.

Waples, R. S., R. P Jones, Jr., B. R. Beckman, and G. A. Swan. 1991. Status Review for Snake River Fall Chinook Salmon. U.S. Department of Commerce, NOAA Technical Memorandum. NMFS F/NWC-201.

\section{Section 2}

Bayley, P. B., and H. W. Li. 1992. Riverine fishes. pp. 251-81. In P. Calow and G. E. Petts (eds.). The rivers handbook: Hydrological and ecological principles. Blackwell Scientific, Oxford, United Kingdom.

Cushman, R. M., S. B. Gough, M. S. Moran, and R. B. Craig. 1980. Sourcebook of Hydrologic and Ecological Features. Water Resource Regions of the Conterminous United States. Ann Arbor Science, Ann Arbor, Michigan.

Easterbrook, D. J. 1993. Surface Processes and Landforms. MacMillan, New York.

Harr, R. D. 1981. Some characteristics and consequences of milt from shallow snowpacks during rainfall in western Oregon. Journal of Hydrology 53:277-304.

Harris, D. D., and L. E. Hubbard. 1983. Magnitude and frequency of floods in eastern Oregon. U.S. Geological Survey Water Resources Investigation Report 82-4078. Portland, Oregon.

Karr, M. H., J. K. Fryer, and P. R. Mundy. 1998. Snake River Water Temperature Control Project. Phase II. Methods for Managing and Monitoring Water Temperatures in Relation to Salmon in the Lower Snake River. Columbia River Inter-Tribal Fish Commission, Portland, Oregon.

Leopold, L. B. 1994. A View of the River. Harvard University Press, Cambridge, Massachusetts. 
McCarthy, K. A., W. D. McFarland, J. M. Wilkinson, and L. D. White. 1992. The dynamic relationship between groundwater and the Columbia River: Using deuterium and oxygen-18 as tracers. Journal of Hydrology 135:1-12.

Rosgen, D. 1996. Applied River Morphology. Wildland Hydrology, Pagosa Springs, Colorado.

Stanford, J. A., and J. V. Ward. 1993. An ecosystem perspective of alluvial rivers: Connectivity and the hyporheic zone. Journal of the North American Benthological Society 12:48-60.

Ward, J. V., and J. A. Stanford. Ecological connectivity in alluvial river ecosystems and its disruption by flow regulation. Regulated Rivers: Research and Management 11:105-19.

Weber, E. 1997. Evidence of groundwater recharge and groundwater-surface water hydraulic continuity along the Columbia River south shore during the flood of 1996. pp. 127-42. In A. Laenen and J. D. Ruff, The Pacific Northwest Floods of February 6-11, 1996. Proceedings of the Pacific Northwest Water Issues Conference, Portland, Oregon, October 7-8, 1997. American Institute of Hydrology, St. Paul, Minnesota.

\section{Section 3}

Barton, D. R., W. D. Taylor, and R. M. Biette. 1985. Dimensions of riparian buffer strips required to maintain trout habitat in southern Ontario streams. North American Journal of Fisheries Management 5:364-78.

Beschta, R. L., and R. L. Taylor. 1988. Stream temperature increases and land-use in a forested Oregon watershed. Water Resources Bulletin 24:19-25.

Bilby, R. E. 1984. Characteristics and frequency of cool-water areas in a western Washington stream. Journal of Freshwater Ecology 2:593-602.

Bisson, P. A., and D. R. Montgomery. 1996. Valley segments, stream reaches, and channel units. pp. 23-52. In F. R. Hauer and G. A. Lamberti (eds.). Methods in stream ecology. Academic Press, San Diego, California, USA.

Bjornn, T. C., and D. W. Reiser. 1991. Habitat requirements of salmonids in streams. pp. 83-138. In W. R. Meehan (ed.). Influences of forest and rangeland management on salmonid fishes and their habitats. American Fisheries Society Special Publication 19.

Brunke, M., andT. Gonser. 1997. The ecological significance of exchange processes between rivers and groundwater. Freshwater Biology 37:1-33. 
Forest Ecosystem Management Assessment Team. 1993. Forest Ecosystem Management: An Ecological, Economic, and Social Assessment. U.S. Department of Agriculture Forest Service, U.S. Department of Commerce National Marine Fisheries Service, U.S. Department of the Interior Bureau of Land Management, U.S. Department of the Interior Fish and Wildlife Service, U.S. Department of the Interior National Park Service, and the U.S. Environmental Protection Agency, Washington, D.C.

Hicks, B. J., J. D. Hall, P. A. Bisson, and J. R. Sedell. 1991. Responses of salmonids to habitat changes. pp. 483-517. In W. R. Meehan (ed.). Influences of forest and rangeland management on salmonid fishes and their habitats. American Fisheries Society Special Publication 19.

Holtby, L. B. 1988. Effects of logging on stream temperatures in Carnation Creek, British Columbia, and associated impacts on the coho salmon (Oncorhynchus kisutch). Canadian Journal of Fisheries and Aquatic Sciences 45:502-15.

Hostetler, S. W. 1991. Analysis and modeling of long-term stream temperatures on the Steamboat Creek basin, Oregon: Implications for land use and fish habitat. Water Resources Bulletin 27:637-647.

Imberger, J., and J. C. Patterson. 1981. A dynamic reservoir simulation model-DYRESM:5. pp. 310-61. In H. Fisher, Transport Models for Inland and Coastal Waters. Academic Press, New York.

Johnson, L. B., and S. H. Gage. 1997. Landscape approaches to the analysis of aquatic ecosystems. Freshwater Biology 37:113-132.

Li, H. W., G. A. Lamberti, T. N. Pearsons, C. K. Tait, J. L. Li, and J. C. Buckhouse. 1994. Cumulative effects of riparian disturbance along high desert trout stream of the John Day Basin, Oregon. Transactions of the American Fisheries Society 123:627-40.

Poff, N. L., and J. V. Ward. 1990. Physical habitat template of lotic systems: Recovery in the context of historical pattern of spatiotemporal heterogeneity. Environmental Management 14:629-45.

Pringle, C. M., R. J. Naiman, G. B. Bretschko, J. R. Karr, M. W. Oswood, J. R. Webster, R. L. Welcomme, and M. J. Winterbourn. 1988. Patch dynamics in lotic systems: The stream as a mosaic. Journal of the North American Benthological Society 7:503-24.

Sinokrot, B. A., and H. G. Stephan. 1993. Stream temperature dynamics: Measurement and modeling. Water Resources Research 29:2299-312.

Taylor, P. D., L. Fahrig, K. Henein, and G. Merriam. 1993. Connectivity is a vital element of landscape structure. Oikos 68:571-73. 
Theurer, F. D., I. Lines, and T. Nelson. 1985. Interaction between riparian vegetation, water temperature, and salmonid habitat in the Tucannon River. Water Resources Bulletin 21:53-64.

Theurer, F. D., K. A. Voos, and W. J. Miller. 1984. Instream flow water temperature model. Instream Flow Information Paper 16. FWS/OBS-84/15. U.S. Fish and Wildlife Service.

Vannote, R. L., and B. W. Sweeney. 1980. Geographic analysis of thermal equilibria: A conceptual model for evaluating the effect of natural and modified thermal regimes on aquatic insect communities. American Naturalist 115:667-95.

Ward, J. V. 1985. Thermal characteristics of running waters. Hydrobiologia 125:31-46.

\section{Section 4}

Berman, C. H., and T. P. Quinn. 1991. Behaviourial thermoregulation and homing by spring chinook salmon, Oncorhynchus tshawytscha (Walbaum), in the Yakima River. Journal of Fish Biology. 39:301-12.

Brett, J. R. 1952. Temperature tolerance in young Pacific salmon, genus Oncorhynchus. Journal of the Fisheries Research Board of Canada 9:265-323.

Brett, J. R. 1960. Thermal requirements of fish-Three decades of study. pp. 110-17. In C. M. Tarzwell, (ed.). Biological Problems in Water Pollution. U.S. Public Health Service Publication No. W60-3. Cincinnati, Ohio.

Brett, J. R. 1971. Energetic responses of salmon to temperature: A study of some thermal relations in the physiology and freshwater ecology of sockeye salmon (Oncorhynchus nerka). American Zoologist 11:99-113.

Brett, J. R., J. E. Shelbourne, and C. T. Shoop. 1969. Growth rate and body composition of fingerling sockeye salmon, Oncorhynchus nerka, in relation to temperature and ration size. Journal of the Fisheries Research Board of Canada 26:2363-94.

Coutant, C. C. 1972. Biological aspects of thermal pollution. II. Scientific basis for water temperature standards at power plants. Critical Reviews in Environmental Control $3(1): 1-24$.

Coutant, C. C. 1977. Compilation of temperature preference data. Journal of the Fisheries Research Board of Canada 34:739-45. 
Coutant, C. C. 1977. Physiological considerations of future thermal additions for aquatic life. pp. 251-66. In M. Marois (ed.). Proceedings of the World Conference Towards a Plan of Actions for Mankind. Volume 3. Biological Balance and Thermal Modifications. Pergamon Press, Oxford and New York.

Coutant, C. C. 1986. Thermal niches of striped bass. Scientific American 254(8):98104.

Coutant, C. C. 1973. Effect of thermal shock on vulnerability of juvenile salmonids to predation. Journal of the Fisheries Research Board of Canada 30:965-73.

Eaton, J. G., and R. M. Scheller. 1996. Effects of climate warming on fish thermal habitat in streams of the United States. Limnology and Oceanography 41:1109-15.

Eaton, J. G., J. H. McCormick, B. Goodman, D. O'Brien, H. G. Stefan, M. Hondoz, and R. M. Scheller. 1995. A field information-based system for estimating fish temperature tolerances. Fisheries 20(4):10-18.

EPA (U.S. Environmental Protection Agency). 1986. Quality Criteria for Water 1986. Report 440/5-86-001, U.S. Environmental Protection Agency, Washington, D.C.

Fry, F. E. J. 1971. The effect of environmental factors on the physiology of fish. pp. 1-98. In W. S. Hoar and D. J. Randall (ed.). Fish Physiology. Volume 6. Academic Press, New York.

Groot, C., and L. Margolis (eds). 1991. Pacific Salmon Life Histories. UBC Press, Vancouver.

Groot, C., L. Margolis, and W. C. Clarke (eds). 1995. Physiological Ecology of Pacific Salmon. UBC Press, Vancouver.

Hansen, J., I. Fung, A. Lacia, S. Ledbedeff, D. Rind, R. Ruedy, and G. Russell. 1988. Global climate changes as forecast by the GISS 3-D model. Journal of Geophysical Research 93:9341-64.

Hokason, K. E. F. 1977. Temperature requirements of some percids and adaptations to the seasonal temperature cycle. Journal of the Fisheries Research Board of Canada 34(10):1524-50.

Howell. P. J., D. V. Buchanan, and J. M. Maule (eds.). 1992. Proceedings of the Gerhart Mountain Bull Trout Workshop. Oregon Chapter of the American Fisheries Society, Corvallis, Oregon. 
Kaya, C. M., L. R. Kaeding, and D. E. Burkhalter. 1977. Use of a cold-water refuge by rainbow and brown trout in a geothermally heated stream. Progressive Fish-Culturist 39:37-38.

Lee, D. S., C. R. Gilbert, C. H. Hocutt, R. E. Jenkins, D. E. McAllister, and J. R. Stauffer, Jr. 1980. Atlas of North American Freshwater Fishes. North Carolina State Museum of Natural History, Raleigh, North Carolina.

Li, H. W., G. A. Lamberti, T. N. Pearsons, C. K. Tait, J. L. Li, and J. C. Buckhouse. 1995. Safe havens: Refuges and evolutionarily significant units. pp. 371-80. In J. L. Nielsen (ed.). Evolution and the aquatic ecosystem: Defining unique units in population conservation. American Fisheries Society Symposium 17, Bethesda, Maryland, USA.

Lindsay, R. B., W. J. Knox, M. W. Flesher, B. J. Smith, E. A. Olsen, and L. S. Lutz. 1986. Study of wild spring chinook salmon in the John Day River system. U.S. Department of Energy, Bonneville Power Administration, Division of Fish and Wildlife, Portland, Oregon, USA.

Magnuson, J. J., J. D. Meisner, and D. K. Hill. 1990. Potential changes in the thermal habitat of Great Lakes fish after global climate warming. Transactions of the American fisheries Society 119:254-64.

Magnuson, J. J., L. B. Crowder, and P. A. Medvick. 1979. Temperature as an ecological resource. American Zoologist 19:331-43.

McCollough, D. A. 1999. A review and synthesis of effects of alterations to the water temperature regime of freshwater life stages of salmonids, with special reference to chinook salmon. Prepared for the U.S. Environmental Protection Agency, Region 10, Seattle, Washington.

Meisner, J. D. 1990. Effect of climate warming on the southern margins of the native range of brook trout, Salvelinus fontinalis. Canadian Journal of Fisheries and Aquatic Sciences 47:1065-70.

Meisner, J. D., J. S. Rosenfeld, and H. A. Regier. 1988. The role of groundwater in the impact of climate warming on stream salmonines. Fisheries 13(3):2-8.

Nakamoto, R. J. 1994. Characteristics of pools used by adult summer steelhead oversummering in the New River, California. Transactions of the American Fisheries Society 123:757-65.

National Academy of Sciences/National Academy of Engineering. 1973. Water Quality Criteria 1972. Report EPA.R3.73.033, U.S. Environmental Protection Agency, Washington, D.C. 
Nielsen, J. L., T. E. Lisle, and V. Ozaki. 1994. Thermally stratified pools and their use by steelhead in northern California streams. Transactions of the American Fisheries Society 123:613-26.

Peterson, J. T., and C. F. Rabeni. 1996. Natural thermal refugia for temperate warmwater stream fishes. North American Journal of Fisheries Management 16:738-46.

Plante, C., and J. A. Downing. 1993. Relationship of salmonine production to lake trophic status and temperature. Canadian Journal of Fisheries and Aquatic Sciences 50:1324-28.

Rahel, F. J., C. J. Keleher, and J. L. Anderson. 1996. Potential habitat loss and population fragmentation for cold water fish in the North Platte River drainage of the Rocky Mountains: Response to climate warming. Limnology and Oceanography 41:1116-23.

Rieman, B. E., and J. D. McIntyre. 1995. Occurrence of bull trout in naturally fragmented habitat patches of varied size. Transactions of the American Fisheries Society 124:285-96.

Roper, B. B., D. L. Scarnecchia, and T. J. La Marr. 1994. Summer distribution of and habitat use by chinook salmon and steelhead within a major basin of the South Umpqua River, Oregon. Transactions of the American Fisheries Society 123:298-308.

Schreck, C. B., and H. W. Li. 1991. Performance capacity of fish: Stress and water quality. pp. 21-29. In D. E. Brune and J. R. Tomasso (eds.). Aquaculture and water quality. Advances in World Aquaculture 3. World Aquaculture Society, Baton Rouge, Louisiana, USA.

Sedell, J. R., G. H. Reeves, F. R. Hauer, J. A Stanford, and C. P. Hawkins. 1990. Role of refugia in recovery from disturbances: Modern fragmented and disconnected river systems. Environmental Management 14:711-24.

Shuter, B. J., and J. R. Post. 1990. Climate, population viability, and the zoogeography of temperate fishes. Transactions of the American Fisheries Society 119:314-36.

Snucins, E. J., and J. M. Gunn. 1995. Coping with a warm environment: Behavioral thermoregulation by lake trout. Transactions of the American Fisheries Society 124:11823.

Somero, G. N., and G. E. Hofmann. 1997. Temperature thresholds for protein adaptation: When does temperature change start to "hurt"? pp. 1-24. In C. M. Wood and D. G. McDonald (eds.). Global warming: Implications for freshwater and marine fish. Society for Experimental Biology. Seminar Series: 61. Cambridge University Press, Cambridge, United Kingdom. 
Thorpe, J. E. 1994. Salmonid flexibility: Responses to environmental extremes. Transactions of the American Fisheries Society 123:606-12.

Torgersen, C. E., D. M. Price, H. W. Li, and B. A. McIntosh. 1999. Multiscale thermal refugia and stream habitat associations of chinook salmon in northeastern Oregon. Ecological Applications 9(1):301-19.

Van der Kraak, G., and N. W. Pankhurst. 1997. Temperature effects on the reproductive performance of fish. Pp. 159-76. In C. M. Wood and D. G. McDonald (eds.). Global warming: Implications for freshwater and marine fish. Society for Experimental Biology. Seminar Series: 61. Cambridge University Press, Cambridge, United Kingdom.

\section{Section 5}

Rondorf, D. W., and K. F. Tiffan. 1997. Identification of the spawning, rearing and migratory requirements of fall chinook salmon in the Columbia River basin. Annual Report for 1995. DOE/BP-21708-5, U.S. Department of Energy, Bonneville Power Administration, Portland, Oregon. (See also preceding and subsequent annual reports with this title.)

\section{Section 6}

Armour, C. L. 1991. Guidance for evaluating and recommending temperature regimes to protect fish. U.S. Fish Wildlịe Service Biological Report 90(20).

EPA (U.S. Environmental Protection Agency). 1986. Quality Criteria for Water 1.986. Report 440/5-86-001, U.S. Environmental Protection Agency, Washington, D.C.

Hicks, M. P. 1998 draft. Evaluating standards for protecting aquatic life in Washington's surface water quality standards. Temperature Criteria. Preliminary Review Draft Discussion Paper (text and supplementary appendix). Water Quality Program, Watershed Management Section, Washington State Department of Ecology, Olympia, Washington.

National Academy of Sciences/National Academy of Engineering. 1973. Water Quality Criteria 1972. Report EPA.R3.73.033, U.S. Environmental Protection Agency, Washington, D.C.

Oregon Department of Environmental Quality. 1995. 1992-1994 Water Quality Standards Review: Temperature. Final Issue Paper. Portland, Oregon.

\section{Section 8}

Coutant, C. C. 1987. Thermal preference: When does an asset become a liability? Environmental Biology of Fishes 18:161-72. 
Gulf States Marine Fisheries Commission. In Press. Proceedings, Striped Bass Restoration Workshop. Pensacola Beach, Florida. November 18-19, 1998. Ocean Springs, Mississippi.

Kerr, R. A. 1998. Acid rain control: Success on the cheap. Science 282:1024-27.

\section{Section 9}

Ebersole, J. L., W. J. Liss, and C. A. Frissell. 1997. Restoration of stream habitats in the western United States: Restoration as reexpression of habitat capacity. Environmental Management 21:1-14.

Karr, M. H., J. K. Fryer, and P. R. Mundy. 1998. Snake River Water Temperature Control Project. Phase II. Methods for Managing and Monitoring Water Temperatures in Relation to Salmon in the Lower Snake River. Columbia River Inter-Tribal Fish Commission, Portland, Oregon. 
ORNL/TM-1999/44

\section{INTERNAL DISTRIBUTION}

1-50. C. C. Coutant

51. J. H. Cushman

52. D. E. Fowler

53. S. G. Hildebrand

54. G. K. Jacobs

55. P. Kanciruk

56. J. M. Loar
57. T. E. Myrick .

58. D. E. Reichle

59. Central Research Library

60-62. ESD Library

63-64. Laboratory Records-OSTI

65. Laboratory Records-RC

\section{EXTERNAL DISTRIBUTION}

66. Jerry Elwood, Acting Director, Environmental Sciences Division, ER-74, Department of Energy, 19901 Germantown Road, Germantown, MD 20874

67. E. G. Cumesty, Assistant Manager for Laboratories and Site Manager, Department of Energy, Oak Ridge National Laboratory, P.O. Box 2008, Oak Ridge, TN 37831-6269

68. John P. Giesy, College of Natural Science, Department of Zoology, Michigan State University, 203 Natural Sciences Building, East Lansing, MI 48824-1115

69-118. Marcia Lagerloef, Mail Stop OW-134, U.S. Environmental Protection Agency, Region 10, Water Quality Standards Coordinator, 1200 Sixth Avenue, Seattle, WA 98101

119. Alan A. Lucier, National Council of the Paper Industry for Air and Stream Improvement, Inc., P.O. Box 13318, 79 T. W. Alexander Drive, Building 4401, Suite 205, Research Triangle Park, NC 27709-3318

120. Michael C. MacCracken, National Assessment Coordination Office, 400 Virginia Avenue, S.W., Suite 750, SW, Washington, DC 20024

121. Larry Robinson, Director, Environmental Sciences Institute, Florida A\&M University, Science Research Facility, 1520 S. Bronough Street, Tallahassee, FL 32307

122. James M. Tiedje, University Distinguished Professor and Director, Center for Microbial Ecology, Michigan State University, 540 Plant and Soil Sciences Building, East Lansing, MI 48824 